\title{
RESULTS FROM THE U.S. DOE 2006 SAVE ENERGY NOW ASSESSMENT INITIATIVE: \\ DOE's Partnership with U.S. Industry to Reduce \\ Energy Consumption, Energy Costs, and Carbon Dioxide Emissions
}

Anthony Wright and Michaela Martin

Oak Ridge National Laboratory

Bob Gemmer, Paul Scheihing, and James Quinn DOE Industrial Technologies Program

September 17, 2007

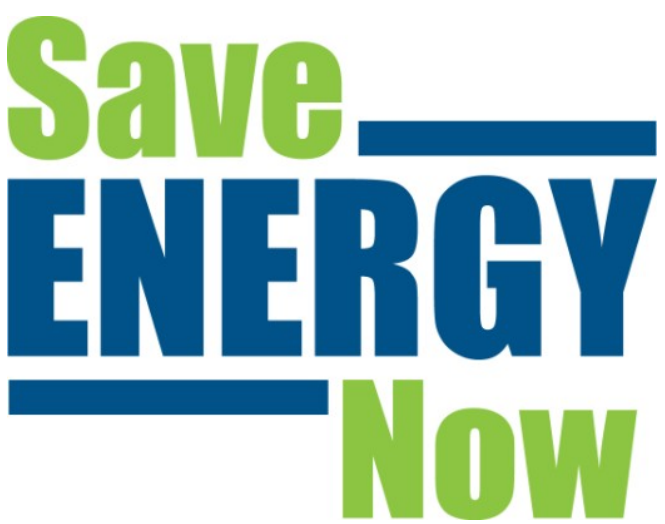





\section{ES-1. INTRODUCTION}

\section{Executive Summary}

In the wake of Hurricane Katrina and other severe storms in 2005, natural gas supplies were restricted, prices rose, and industry sought ways to reduce its natural gas use and costs. In October 2005, U.S. Department of Energy (DOE) Energy Secretary Bodman launched his Easy Ways to Save Energy campaign with a promise to provide energy assessments to 200 of the largest U.S. manufacturing plants. A major thrust of the campaign was to ensure that the nation's natural gas supplies would be adequate for all Americans, especially during home heating seasons. In a presentation to the National Press Club on October 3, 2005, Secretary Bodman said:

"America's businesses, factories, and manufacturing facilities use massive amounts of energy. To help them during this period of tightening supply and rising costs, our Department is sending teams of qualified efficiency experts to 200 of the nation's most energy-intensive factories. Our Energy Saving Teams will work with on-site managers on ways to conserve energy and use it more efficiently."

DOE's Industrial Technologies Program (ITP) responded to the Secretary's campaign with its Save Energy Now initiative, featuring a new and highly cost-effective form of energy assessments. The approach for these assessments drew heavily on the existing resources of ITP's Technology Delivery component. Over the years, ITP-Technology Delivery had worked with industry partners to assemble a suite of respected software decision tools, proven assessment protocols, training curricula, certified experts, and strong partnerships for deployment. Because of the program's earlier activities and the resources that had been developed, ITP was prepared to respond swiftly and effectively to the sudden need to promote improved industrial energy efficiency.

Because of anticipated supply issues in the natural gas sector, the Save Energy Now initiative strategically focused on natural gas savings and targeted the nation's largest manufacturing plants - those that consume a total of 1 trillion British thermal units (Btu) or more annually. The approximately 6800 U.S. facilities that fall into this category collectively account for about $53 \%$ of all energy consumed by industry in the United States.

The 2006 Save Energy Now energy assessments departed from earlier DOE plant assessments by concentrating solely on steam and process heating systems, which are estimated to account for approximately $74 \%$ of all natural gas use for manufacturing. The assessments also integrated a strong training component designed to teach industrial plant personnel how to use DOE's steam or process heating opportunity assessment software tools. This approach had the advantages of promoting strong buy-in of plant personnel for the assessment and its outcomes and preparing them better to independently replicate the assessment process at the company's other facilities.

The Save Energy Now initiative also included provisions to help plants that applied for but did not qualify for assessments (based on the 1 trillion Btu criterion). Services offered to these plants included (1) an assessment by one of DOE's 26 university-based Industrial Assessment Centers (IACs), (2) a telephone consultation with a systems expert at the DOE's Energy Efficiency and Renewable Energy Information Center, or (3) other technical materials and services available through ITP (e.g., the Save Energy Now CD).

By the end of 2006, DOE had completed all 200 of the promised assessments, identifying potential natural gas savings of more than 50 trillion Btu and energy cost savings of about $\$ 500$ million. These savings, if fully implemented, could reduce $\mathrm{CO}_{2}$ emissions by 4.04 million metric tons annually. These results, along with the fact that a large percentage of U.S. energy is used by a relatively small number of 
very large plants, clearly suggest that assessments are an expedient and cost-effective way to significantly affect large amounts of energy use.

Building on the success of the 2006 initiative, ITP has expanded the effort in 2007 with the goal of conducting 250 more assessments in large U.S. industrial plants. The 2007 assessments are addressing not only steam and process heating, but also pumping, compressed air, and fan systems.

The full report reviews the tools and resources developed by the DOE ITP program before 2006, which are the foundation and catalyst for the Save Energy Now assessment efforts. The report describes the process by which industrial plants applied to obtain assessments in 2006 and the overall process and philosophy of conducting assessments. A comprehensive review of the results from the 2006 assessments is presented, along with a summary of key accomplishments and findings.

\section{ES-2. DOE ITP PRECEDING THE 2006 SAVE ENERGy Now AsSeSSMENTS}

The approach used in conducting the Save Energy Now assessments evolved from the resources and concepts developed in the DOE ITP program over the last decade. Plant-wide assessments (PWAs), Industrial Assessment Center (IAC) assessments, decision software tools, end user and specialist qualification training, and Collaborative Targeted Assessments (CTAs) all contributed significantly to the development of the Save Energy Now assessment concept. These individual ITP program elements are described in more detail in Section 2 of this report. Because these ITP activities were already well established when Save Energy Now assessments were introduced, ITP was able to expedite its contribution to Save Energy Now, bringing mature strategies and tools to bear immediately. ITP's previous efforts laid the groundwork for conducting Save Energy Now assessments. The final important element of the initial assessment efforts was the decision to focus on large plants. There are about 226,000 manufacturing plants in the U.S. Of these about 6800 plants are "large" - with annual energy costs greater than \$2 million/year. These large plants, based on the 1998 Energy Information Administration (EIA) Manufacturing Energy Consumption Survey (MECS) data, consume about 53\% of the total annual industrial energy use in the U.S. Focusing on these large plants for Save Energy Now assessments resulted in the greatest potential impact on U.S. manufacturing energy use.

\section{ES-3. The 2006 SaVe Energy Now assessment Application Process}

The application process for large industrial plants to qualify for Save Energy Now assessments in 2006 was initiated on November 8, 2005, and closed on January 17, 2006, after the majority of qualified plants had been identified. Manufacturing facilities in the United States and its territories were eligible to apply.

To be considered for Save Energy Now assessments in 2006, companies completed and submitted an application form on the DOE Save Energy Now Web site. The application asked for contact information and energy use data for the plant or plants that were seeking assessments. To focus the assessments on large plants, DOE required that applicants have a total energy use of at least 1 trillion Btu per year, either in one or several plants. If the applicant's energy use was greater than 10 trillion Btu per year, the company could potentially obtain more than one assessment.

DOE ITP program staff reviewed all of the Save Energy Now assessment applications that were submitted. DOE evaluated the total energy consumption, especially natural gas, toward qualification for obtaining assessments. All companies that completed the application process received some type of support from the DOE ITP program.

The first DOE contact with plants whose applications indicated that they met the energy use requirements to obtain an assessment was from DOE Regional Office personnel, who confirmed the information from the application such as the type of assessment requested (steam or process heating), potential dates for 
conducting the assessment, plant description and address, and who the Energy Expert should initially contact. This information was forwarded to the ORNL Save Energy Now staff so that they could begin the process of identifying the Energy Experts to perform the assessments and facilitate their first contacts with the plants.

\section{ES-4. The Save Energy Now Assessment Process}

The Save Energy Now initiative used a unique approach for conducting in-plant energy efficiency assessments. Energy audits or assessments are typically done by energy experts who go into a plant, identify potential savings opportunities, and write reports that are left with the plant personnel after the assessments are completed. Save Energy Now assessments, in contrast, are training assessments. The 2006 assessments focused on training industrial plant personnel specifically on how to use either the DOE steam or process heating software tools. Assessments are done in no more than 3 days, so, by necessity, they are very focused assessments. When an Energy Expert makes contact with a plant, he identifies a Plant Lead who has to agree to stay with the Energy Expert during the entire three-day assessment. The Energy Expert, Plant Lead, and other plant personnel who participate in the assessment identify some "target" opportunities to investigate using the DOE software. The target opportunities chosen are often ones with the potential to achieve significant plant energy and cost savings. The Energy Expert and plant personnel identify any data requirements for assessing the target opportunity, obtain or measure data as necessary, and enter that data in the DOE software to quantify a specific energy savings opportunity. Often, no more than three or four target opportunities are investigated during an assessment.

On the last day of the assessment, a required Closeout Meeting is held to review and discuss the opportunities identified in the assessment. Plant management are invited to attend and participate. Prior to the Closeout Meeting, the Energy Expert and the Plant Lead agree on the opportunities that will be highlighted at the meeting and documented in the final assessment report. No opportunities are discussed at the Closeout Meeting or presented in the assessment report without the Plant Lead's approval.

The positive effect of using this approach for conducting assessments is that: 1) plant personnel get hands-on experience in how to effectively use the DOE software tools and on the value of applying these tools to their operations; 2) plant personnel have buy-in to the opportunities identified and evaluated during the assessment, which increases the likelihood that many of the identified opportunities will implemented ; and 3) plant opportunities are investigated that often can result in significant energy and cost savings for the host plant.

\section{ES-5. Comprehensive ReView of the 2006 SaVe Energy Now Assessment Results}

\section{ES-5.1 Location and Industry of the Assessed Plants}

The assessments were conducted in 40 states and Puerto Rico, mostly in the midwestern, eastern, and southern United States, where the majority of large U.S. industrial sites are located. The states with the most assessments were Texas, with 30, and Louisiana, with 15 . In 17 states, 4 or more assessments were completed.

In 2006, 114 steam assessments and 86 process heating assessments were conducted. The 200 plants were in 18 major U.S. industry groups, with 163 of the assessments done in six industries: chemical manufacturing, paper manufacturing, primary metals, food, non-metallic mineral products, and fabricated metal products.

Process heating assessments were performed in 30 states, with about $82 \%$ of the potential energy cost savings in 12 states. Steam assessments were done in 36 states and one territory (Puerto Rico), and about $84 \%$ of the potential energy cost savings were in 12 states. 


\section{ES-5.2 Summary of Overall Results}

The magnitude of the recommended potential cost, natural gas, and $\mathrm{CO}_{2}$ savings identified in the 2006 steam and process heating assessments is exceptionally large. An overall summary of the results from the 2006 assessments is presented in Table ES-1, for all assessments, for steam assessments, and for process heating assessments. Some key results include the following.

- The average recommended cost savings for all of the assessments taken together was about $\$ 2.5$ million per year, or $10.4 \%$ of the average plant energy bill for the assesssed plants.

- The results of the assessments clear reflect the 2006 program's focus on natural gas savings. The assessments showed that $17.3 \%$ of the natural gas used in the assessment plants could be saved if all of the recommendations from the assessments were implemented.

- The average potential cost and natural gas savings identified for both steam and process heating assessments was large - about \$3.2 million per year for steam and \$1.6 million per year for process heating. Considering that assessments were done in only three days, including a strong tool training element, the magnitude of potential savings is surprisingly large.

Table ES-1. Summary of results for all year 2006 assessments, steam assessments, and process heating assessments

\begin{tabular}{|c|c|c|c|}
\hline & $\begin{array}{c}\text { For all } 200 \\
\text { assessments in } \\
2006\end{array}$ & $\begin{array}{c}\text { For the } 114 \\
\text { steam } \\
\text { assessments }\end{array}$ & $\begin{array}{c}\text { For the } 86 \\
\text { process } \\
\text { heating } \\
\text { assessments }\end{array}$ \\
\hline Total recommended cost savings (\$/year) & $\$ 500,200,000$ & $\$ 364,300,000$ & $\$ 135,900,000$ \\
\hline Recommended cost savings per assessment (\$/year) & $\$ 2,501,000$ & $\$ 3,200,000$ & $\$ 1,580,000$ \\
\hline $\begin{array}{l}\text { Average recommended cost savings per assessment } \\
\text { (\%/year) }\end{array}$ & $10.4 \%$ & $11.4 \%$ & $9.0 \%$ \\
\hline Total recommended energy savings, site (MMBtu/year) & $49,470,000$ & $32,370,000$ & $17,100,000$ \\
\hline $\begin{array}{l}\text { Recommended total energy savings, site, per assessment } \\
\text { (MMBtu/year) }\end{array}$ & 247,400 & 283,900 & 198,800 \\
\hline $\begin{array}{l}\text { Average recommended total energy savings, site, per } \\
\text { assessment (\%/year) }\end{array}$ & $8.8 \%$ & $7.8 \%$ & $10.1 \%$ \\
\hline Total recommended natural gas savings (MMBtu/year) & $52,870,000$ & $39,040,000$ & $13,830,000$ \\
\hline $\begin{array}{l}\text { Recommended natural gas savings per assessment } \\
\text { (MMBtu/year) }\end{array}$ & 264,400 & 342,500 & 160,800 \\
\hline $\begin{array}{l}\text { Average recommended natural gas savings per } \\
\text { assessment (\%/year) }\end{array}$ & $17.3 \%$ & $20.4 \%$ & $13.3 \%$ \\
\hline $\begin{array}{l}\text { Total recommended } \mathrm{CO}_{2} \text { savings (million metric tons } \\
\mathrm{CO}_{2} / \text { year) }\end{array}$ & 4.04 & 2.92 & 1.11 \\
\hline $\begin{array}{l}\text { Recommended } \mathrm{CO}_{2} \text { savings per assessment (metric tons } \\
\mathrm{CO}_{2} \text { /year) }\end{array}$ & 20,200 & 25,600 & 13,000 \\
\hline
\end{tabular}

Note: Savings designated as "site" savings refer to energy used at the site and do not include losses that occur in the generation, transmission and distribution of energy.

Estimates for $\mathrm{CO}_{2}$ emission reductions were calculated for each assessment based on the energy savings and fuel type data provided by the Energy Experts. Currently, 22 categories of industrial fuels including electricity, natural gas, light fuel oil (\#1, \#2,\#4), heavy fuel oil (\#5, \#6), coal, coke, coke oven gas, black liquor, blast furnace gas, propane, and hog fuel, are analyzed for $\mathrm{CO}_{2}$ content. Coefficients for converting fuel consumption (MMBtu) into metric tons of $\mathrm{CO}_{2}$ were provided through direct consultation with EIA's greenhouse gas voluntary reporting team. These coefficients were applied to the appropriate fuel savings to develop estimates of emissions impacts. The total potential $\mathrm{CO}_{2}$ emissions reduction - if all assessment recommendations are implemented - is about 4.04 million metric tons of $\mathrm{CO}_{2}$. 
In performing the steam and process heating assessments, Experts used standard — or "pick-list" descriptions - whenever possible in classifying the identified opportunities. This was done so that the savings opportunity data could be analyzed by these pick-list categories.

For both steam and process heating assessments, the top 10 opportunities capture the majority of the energy cost savings identified in the assessments. For steam assessments, the top 10 opportunities captured $\$ 334$ million per year of potential savings - 92\% of the total identified steam savings. For process heating assessments, the top 10 opportunities captured $\$ 100$ million per year of potential savings $-74 \%$ of the total identified process heating savings.

\section{ES-5.3 Estimated Paybacks Are Less Than Two Years for Most Identified Savings Opportunities}

While the magnitude of the potential cost and energy savings identified by the 2006 assessments is impressive, the impact on U.S. industry will only be proportional to the magnitude of implemented opportunities. A primary determinant of whether potential savings become real savings is the payback period for implementation. Payback is defined as follows.

Savings payback period $=($ Cost to implement opportunity $) /($ Yearly savings for the opportunity $)$

Most industrial plants will not consider implementing savings opportunities that have paybacks of greater than two years.

The assessment experts estimated high and low values of the capital costs for implementing each identified savings opportunity and used the higher values to estimate payback periods. The results show that the majority of the estimated paybacks for the identified opportunities - $76 \%$ of all steam opportunities and $73 \%$ of all process heating opportunities - were less than two years. The opportunities with estimated paybacks of less than two years also accounted for most of the potential cost savings for both steam and process heating - for steam assessments, \$263 million per year, or $72 \%$ of all potential savings; and for process heating assessments, $\$ 109$ million per year, or $73 \%$ of all potential savings.

Tables ES-2 and ES-3 present potential savings data in terms of the average percentages of plant energy use and energy cost represented by each individual category of opportunity. These results show that potential savings identified in many of these categories could be greater than $1 \%$ of total plant energy costs. For the steam assessments, 14 of the opportunity categories showed average potential cost savings greater than $1 \%$ of plant energy costs. For the process heating assessments, 17 of the opportunity categories showed average potential cost savings greater than $1 \%$ of plant energy costs.

The estimated paybacks indicate that implementation of the majority of identified opportunities should be appealing to industrial plants. 
Table ES-2. Potential percentage savings in plant energy costs and plant energy use from steam opportunities (averages of all individual identified opportunities), by opportunity category.

\begin{tabular}{|c|c|c|}
\hline \multirow[b]{2}{*}{ Steam opportunity category } & \multicolumn{2}{|c|}{ Potential savings } \\
\hline & $\begin{array}{c}\text { Average } \\
\text { percentage of plant } \\
\text { energy costs }\end{array}$ & $\begin{array}{c}\text { Average } \\
\text { percentage of } \\
\text { plant energy use } \\
\text { (site) }\end{array}$ \\
\hline 1.2 - Use alternate fuel & $15.1 \%$ & $-0.5 \%$ \\
\hline 1.1 - Reduce steam demand & $3.3 \%$ & $3.6 \%$ \\
\hline 1.20 - Optimize multiple boilers & $3.2 \%$ & $-0.3 \%$ \\
\hline 2.2-Clean heat transfer surfaces & $2.6 \%$ & $3.2 \%$ \\
\hline 1.7 - Add / modify backpressure steam turbine & $2.4 \%$ & $0.1 \%$ \\
\hline 1.17 - Other - miscellaneous steam & $1.9 \%$ & $1.4 \%$ \\
\hline 1.21 - Reduce / recover vented steam & $1.9 \%$ & $2.4 \%$ \\
\hline 1.12 - Improve medium pressure condensate flash & $1.6 \%$ & $1.5 \%$ \\
\hline 1.18 - Feedwater heat recovery - general & $1.6 \%$ & $2.3 \%$ \\
\hline 1.8 - Add / modify condensing steam turbine & $1.5 \%$ & $0.6 \%$ \\
\hline 1.3 - Improve boiler efficiency & $1.5 \%$ & $1.6 \%$ \\
\hline 1.6 - Improve steam generation conditions & $1.0 \%$ & $0.8 \%$ \\
\hline 1.19 - Improve deaerator heat recovery & $1.0 \%$ & $1.1 \%$ \\
\hline 1.11 - Improve condensate recovery & $1.0 \%$ & $1.1 \%$ \\
\hline 1.13 - Improve low pressure condensate flash & $0.9 \%$ & $0.9 \%$ \\
\hline 1.1 - Reduce flue gas oxygen content & $0.8 \%$ & $1.0 \%$ \\
\hline 3.5 - Use waste heat for cooling & $0.7 \%$ & $0.6 \%$ \\
\hline 1.14 - Implement steam trap maintenance program & $0.7 \%$ & $0.8 \%$ \\
\hline 1.9 - Improve condensate tank vent feedwater heat recovery & $0.6 \%$ & $0.8 \%$ \\
\hline 1.10 - Improve blowdown feedwater heat recovery & $0.5 \%$ & $0.6 \%$ \\
\hline 1.16 - Improve insulation & $0.5 \%$ & $0.5 \%$ \\
\hline 3.1 - Use flue / exhaust gas for combustion air preheating & $0.4 \%$ & $0.4 \%$ \\
\hline 1.15 - Implement steam leak maintenance program & $0.4 \%$ & $0.3 \%$ \\
\hline 1.4 - Improve boiler blowdown rate & $0.4 \%$ & $0.3 \%$ \\
\hline 5.1 - Improve furnace scheduling, loading, shutdown & $0.4 \%$ & $0.0 \%$ \\
\hline 6.2 - Other - miscellaneous process heating & $0.2 \%$ & $0.2 \%$ \\
\hline 1.5 - Install blowdown flash to low pressure steam & $0.1 \%$ & $0.2 \%$ \\
\hline
\end{tabular}


Table ES-3. Potential percentage savings in plant energy costs and plant energy use from process heating opportunities (averages of all individual identified opportunities), by opportunity category.

\begin{tabular}{|c|c|c|}
\hline \multirow[b]{2}{*}{ Process heating opportunity category } & \multicolumn{2}{|c|}{ Potential savings } \\
\hline & $\begin{array}{c}\text { Average } \\
\text { percentage of plant } \\
\text { energy costs }\end{array}$ & $\begin{array}{c}\text { Average } \\
\text { percentage of } \\
\text { plant energy use } \\
\text { (site) }\end{array}$ \\
\hline 1.4 - Use alternate fuel or energy source & $9.3 \%$ & $13.1 \%$ \\
\hline 3.5 - Use waste heat for cooling & $8.0 \%$ & $8.7 \%$ \\
\hline 3.3 - Heat cascading & $3.3 \%$ & $3.4 \%$ \\
\hline 3.4 - Furnace heat recovery & $2.9 \%$ & $3.5 \%$ \\
\hline 1.5 - Use oxygen for combustion & $2.8 \%$ & $3.6 \%$ \\
\hline 6.1 - Other - non process heating measures & $2.8 \%$ & $1.8 \%$ \\
\hline 1.3 - Use of proper heating methods & $2.7 \%$ & $3.1 \%$ \\
\hline 5.3 - Control oven makeup air & $2.7 \%$ & $2.7 \%$ \\
\hline 6.2 - Other - miscellaneous process heating & $2.6 \%$ & $3.1 \%$ \\
\hline 2.1 - Improving furnace / oven heat transfer & $2.4 \%$ & $3.0 \%$ \\
\hline 3.1 - Use flue / exhaust gas for combustion air preheating & $2.1 \%$ & $2.2 \%$ \\
\hline 3.2 - Improve load charge preheating & $1.7 \%$ & $1.9 \%$ \\
\hline 5.1 - Improve furnace scheduling, loading, shutdown & $1.4 \%$ & $1.4 \%$ \\
\hline 1.6 - Use process or exhaust air for combustion & $1.4 \%$ & $1.5 \%$ \\
\hline 1.1 - Reduce steam demand & $1.2 \%$ & $1.5 \%$ \\
\hline 4.3 - Reduce / eliminate furnace openings and leakage & $1.2 \%$ & $1.3 \%$ \\
\hline 4.1 - Proper furnace insulation / maintenance & $1.1 \%$ & $1.3 \%$ \\
\hline 1.1 - Reduce flue gas oxygen content & $0.9 \%$ & $1.1 \%$ \\
\hline 1.3 - Improve boiler efficiency & $0.8 \%$ & $1.1 \%$ \\
\hline 1.16 - Improve insulation & $0.7 \%$ & $0.9 \%$ \\
\hline 2.2 - Clean heat transfer surfaces & $0.4 \%$ & $1.6 \%$ \\
\hline 5.2 - Reduce weight of fixtures, trays, etc. & $0.2 \%$ & $0.2 \%$ \\
\hline 4.2 - Reduce-eliminate internal cooling & $0.1 \%$ & $0.1 \%$ \\
\hline 5.4 - Eliminate continuous flame curtains, pilots & $0.1 \%$ & $0.07 \%$ \\
\hline 1.7 - Use outdoor air for combustion or makeup air & $0.05 \%$ & $0.02 \%$ \\
\hline 1.20 - Optimize multiple boilers & $0.01 \%$ & $0.03 \%$ \\
\hline
\end{tabular}

\section{ES-5.4 Six-Month Results: Immediately Implemented Measures Are Saving \$30.4 Million Per Year}

Implementation results for assessed plants were reported about six months after the 2006 assessments were completed. Participants are committed to reporting results at intervals of 6, 12, and 24 months after their assessments. At the writing of this report, 179 follow-up calls were completed - 103 on steam assessments and 76 on process heating assessments.

The six-month results included the implementation status of each savings opportunity identified in the assessment reports, categorizing each as either 1) immediately implemented, 2) in progress, 3) planning, 
under review, or awaiting funding, 4) rejected, or 5) tried and rejected. Savings results for the first three categories are summarized in Tables ES-4 and ES-5.

Table ES-4. Six-month results for 179 year-2006 Save Energy Now assessments ${ }^{a}$

\begin{tabular}{|c|c|c|c|}
\hline & $\begin{array}{l}\text { Immediately } \\
\text { implemented }\end{array}$ & In progress & $\begin{array}{l}\text { Planned, under review, } \\
\text { or awaiting funding }\end{array}$ \\
\hline Total cost savings (\$/year) & $\$ 30,397,400$ & $\$ 98,109,200$ & $\$ 179,430,300$ \\
\hline Cost savings per assessment (\$/year) & $\$ 169,800$ & $\$ 548,100$ & $\$ 1,002,400$ \\
\hline $\begin{array}{l}\text { Average cost savings per assessment as \% } \\
\text { of annual plant energy costs }\end{array}$ & $1.0 \%$ & $2.0 \%$ & $4.5 \%$ \\
\hline Total site energy savings (MMBtu/year) & $4,035,800$ & $16,685,600$ & $9,771,600$ \\
\hline $\begin{array}{l}\text { Site energy savings per assessment } \\
\text { (MMBtu/yr) }\end{array}$ & 22,500 & 93,200 & 54,600 \\
\hline $\begin{array}{l}\text { Average site energy savings per } \\
\text { assessment as \% of annual site energy }\end{array}$ & $1 \%$ & $1.9 \%$ & $3.6 \%$ \\
\hline Total natural gas savings (MMBtu/year) & $3,495,000$ & $10,161,200$ & $18,449,100$ \\
\hline $\begin{array}{l}\text { Natural gas savings per assessment } \\
\text { (MMBtu/year) }\end{array}$ & 19,500 & 56,800 & 103,100 \\
\hline $\begin{array}{l}\text { Average natural gas savings per } \\
\text { assessment (\%/year) }\end{array}$ & $1.4 \%$ & $4.8 \%$ & $6.9 \%$ \\
\hline Total $\mathrm{CO}_{2}$ savings (metric tons/year) & 234,000 & 984,300 & $1,285,800$ \\
\hline $\begin{array}{l}\mathrm{CO}_{2} \text { savings per assessment (metric } \\
\text { tons/year) }\end{array}$ & 1,307 & 5,500 & 7,200 \\
\hline
\end{tabular}

${ }^{a}$ All percentages in the table and associated text are based only on energy and cost data for the 179 responding plants.

Table ES-5. Distribution of payback periods for savings opportunities, by implementation status.

\begin{tabular}{|c|c|c|c|c|c|}
\hline Payback Category $^{\text {Immediately }}$ & $\begin{array}{c}\text { Implemented } \\
\text { Impinoff }\end{array}$ & In Progress & Planned & Rejected & $\begin{array}{c}\text { Tried and } \\
\text { Rejected }\end{array}$ \\
\hline Sp-9 months $^{\mathrm{a}}$ & $0.1 \%$ & $0.9 \%$ & $0.9 \%$ & $1.0 \%$ & $0.0 \%$ \\
\hline 9 months -2 years & $9.6 \%$ & $10.2 \%$ & $14.7 \%$ & $6.9 \%$ & $0.3 \%$ \\
\hline $2-4$ years & $0.9 \%$ & $7.0 \%$ & $14.5 \%$ & $6.8 \%$ & $0.0 \%$ \\
\hline $4+$ years & $0.7 \%$ & $0.9 \%$ & $8.2 \%$ & $4.7 \%$ & $0.0 \%$ \\
\hline
\end{tabular}

${ }^{a}$ Spinoff is defined as an opportunity identified by an assessed plant as a direct and immediate result of their assessment experience. These opportunities may have been suggested by the Energy Expert, but not documented in the report, or the plant may have identified a new opportunity based on their assessment training or immediate application of the software tools. Plants report these opportunities during the follow-up interviews and only those that are identified as attributed to the assessment are recorded.

The six-month results indicated that most plants had embraced their assessments and were making progress on implementing the savings opportunities. The percentages noted below are data based on the 179 plant responses. Several key trends are indicated:

- Assessed plants reporting results have implemented or are pursuing implementation of $70 \%$ of the potential energy cost savings identified in their assessments. Projects representing the remaining $30 \%$ of identified cost savings have been either rejected or tried and rejected.

- At six months, according to reports from 179 plants, about $7 \%$ of identified potential energy cost savings had been implemented, another $23 \%$ were in progress, and another $41 \%$ were planned, under review, or awaiting funds for implementation. 
- Assessed plants reporting results at 6 months are pursuing $52 \%$ of the natural gas energy savings and $71 \%$ of the total site energy savings identified in the assessments.

- Assessed plants select measures with near-term paybacks for immediate implementation. Those opportunities with longer-term paybacks are more likely to undergo additional technical review or require additional planning.

\section{ES-5.5 Save Energy Now Assessment Process Deemed Highly Useful and Influential in Plants' Decisions to Implement Savings Opportunities}

The six-month interviews with assessment participants at industrial plants also provided feedback to help ITP measure the success of the assessment process and its focus on training plant personnel and fostering their adoption of energy assessment tools. Interviewers asked them about the usefulness of the assessments in their adopting DOE software tools and technical products and the degree of influence that the assessment had on implementation of savings opportunities. Recall that in the Save Energy Now assessment protocol, not only were potential energy savings identified, but Energy Experts also trained participants to use the steam and process heating energy assessment software in their own facilities and introduced other DOE technical tools and resources as well. Nearly $75 \%$ of plants reported that the assessment encouraged the use of DOE software and other products.

Slightly more than $90 \%$ reported that the assessment played an influential or highly influential role in their decisions to implement identified energy savings projects. Only $9 \%$ of assessment participants reported that assessments had slight or no influence on implementation.

Participants were also asked about the culture in their organizations with respect to energy efficiency. Nearly $70 \%$ of assessed plants reported having a written CEO- or Board-approved policy in place that includes the reduction of energy consumption.

\section{ES-6. Key Accomplishments and Findings from the 2006 Save Energy Now Assessment Efforts}

When the Save Energy Now "call to arms" was made by Secretary of Energy Bodman in October 2005, it is unlikely that anyone anticipated the impact that the assessment effort would have on U.S. industry. The following key accomplishments and findings illustrate the value of the 2006 assessment efforts.

From October 2005 to December 2006, the DOE Industrial Technologies Program mobilized to direct and support the Save Energy Now assessment effort and accomplish the goal of conducting 200 industrial plant assessments by the end of 2006. The ability of DOE and its support contractors to achieve this goal was due largely to ITP's past initiatives, including software tool and training development, the IAC program, the Collaborative Targeted Assessment efforts, and the Plant-Wide Assessment program. These programs provided the foundation for development of the protocols for conducting Save Energy Now assessments - specifically, the aspects of the program that defined them as "training assessments."

Large industry and the states have, and continue to, enthusiastically support and value the Save Energy Now assessment efforts. The 2006 assessments were done in 41 states and Puerto Rico for industry plants in 18 U.S. industrial groups. The program's efforts are continuing in 2007 with the goal of conducting 250 assessments, and at this writing (summer 2007), more than 250 plants have been identified for the 2007 assessments. In addition, states including Wisconsin and California are working with DOE to support Save Energy Now assessment efforts through cost sharing. The broad-based participation of U.S. industry and expansion of the program are clear reflections of the value of the assessments to U.S. industry and the states. 
No one anticipated that the average assessment in 2006 would recommend improvements to annually save \$2.5 million in energy costs, 247,000 MMBtu of natural gas, and 20,200 metric tons of plant $\mathrm{CO}_{2}$ emissions. These results are far larger than anticipated. Focusing on large U.S. industrial plants having total energy use greater than 1 trillion Btu per year was a major factor in identifying large potential savings, as was the focus on steam and process heating. The capabilities of the Energy Experts who performed the assessments and the quality of the DOE steam and process heating software tools also contributed to finding large potential savings in the plants.

Even though Save Energy Now assessments were done in only three days, they identified potential energy savings that on average equaled about $10 \%$ of the assessed plant's energy costs. Considering the assessments' tight schedules and training focus, it was encouraging that the average identified potential energy cost savings was about $10 \%$ of plant energy bills. Potential natural gas savings identified through the 2006 assessments was even larger, averaging about $17 \%$ of plant natural gas usage. These results show that it is not necessary to perform long-duration plant energy assessments to identify significant potential savings. The results also indicate that in large plants where assessments have not yet been performed, we can realistically expect savings in the range of $10 \%$ of total plant energy costs to be identified.

For the assessments completed in 2006, the majority of the identified savings opportunities had estimated paybacks of less than two years. This is a very important and unanticipated result. Large potential plant energy savings were identified, and the majority of these savings were for opportunities with paybacks that made their implementation very attractive to plant managers. And, these large savings with attractive paybacks were found in training assessments that were done in just three days.

Many of the individual steam and process heating assessment recommendations have the potential to save more than $1 \%$ of industrial plant energy costs. On average, the recommendations from each of 14 steam opportunity categories and 17 process heating opportunity categories have the potential to save more than $1 \%$ of plant energy costs. Many of the other savings recommendations, in individual plant applications, can also result in substantial energy cost savings. These results suggest the substantial value of implementing the findings from the assessments.

Based on the six-month follow-up interviews with 179 assessed plants, about $7 \%$ of the total number of recommendations for these plants have already been implemented, and an additional $64 \%$ are either in progress or undergoing additional analysis, indicating the potential for the implementation of three quarters of all recommendations. So far, these 179 plants have implemented measures accounting for energy cost savings totaling \$30.4 million per year, natural gas savings of 3.5 trillion Btu per year, and 0.2 million metric tons of reduced $\mathrm{CO}_{2}$ emissions per year. It is likely that one reason for this high rate of implementation is that most recommendations had estimated paybacks of less than two years. The follow-up results at 12 months and 24 months will provide a better picture of the level of implementation of the recommendations.

The philosophy and approach for conducting the assessments - focusing on "training assessments" rather than audits - is clearly a success. The results from six-month follow-ups indicated that $74 \%$ of the plants found that the assessments were useful with respect to encouraging their organizations to adopt DOE software and technical products. Also, over $90 \%$ of the plants found that the assessments played influential to extremely influential roles in their implementing energy savings projects. ORNL conducted immediate follow-up phone calls with Plant Leads immediately after their assessments to discuss how they went. The results from these immediate follow-up calls were overwhelmingly positive. Plant leads perceived high value in the assessment activities, further confirming the effectiveness of the Save Energy Now assessment approach. 


\section{Contents}

\section{EXECUTIVE SUMMARY}

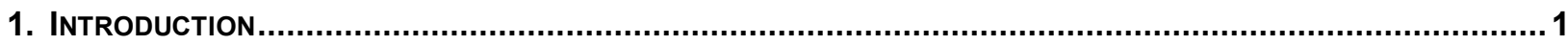

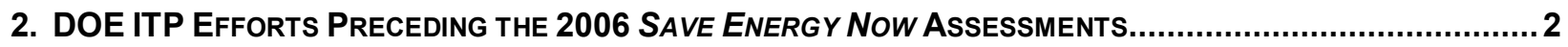

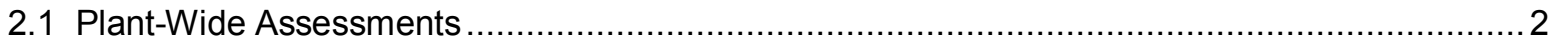

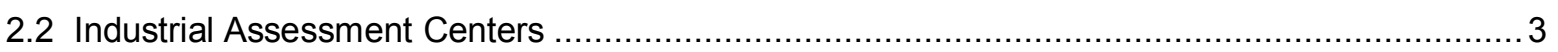

2.3 ITP Decision Software Tools...................................................................................... 3

2.3.1 Process Heating Assessment and Survey Tool (PHAST) and Process Heating

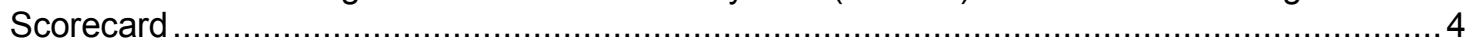

2.3.2 Steam System Scoping Tool (SSST), Steam System Assessment Tool (SSAT) and 3E-

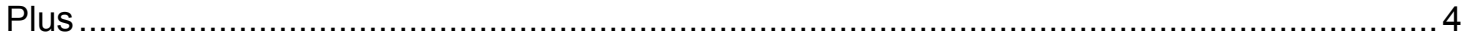

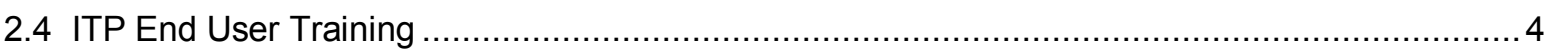

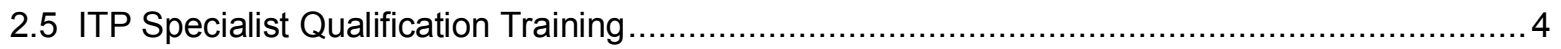

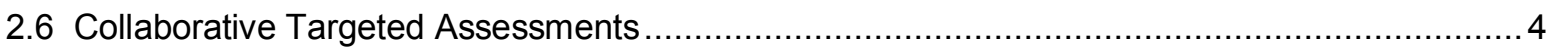

2.7 How Save Energy Now Assessments Evolved From ITP Activities....................................... 5

3. The 2006 SaVe Energy Now Assessment Application Process ................................................. 6

4. The SAVe Energy Now AsSessment Process ....................................................................... 7

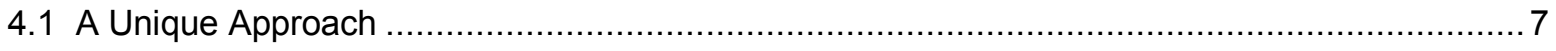

4.2 The Energy Experts Performing the Assessments.......................................................... 7

4.3 Conducting Save Energy Now Assessments - The Full Process ........................................ 8

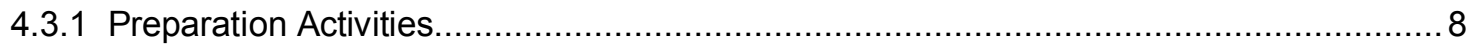

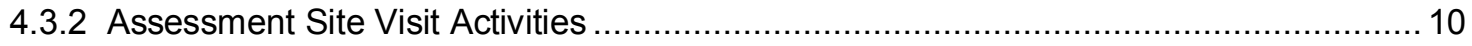

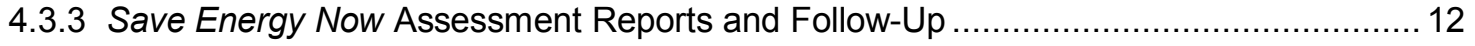

4.4 Summary of Key Save Energy Now Assessment Reports and Deliverables ........................ 16

5. Comprehensive ReView of the 2006 SaVe Energy Now Assessment Results ...............................16

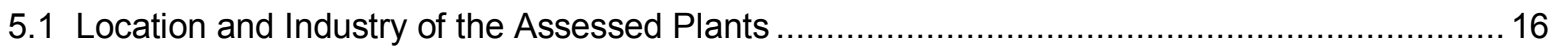

5.2 Summary of Overall Results ................................................................................. 21

5.3 Estimated Paybacks Are Less Than Two Years for Most Identified Savings Opportunities....... 32

5.4 Six-Month Results: Immediately Implemented Measures Are Saving \$30.4 Million Per Year .. 41

5.5 Assessment Process Deemed Highly Useful and Influential in Plants' Decisions to Implement

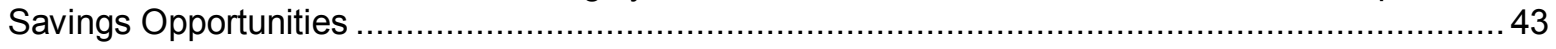

5.6 Implementation of Identified Opportunities by State and Industry ..................................... 45

6. Key Accomplishments and Findings From the 2006 SaVe Energy Now Assessment Efforts ....... 48 


\title{
RESULTS FROM THE U.S. DOE 2006 SAVE ENERGY NOW ASSESSMENT INITIATIVE:
}

\author{
DOE's Partnership with U.S. Industry to Reduce \\ Energy Consumption, Energy Costs, \\ and Carbon Dioxide Emissions
}

\section{INTRODUCTION}

In the wake of Hurricane Katrina and other severe storms in 2005, natural gas supplies were restricted, prices rose, and industry sought ways to reduce its natural gas use and costs. In October 2005, U.S. Department of Energy (DOE) Energy Secretary Bodman launched his Easy Ways to Save Energy campaign with a promise to provide energy assessments to 200 of the largest U.S. manufacturing plants. A major thrust of the campaign was to ensure that the nation's natural gas supplies would be adequate for all Americans, especially during home heating seasons. In a presentation to the National Press Club on October 3, 2005, Secretary Bodman said:

"America's businesses, factories, and manufacturing facilities use massive amounts of energy. To help them during this period of tightening supply and rising costs, our Department is sending teams of qualified efficiency experts to 200 of the nation's most energy-intensive factories. Our Energy Saving Teams will work with on-site managers on ways to conserve energy and use it more efficiently."

DOE's Industrial Technologies Program (ITP) responded to the Secretary's campaign with its Save Energy Now initiative, featuring a new and highly cost-effective form of energy savings assessments. The approach for these assessments drew heavily on the existing resources of ITP's Technology Delivery component. Over the years, ITP-Technology Delivery had worked with industry partners to assemble a suite of respected software decision tools, proven assessment protocols, training curricula, certified experts, and strong partnerships for deployment. Because of the program's earlier activities and the resources that had been developed, ITP was fully prepared to respond swiftly and effectively to the sudden need to promote improved industrial energy efficiency.

Because of anticipated supply issues in the natural gas sector, the Save Energy Now initiative strategically focused on natural gas savings and targeted the nation's largest manufacturing plants - those that consume a total of 1 trillion British thermal units (Btu) or more annually. The approximately 6800 U.S. facilities that fall into this category collectively account for about $53 \%$ of all energy consumed by industry in the United States.

The 2006 Save Energy Now assessments departed from earlier DOE plant assessments by concentrating solely on steam and process heating systems, which are estimated to account for approximately $74 \%$ of all natural gas use for manufacturing. The assessments also integrated a strong training component designed to teach industrial plant personnel how to use DOE's steam or process heating opportunity assessment software tools. This approach had the advantages of promoting strong buy-in of plant personnel for the assessment and its outcomes and preparing them better to independently replicate the assessment process at the company's other facilities.

The Save Energy Now initiative also included provisions to help plants that applied for but did not qualify for assessments (based on the 1 trillion Btu criterion). Services offered to these plants included (1) an assessment by one of DOE's 26 university-based Industrial Assessment Centers (IACs), (2) a telephone 
consultation with a systems expert at the DOE's Energy Efficiency and Renewable Energy Information Center, or (3) other technical materials and services available through ITP (e.g., the Save Energy Now CD).

By the end of 2006, DOE had completed all 200 of the promised assessments, identifying potential natural gas savings of more than 50 trillion Btu and energy cost savings of about $\$ 500$ million. These savings, if fully implemented, could reduce $\mathrm{CO}_{2}$ emissions by 4.04 million metric tons annually. These results, along with the fact that a large percentage of U.S. energy is used by a relatively small number of very large plants, clearly suggest that assessments are an expedient and cost-effective way to significantly affect large amounts of energy use.

Building on the success of the 2006 initiative, ITP has expanded the effort in 2007 with the goal of conducting 250 more assessments in large U.S. industrial plants. The 2007 assessments are addressing not only steam and process heating, but also pumping, compressed air, and fan systems.

This report reviews the tools and resources developed by the DOE ITP program before 2006, which are the foundation and catalyst for the Save Energy Now assessment efforts. The report describes the process by which industrial plants applied to obtain assessments in 2006 and the overall process and philosophy of conducting assessments. A comprehensive review of the results from the 2006 assessments is presented, along with a summary of key accomplishments and findings.

\section{DOE itP Efforts Preceding the 2006 SaVe Energy Now Assessments}

The approach used in conducting the Save Energy Now assessments evolved from the resources and concepts developed in the DOE ITP program over the last decade. This section describes those assessment efforts and resource developments that preceded the 2006 assessment activities:

- $\quad$ Plant-Wide Assessments

- Industrial Assessment Centers

- BestPractices Decision Software Tools

- BestPractices End User Training

- BestPractices Specialist Qualification Training

- Collaborative Targeted Assessments

\subsection{Plant-Wide Assessments}

A plant-wide assessment (PWA) is a systematic assessment of plant-wide operations that addresses a variety of generic and industry-specific technology areas and considers methods for optimizing plant processes. Assessment teams also point out energy management best practices where they see them, and review all best practices in areas such as plant steam, process heating, pumping, and compressed air systems with plant personnel. An assessment typically results in a set of recommendations for specific projects to improve energy efficiency and productivity and to decrease waste and emissions. The PWA is tailored to the facility by the assessment team, and plants are encouraged to identify and employ strategies that can be replicated for facilities and processes similar to their own.

Potential energy and cost savings and reduced environmental impacts are estimated for implementation of identified projects. In many cases, projected cost savings result not only from electricity and/or fuel savings, but also from benefits such as increased productivity, reduced maintenance requirements, reduced production of scrap material, and process improvements. 
The DOE ITP program sponsored PWAs starting in 1999. Plants were selected through an open solicitation process and agreed to a minimum $50 \%$ cost share for conducting the PWAs; the maximum plant award was $\$ 100,000$. PWAs were initiated in 49 facilities through fiscal year 2005 . To date, 40 plants completed final reports documenting assessment results. The combined potential annual cost savings identified at these 40 facilities was about \$200 million per year. Average investment payback periods for the identified savings opportunities were typically less than two years and in many cases less than one year. The last solicitation for PWAs was done in 2005.

More details about the DOE PWA efforts can be found at the following web link: http://www1.eere.energy.gov/industry/bestpractices/plant_wide_assessments.html.

\subsection{Industrial Assessment Centers}

Sponsored by ITP, Industrial Assessment Centers (IACs) provide energy, waste, and productivity assessments at no charge to small and mid-sized manufacturers (having gross annual sales below $\$ 100$ million and annual energy bills between $\$ 100,000$ and $\$ 2$ million). The assessments are performed by teams of engineering faculty and students from one of 26 participating U.S. universities. IAC teams conduct one- or two-day site visits to identify energy and cost saving opportunities. In addition to direct energy and cost savings benefits, the IAC program offers industry a longer-term benefit - a trained workforce of students who become energy engineers and contribute to improving energy efficiency throughout their careers, including playing active roles as DOE Qualified Specialists and Energy Experts.

The IAC results database is recognized as one of the most comprehensive industrial energy databases in the world. This database includes information on nearly 100,000 cost saving opportunities identified for industry through 13,500 assessments conducted over the last 20 years. These assessments have saved IAC clients an average of more than $\$ 55,000$ per year for each assessment, with paybacks typically averaging a year or less.

More details about the DOE IAC efforts can be found at the following web link: http://www1.eere.energy.gov/industry/bestpractices/iacs.html.

\subsection{ITP Decision Software Tools}

The ITP program developed a suite of software-based decision tools to help industrial plant personnel identify energy efficiency improvements for plant process and utility systems. These tools use analytical models to evaluate process heating, steam, pumping, compressed air, fan, motor, and other plant utility systems. There is also a Quick Plant Energy Profiler, or "Quick PEP," online software tool that helps industrial plant personnel to quickly understand how energy is used at the plant and how they might save energy and reduce costs.

All of the software tools focus on energy efficiency "opportunity" assessments - quantifying the potential savings from specific improvements. For example, there are often potential savings from increasing condensate return in steam systems or reducing excess oxygen to furnaces for process heating.

DOE ITP has partnered with key trade associations and focused technical groups to develop the software tools. For example, DOE worked with the Hydraulics Institute to develop the pump tool, with the International Heating Equipment Association to develop the process heating tool, and with the Air Movement and Controls Association to develop the fan tool.

The DOE steam and process heating decision tools, described below, were used for the 2006 assessments. 


\subsubsection{Process Heating Assessment and Survey Tool (PHAST) and Process Heating Scorecard}

PHAST is a tool for surveying process heating equipment that uses fuel, electricity, or steam (though only the direct-fuel-fired systems modeling is presently developed) and identifying the most energy-intensive equipment. PHAST performs energy (heat) balances on furnaces to identify ways to improve efficiency. PHAST has several calculators that compare the performance of individual pieces of equipment under various operating conditions. The Process Heating Scorecard is a pre-screening tool.

\subsubsection{Steam System Scoping Tool (SSST), Steam System Assessment Tool (SSAT) and 3E-Plus}

Three tools address steam systems. The SSST is a steam system pre-screening tool that allows plants to develop a greater awareness of steam system improvement opportunities in their facilities. An SSST analysis was performed for each steam assessment. The SSAT estimates the impacts of key steam system improvements for models of representative plant steam systems. SSAT generates results detailing the energy, cost, and emissions savings that could be achieved by up to 18 different improvements. 3E-Plus calculates the most economical thickness of industrial insulation for operating conditions entered by the user.

More details about all of the DOE ITP decision software tools can be found at the following web link: http://wwwl.eere.energy.gov/industry/bestpractices/software.html.

\subsection{ITP End User Training}

DOE ITP conducts instructor-based training for end users that focuses on reviewing key plant energy savings opportunities in plant utility and process systems. End user training also introduces the ITP software tools relevant to the training provided. These sessions, typically one day long, are presently available for motors, compressed air systems, pumping systems, steam systems, process heating systems, and fan systems. More than 10,000 people have attended end user training sessions, which are offered year-round throughout the United States.

\subsection{ITP Specialist Qualification Training}

Specialist Qualification training focuses on how to use individual ITP software tools to make valid estimates of energy and cost savings in industrial plants. This training is presently offered for the DOE ITP software tools for compressed air, pump, steam, process heating, and fan systems. These instructorbased training sessions are typically two and a half days long. The first two days focus on specific issues associated with using a particular software tool. A three- to four-hour hour exam is given during the last half day of training. Trainees who pass this exam are designated as "Qualified Specialists" for a specific software tool, and their contact information is put on the DOE ITP web site. More than 460 individuals have been designated as Qualified Specialists to use the DOE ITP software tools, and most of the university-based IACs have staff who are Qualified Specialists. All of the Energy Experts for 2006 had achieved the Qualified Specialist designation for using the steam or process heating tools as part of the requirements for qualifying as Energy Experts.

More details about ITP end user and specialist qualification training and when these training sessions are offered can be found at the following web link:

http://www1.eere.energy.gov/industry/bestpractices/training.html.

\subsection{Collaborative Targeted Assessments}

Starting in fiscal year 2001, the ITP program sponsored Collaborative Targeted Assessments (CTAs) in selected industrial plants. These three-day CTAs were done to reinforce the information presented in the end user training and to provide training on the use of the ITP decision software tools. To be selected for 
these CTAs, plants had to have one or more staff who had attended the ITP end user training in the area of interest (e.g., process heating for PHAST use). The two primary benefits of the CTAs were that plant personnel had the opportunity to reinforce the information learned while attending the training workshop, and that energy efficiency improvement opportunities were identified during the CTA.

From fiscal years 2001 through 2005, 85 CTAs were performed to investigate steam, process heating, pump, compressed air, and fan system improvements. The total potential energy savings identified from these CTAs was about $\$ 40$ million per year. In addition, the average process heating CTA identified about $\$ 1.1$ million per year in potential savings, and the average steam CTA identified about $\$ 600,000$ per year in potential savings.

\subsection{How Save Energy Now Assessments Evolved From ITP Activities}

Plant-wide assessments, IAC assessments, decision software tools, end user and specialist qualification training, and CTAs all contributed significantly to the development of the Save Energy Now assessment concept. Because these ITP activities were already well established when these assessments were introduced, ITP was able to expedite its contribution to Save Energy Now, bringing mature strategies and tools to bear immediately. ITP's previous efforts laid the groundwork for the assessments:

1. PWAs demonstrated that significant savings opportunities could result from assessments performed in large industrial plants.

2. IAC assessment results indicated that significant savings could be identified in small and medium-size industrial plants. Perhaps more importantly, the IAC directors, staff, and alumni who became Qualified Specialists became a significant core group of the Energy Experts who performed process heating and steam assessments in 2006. Also, IAC students with experience conducting energy assessments were called on to follow up after the assessments and collect implementation data from the assessment participants.

3. The ITP decision software tools provided the capability to identify significant energy savings opportunities in energy-intensive systems in industrial plants.

4. The ITP end user training provided information to plant personnel about the types and magnitudes of energy savings opportunities available in industrial plant systems and with an introduction to the decision software tools.

5. The Specialist Qualification training provided extensive details on how the decision software tools could be appropriately applied in plant systems. The Qualified Specialists became decision software tool experts who could be called on to perform assessments in large industrial plants.

6. CTAs were the testing ground for the concepts that were adopted for the Save Energy Now assessment process, such as the strong training element, and the requirements for plant personnel to attend end user training and take an active role in the assessment. The results of the process heating and steam CTAs proved the concept, clearly showing that these kinds of assessments could yield large cost and energy savings. The reporting form for CTAs was actually used as the basis for what became the assessment summary report form.

7. The final important element of the initial assessment efforts was the decision to focus on large plants. ITP did an analysis of the 1998 Energy Information Administration (EIA) 
Manufacturing Energy Consumption Survey (MECS) data. This data indicates relatively few manufacturing plants in the U.S. use the majority of the energy. There are about 226,000 manufacturing plants in the U.S. Of these about 6800 plants are "large" - with annual energy costs greater than \$2 million/year. These large plants, based on the 1998 MECS data, consume about $53 \%$ of the total annual industrial energy use in the U.S. Focusing on these large plants for assessments will lead to the greatest potential impact on U.S. manufacturing energy use.

\section{The 2006 Save Energy Now Assessment Application Process}

The application process for large industrial plants to qualify for Save Energy Now assessments in 2006 was initiated on November 8, 2005, and closed on January 17, 2006, after the majority of qualified plants had been identified. Manufacturing facilities in the United States and its territories were eligible to apply.

To be considered for assessments in 2006, companies completed and submitted an application form on the DOE Save Energy Now Web site. The application asked for contact information and energy use data for the plant or plants that were seeking assessments. To focus the assessments on large plants, DOE required that applicants have a total energy use of at least 1 trillion Btu per year, either in one or several plants. If the applicant's energy use was greater than 10 trillion Btu per year, the company could potentially obtain more than one assessment.

Applicants for assessments also completed a user agreement pledging that if awarded an assessment, the company would do the following:

1. Provide a single point of contact for coordination with the DOE Energy Expert.

2. Work with plant managers that participate in the assessment to consider investing in the energy savings opportunities that the assessment identified, consistent with corporate financial policies.

3. Have DOE recognize the company and plants involved in the assessment for participating in the Save Energy Now initiative.

4. Have staff from participating plants attend a DOE end user training on steam or process heating systems either before the assessment or as soon after as possible.

5. Allow a DOE Energy Expert to work with their staff to identify energy savings opportunities.

6. Allow the DOE Energy Expert to report on the energy savings opportunities identified.

7. Provide information to DOE on progress toward implementing the identified savings 6,12 , and 24 months after the assessment.

8. Provide information to DOE on replication of the assessment findings at other company plants 6,12 , and 24 months after the assessment.

DOE ITP program staff reviewed all of the assessment applications that were submitted. DOE evaluated the total energy consumption, especially natural gas, toward qualification for obtaining assessments. All companies that completed the application process received some type of support from the DOE ITP program.

The first DOE contact with plants whose applications indicated that they met the size and energy use requirements to obtain an assessment was from DOE Regional Office personnel, who confirmed the information from the application such as the type of assessment requested (steam or process heating), potential dates for conducting the assessment, plant description and address, and who the Energy Expert should initially contact. This information was forwarded to the ORNL Save Energy Now staff so that they 
could begin the process of identifying the Energy Experts to perform the assessments and facilitate their first contacts with the plants.

Applications that did not meet the minimum 1 trillion Btu per year energy use threshold received either an IAC assessment, technical support from the Energy Efficiency and Renewable Energy (EERE) Information Center staff, or a package of technical information on DOE ITP software and resources.

\section{The Save Energy Now Assessment Process}

\subsection{A Unique Approach}

Save Energy Now assessments use a unique approach for conducting in-plant energy efficiency assessments. Energy audits or assessments are typically done by energy experts who go into a plant, identify potential savings opportunities, and write reports that are left with the plant personnel after the assessments are completed. Save Energy Now assessments, in contrast, are training assessments. The 2006 assessments focused on training industrial plant personnel specifically on how to use either the DOE steam or process heating software tools. Save Energy Now assessments are done in no more than 3 days, so, by necessity, they are very focused assessments. When an Energy Expert makes contact with a plant, he identifies a Plant Lead who has to agree to stay with the Energy Expert during the entire 3-day assessment. The Energy Expert, Plant Lead, and other plant personnel who participate in the assessment identify some "target" opportunities to investigate using the DOE software. The target opportunities chosen are often ones with the potential to achieve significant plant energy and cost savings. The Energy Expert and plant personnel identify any data requirements for assessing the target opportunity, obtain or measure data as necessary, and enter that data in the DOE software to quantify a specific energy savings opportunity. Often, no more than 3 or 4 target opportunities are investigated during an assessment.

On the last day of the assessment, a required Closeout Meeting is held to review and discuss the opportunities identified in the assessment Plant management are invited to attend and participate. Prior to the Closeout Meeting, the Energy Expert and the Plant Lead agree on the opportunities that will be highlighted at the meeting and documented in the final assessment report. No opportunities are discussed at the Closeout Meeting or presented in the assessment report without the Plant Lead's approval.

The positive effect of using this approach for conducting assessments is that: 1) plant personnel get hands-on experience in how to effectively use the DOE software tools and on the value of applying these tools to their operations; 2) plant personnel have buy-in to the opportunities identified and evaluated during the assessment, which increases the likelihood that many of the identified opportunities will implemented ; and 3) plant opportunities are investigated that often can result in significant energy and cost savings for the host plant.

The remainder of this section describes the overall process used in carrying out the DOE assessments how the "Energy Experts" were chosen to conduct the assessments, the protocol for performing assessments, and the information provided to DOE after assessments are completed.

\subsection{The Energy Experts Performing the Assessments}

The Energy Experts in steam and process heating for 2006 were chosen based on two solicitations that were open to Energy Experts who had completed the Qualified Specialist training and passed the DOE Qualified Specialist exam for either the steam or process heating software tools.

The ORNL ITP support program staff conducted the first solicitation in October - November 2005. As a result of this solicitation, 29 Energy Experts were chosen - 21 steam experts and 9 process heating 
experts (one with qualifications in both steam and process heating). A session to train the experts in the protocols for conducting assessments was completed in mid December 2005.

As scheduling for the assessments began in late December 2005 and early January 2006, it became clear that not enough process heating experts were available to perform the number of process heating assessments that were requested, so an additional solicitation was conducted in February 2006. Seven additional process heating experts and one additional steam expert were identified through the second solicitation and were trained in the assessment protocols in March and April 2006.

The overall process of conducting assessments started with the selection of individual Energy Experts to perform each of the assessments. The initial decisions on who would do which assessment was based on: 1) availability of an Expert to perform the assessment on the dates requested by the individual plant; 2) the capabilities of the Energy Experts relevant to performing assessments in specific industries; and 3) an attempt to minimize travel for the Energy Experts. In some cases, plants requested specific Energy Experts to perform their assessments, and in almost all cases these requests could be accommodated.

\subsection{Conducting Save Energy Now Assessments - The Full Process}

\subsubsection{Preparation Activities}

Figure 1 illustrates the Save Energy Now assessment activities from the time of the initial contact with the host plant to when the expert arrives on site to perform the assessment. The substantial interaction between the Energy Expert and the plant during this period was designed to make the on-site assessment activities as effective as possible. The preparations for the assessment began after the Energy Expert was designated for the assessment and he or she called the contact personal at the plant (the Industrial Plant Contact).

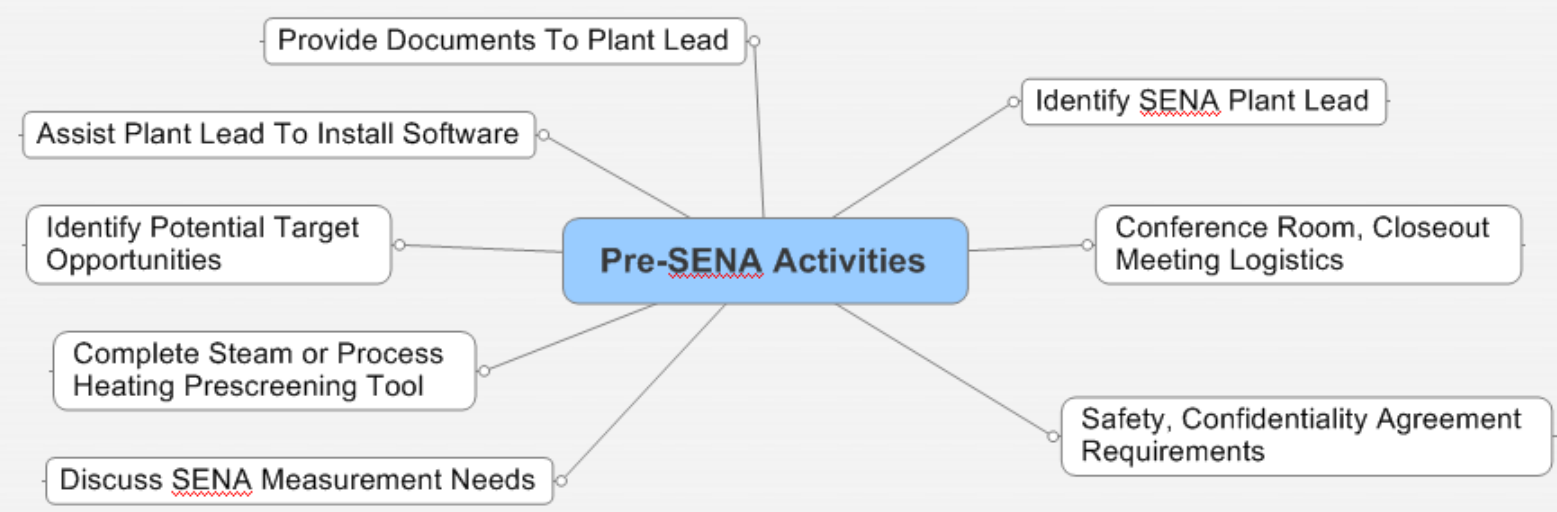

Figure 1. Before a Save Energy Now assessment (SENA), the expert works with the Plant Lead to prepare for a successful assessment.

The first order of business in contacting the plant is to establish who is the Plant Lead - a very important initial step. A primary condition for assessment eligibility is that a Plant Lead be named who agrees to stay with the Energy Expert during the full three days of assessment activities. The Plant Lead's role and full participation are vital to making the process work and getting full value from the assessment. The assessment truly begins when the Energy Expert and Plant Lead begin preparations. 


\section{Safety and Confidentiality Requirements}

The Energy Expert also needs to determine what the safety requirements are for the participating plant and whether he or she will be required to comply with any confidentiality agreements. Generally the expert will attend a safety briefing early on the first day, but in some instances more detailed safety training may be required. Many of the plants have required the expert to sign a confidentiality agreement to protect plant information.

\section{$\underline{\text { Logistics }}$}

Before the site visit, the Energy Expert requests that a conference room with internet connection be reserved for the on-site assessment activities and that a closeout meeting be scheduled for the last afternoon of the assessment. Having a dedicated conference room ensures that the Energy Expert and Plant Lead can efficiently work together with the DOE software tools for assessment analyses. Setting up the closeout meeting is important to ensure that the assessment results are discussed with plant personnel - ideally with upper management participation — at the end of the assessment.

\section{$\underline{\text { Program Documents }}$}

The Energy Expert provides a number of documents and forms to the Plant Lead before arriving at the site, the most important being 1) a copy of the plant data that the company submitted in its application (the Plant Lead needs to confirm that the plant energy use data is correct), 2) a copy of the agreements the company made when filing the assessment application (the Plant Lead needs to confirm that he or she understands these agreements); and 3) the "Energy Management Practices Questionnaire" for the Plant Lead to complete and submit to the Energy Expert.

\section{$\underline{\text { Prescreening Tools }}$}

The Energy Expert also provides a prescreening tool to the Plant Lead - for steam assessments, the Steam System Scoping Tool (SSST) and for process heating assessments the Process Heating Scorecard. The Plant Lead is to complete the prescreening prior to the assessment (in some cases with the expert's help). The answers that the plant provides to the SSST or Process Heating Scorecard often provide insights into savings opportunities to investigate during the assessment.

\section{Identifying Target Opportunities}

An important goal of pre-assessment activities is to identify the potential opportunities that merit investigation during the three-day assessment. The Energy Expert and Plant Lead need to do this because it is unlikely that all potential opportunities can be investigated in three days. The objective is to identify opportunities that can be good vehicles for training the Plant Lead to use the software tools and can also lead to meaningful cost and energy savings for the plant.

\section{$\underline{\text { Software Decision Tools }}$}

The Energy Expert also informs the Plant Lead that he or she will need to install the steam or process heating software decision tool on his computer, and that the Plant Lead will be duplicating the software data entry that the Energy Expert does to evaluate identified savings opportunities. This is a part of the training element of the assessment process - helping the Plant Lead to become familiar with applying the software tools to estimate potential plant energy savings. The Energy Expert either provides a web link so that the Plant Lead can download and install the software tool, or he/she sends a copy of the software installation file directly to the Plant Lead so that he can install the software on his computer. 


\section{Data and Measurement Needs}

The Energy Expert and the Plant Lead will discuss the data needed for the software tool analysis and whether the plant has the equipment (instruments such as combustion analyzers and temperature measurement devices) for collecting the data. If not, the Energy Expert's own equipment or equipment purchased by DOE (available through ORNL) can be used.

\subsubsection{Assessment Site Visit Activities}

The on-site portion of the three-day assessment is intense, with much to be accomplished to achieve the goals of the assessment. Figure 2 illustrates the major activities of these three days. A typical assessment schedule is reviewed below.

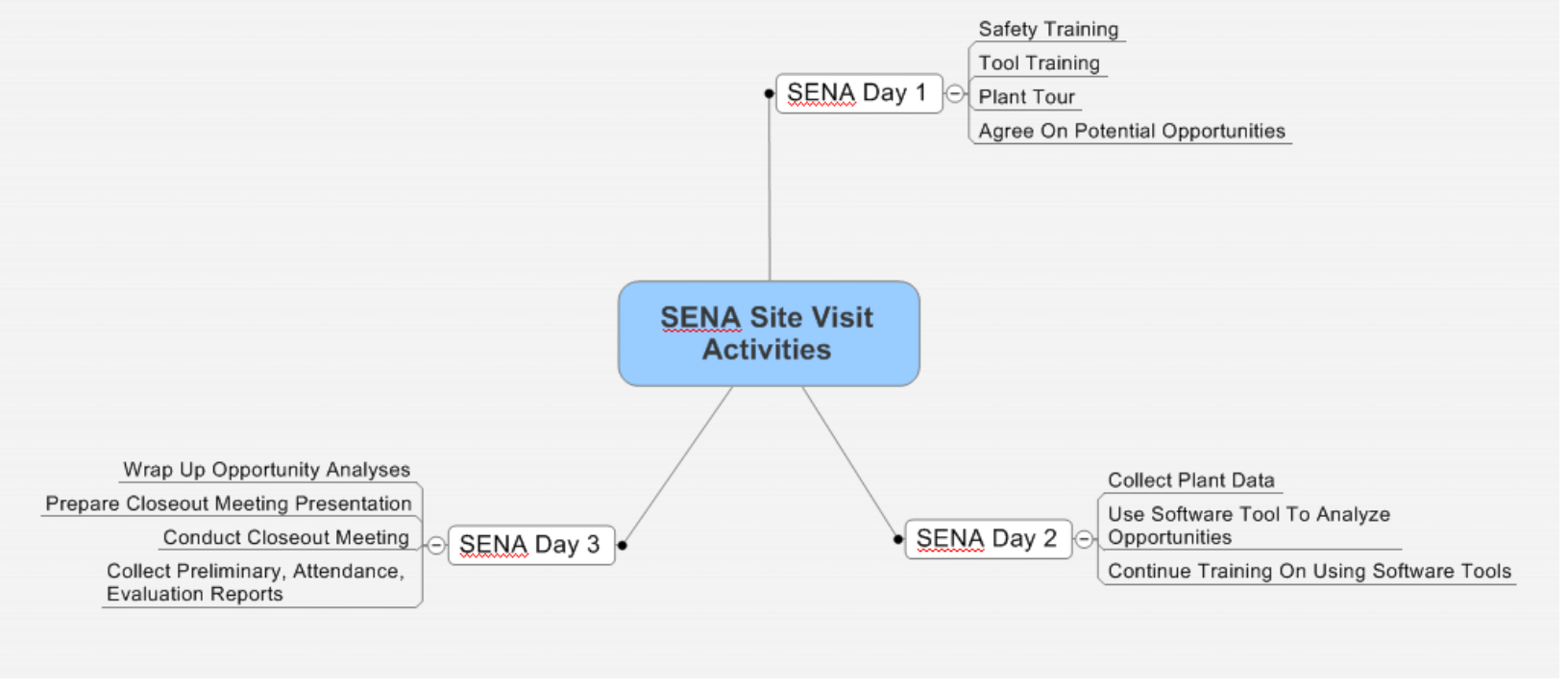

Figure 2. Save Energy Now assessments (SENAs) are focused, three-day training assessments.

\section{Assessment Day 1}

The activities listed below generally take place on the first day of the assessment, though not always precisely in this order.

- Energy Expert fulfills safety requirements

- Energy Expert leads meeting with Plant Lead and other plant participants

- Distributes sign-in sheet

- Distributes assessment evaluations sheets for participants to complete and return to the Expert at the end of the assessment

- Overview of the software decision tool that will be used (steam or process heating). This is a first step in training plant personnel to use the tool.

- Discussion of results from the Steam System Scoping Tool or Process Heating Scorecard for the plant

- Walk-through of the plant (or parts to be assessed)

- Discussion and initial agreement on the target opportunities for investigation in the assessment. 
- Some data collection (possibly on the first day).

In summary, by the end of the first day the plant personnel have had an initial exposure to the DOE steam or process heating tool, the team has done a thorough walk-through of the plant areas relevant to assessment analyses, the scope of the assessment has been agreed on, and, ideally, data collection has begun.

\section{$\underline{\text { Assessment Day } 2}$}

Day 2 of an assessment is the "meat and potatoes" day. Data collection continues until sufficient results are obtained to permit opportunity analyses to be performed. The entire assessment team may stay together to collect the needed data, perhaps led by the Energy Expert. In cases where there is a lot of data to collect in a short time, small teams may collect data on different systems in parallel. After the necessary data is collected, the real training element of the assessment begins.

To perform individual assessment opportunity analyses, the Energy Expert enters data into the software while explaining what he is doing to apply the software to investigate the opportunity. At the same time, the Plant Lead is also entering data into a second copy of the software, and the expert and Plant Lead work together to ensure that the same data is entered in both systems.

This process is continued for the different opportunities that are investigated for the assessment. Some opportunities will be clear "winners" that the expert and Plant Lead easily agree should be included in the final report and their implementing investigated. Some will clearly not be worth pursuing further. And for some opportunities the analysis will raise questions that need to be answered by more data collection and/or more data analysis.

By the end of the second day of the assessment, significant training on the use of the DOE software tool will have been done by analyzing potential savings opportunities in the plant. The Plant Lead will have hands-on experience in applying the software tool, under the leadership of the Energy Expert. The Expert and Plant Lead should be reaching agreement on the opportunities that will be included in the final report for further investigation and possibly implementation.

After leaving the plant for the day (typically), the Energy Expert has enough information to draft the "preliminary report," to be submitted for review on day 3 and approved by plant personnel before the assessment is completed.

\section{Assessment Day 3}

The main activities for Day 3 are wrapping up the opportunity analyses and preparing for and holding the Closeout meeting.

During the morning, the Energy Expert and Plant Lead will

- finalize the calculations performed to quantify potential savings from the identified opportunities

- agree on all opportunities that will be discussed during the Closeout meeting

- prepare for the Closeout Meeting, including developing PowerPoint slides to summarize the assessment activities, and again ensure that they are agreed on what will be presented and discussed during the meeting.

Closeout Meetings are typically one to two hours long. Plant management personnel are invited to attend these meetings. The Plant Lead may making the presentation if comfortable doing so; otherwise, the Energy Expert makes this presentation. The closeout presentation covers

- an overview of the assessment activities conducted, 
- a discussion of Plant Best Practices identified during the assessment (excellent operational practices such as having an effective steam trap maintenance program in place), and

- a thorough review of the assessment opportunities evaluated and the estimated cost and energy savings for these opportunities.

When the Energy Expert leaves the plant on Day 3, he or she will hopefully have the completed assessment attendance list, evaluations from the plant personnel who participated in the assessment, and a site-approved version of the assessment preliminary report.

By the end of the assessment, the Plant Lead should have a good understanding of how to use the DOE steam or process heating software to evaluate energy savings opportunities, and should be confident that at least some of the opportunities evaluated will provide good cost and energy savings for the plant if they are implemented. Finally, participants from other company plants will now have access to someone with experience in applying and using the DOE software to evaluate energy savings opportunities.

\subsubsection{Save Energy Now Assessment Reports and Follow-Up}

After the site visit, the focus of the Energy Expert is on completing the major assessment reports and obtaining Plant Lead approval for them.

$\underline{\text { One-Day Reports }}$

Several reports are sent to the DOE through ORNL within one business day after the assessment has been completed. The "one-day" reports include:

- the approved preliminary report,

- a summary of assessment attendance,

- a summary of assessment evaluations from plant personnel who participated in the assessment, and

- a summary of the energy management questionnaire results submitted by the plant to the Energy Expert.

These reports are submitted electronically to ORNL and after technical review and evaluation are submitted to DOE.

\section{Assessment Summary Report and Savings Spreadsheet}

The main post-assessment activity for the Energy Expert is to prepare a Draft Assessment Summary Report and a Draft Assessment Savings Spreadsheet. Figures 3 and 4 show the template used for the summary report. The first page (Figure 3) provides a summary of background information for the assessment, a summary table of the identified opportunities with associated dollar and energy savings, and a summary of any Best Practices identified at the plant. The Energy Expert uses specific "pick list" words to describe the identified opportunities. These pick lists were developed (separately for steam and process heating) so that the opportunity descriptions could be sorted by pick list phrases. For example, DOE could easily determine that many process heating opportunities associated with "reduce excess air" were identified.

Figure 4 shows the template for the narrative portion of the Assessment Summary Report. The Experts were directed to keep the narratives brief - preferably no longer than 2 to 3 pages. The narrative is intended to provide some background information on the assessment, highlight the main energy savings opportunities identified in the assessment, and characterize them as near-, medium-, or long-term opportunities (defined in Figure 4). 
SENA-xxx 10 Day Summary Report (revl)

\begin{tabular}{|c|l|c|l|}
\hline Company & & SENA Dates & \\
\hline Plant & & SENA Type & \\
\hline Product & & $\begin{array}{c}\text { SENA } \\
\text { Specialist }\end{array}$ & \\
\hline \multicolumn{2}{|c|}{ PLANT CONTACT INFORMATION } & & \\
\hline Name & & & \\
\hline Address & & & \\
\hline City/State & & & \\
\hline Phone & & & \\
\hline e-mail & & & \\
\hline & & & \\
\hline & & & \\
\hline & & & \\
\hline
\end{tabular}

\begin{tabular}{|c|c|c|c|c|c|}
\hline \multicolumn{6}{|c|}{ ENERGY SAVINGS OPPORTUNITY SUMMARY INFORMATION } \\
\hline \multirow[b]{2}{*}{ Identified Opportunity } & \multicolumn{5}{|c|}{ Savings/yr } \\
\hline & $\$$ & kWh & MMBty & Fuel Type & $\mathrm{N}, \mathrm{M}, \mathrm{L}$ \\
\hline & & & & & \\
\hline & & & & & \\
\hline & & & & & \\
\hline & & & & & \\
\hline & & & & & \\
\hline
\end{tabular}

\section{IDENTIFIED PLANT BEST PRACTICES}

\begin{tabular}{|l|l|}
\hline & \\
\hline & \\
\hline & \\
\hline & \\
\hline
\end{tabular}

Figure 3. Template of the first page of the Assessment Summary Report. 
Brief Narrative Summary Report for the Save Energy Now Assessment:

Introduction:

Objective of SENA:

Focus of Assessment:

Approach for SENA:

General Observations of Potential Opportunities:

- Indicate total plant natural gas cost for base year, 2005 ? (please obtain this if possible)

- Indicate impact fuel cost in W/MMBtu, impact electrical cost in centsikWh if necessary for SENA

- Note what you would expect would be Near Tem, Medium Tem, Long Tem opportunities. See definitions below:

a Near tem opportunities would include actions that could be taken as improvements in operating practices, maintenance of equipment or relatively low cost actions or equipment purchases.

- Medium tem opportunities would require purchase of additional equipment andior changes in the system such as addition of recuperative air preheaters and use of energy to substitute current practices of steam use etc. It would be necessary to carryout further engineering and retum on investment analysis.

- Long tem opportunities would require testing of new technology and confimation of perfomance of these technologies under the plant operating conditions with economic justification to meet the corporate investment criteria.

- Estimate, if possible, $\%$ plant natural gas savings from a) Near Term opportunities; b) Medium Tem opportunities, c) Long Tem opportunities.

Management Support and Comments:

DOE Contact at Plant/Company: (who DOE would contact for follow-up regarding progress in implementing SENA results...)

Figure 4. Template for the narrative section of the Assessment Summary Report.

The format for entering data into the Draft Assessment Savings Spreadsheet is shown in Figure 5. The Expert provides energy information for the participating plant, consumption and cost of natural gas, electricity, and "other" fuels. The expert also enters data on the identified opportunities (much of it the same data as summarized in the Assessment Summary Report), and also enters low and high estimates of capital expenses to implement each identified opportunity. These conceptual capital expense estimates are not based on detailed analyses, but on the experts' experience with implementing steam or process heating opportunities in plants.

The Energy Expert submits the Draft Assessment Summary Report to the Plant Lead for review, comment, and final approval and to ORNL for technical review and comment. After approval by the plant, the report is sent to ORNL for final approval. ORNL either asks for final revisions to be made to 
the submitted report or approves it as submitted and forwards the report to the DOE Energy Savings Assessment Management System (ESAMS) database. The detailed plant and energy savings information in the ESAMS database is held confidential.No information on individual plants is reported by the DOE in public documents. All of the information provided to Energy Experts for the Assessment Summary Report and the Assessment Savings Spreadsheet is held confidential by DOE. There are public reports available on the DOE Web site for many of the assessments, but none of these are made public until plant personnel have approved their release to the public.

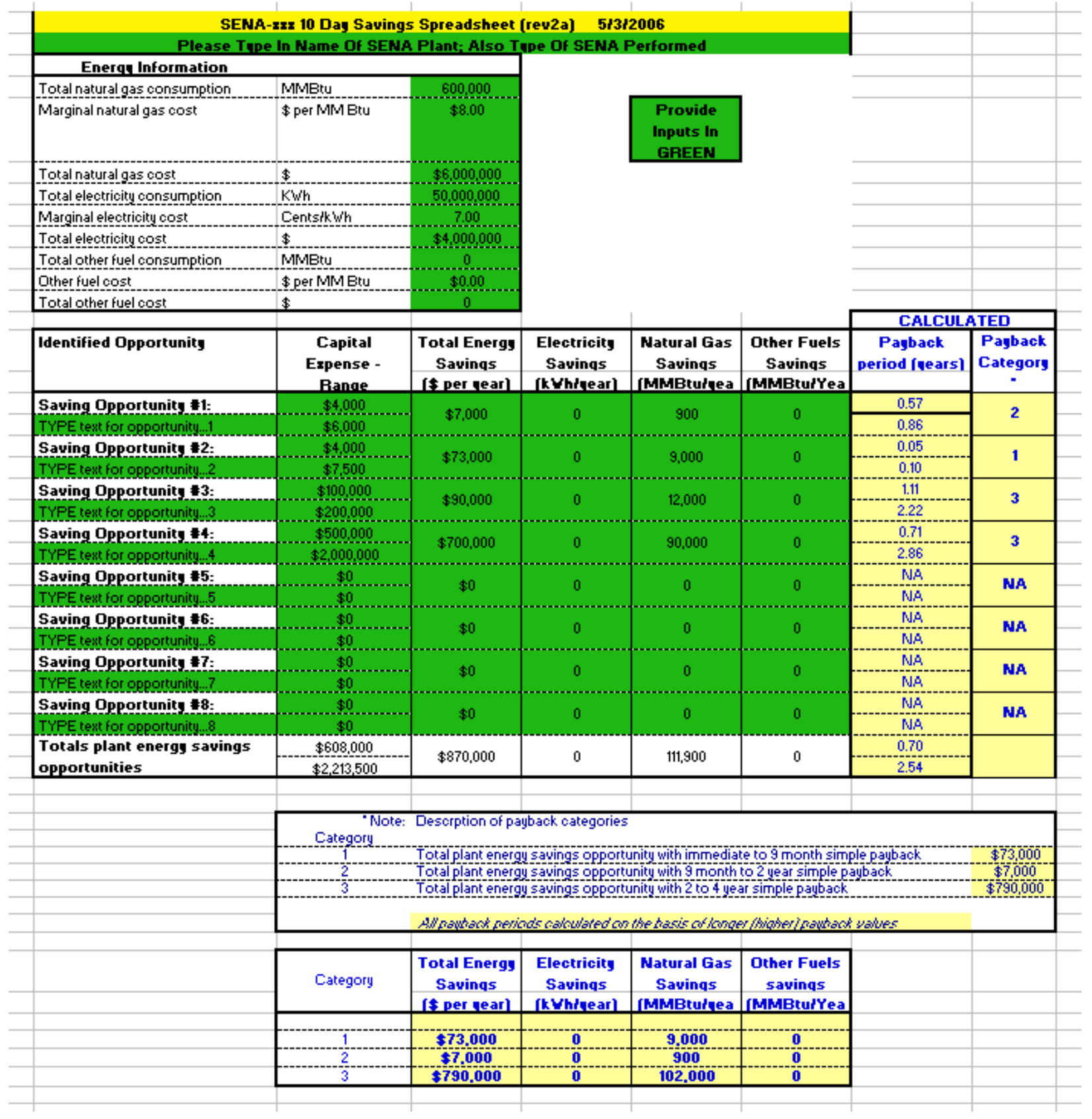

Figure 5. Assessment Savings Spreadsheet template. 
After the Assessment Summary Report is approved as final by ORNL, the final contact between the Energy Expert and the Plant Lead occurs to see if any identified opportunities have yet been fully implemented. In most cases, no implementation has been done, but there have been cases where identified opportunities have been implemented very quickly. The Energy Expert informs ORNL of this information, and the information is submitted to the ESAMS database.

As part of their agreement with DOE, participating plants provide implementation information 6,12 , and 24 months after the assessment. This information is gathered through interviews conducted by knowledgeable engineering students from DOE's IACs. ORNL manages collection of this information, and implementation data is recorded in the ESAMS database.

Finally, ORNL manages the technical review and evaluation of all of the Save Energy Now assessment program metrics including energy, cost, and emission savings data, payback period information, and implementation follow-up information.

\subsection{Summary of Key Save Energy Now Assessment Reports and Deliverables}

The following reports and deliverables were assembled, technically evaluated and reviewed, and provided to DOE and the ESAMS database for each of the assessments:

1. An approved preliminary report;

2. Attendance information for plant personnel who participated in the assessment;

3. An assessment evaluation summary - plant personnel responses to questions on the performance of the Energy Expert and on the value of the DOE software tools;

4. A completed energy management questionnaire;

5. An approved Final Assessment Summary Report (see figures 3 and 4);

6. A submitted Final Assessment Savings Spreadsheet (see Figure 5);

7. A completed copy of the Steam System Scoping Tool results or the Process Heating Scorecard results; and

8. A copy (for archival purposes only, these were not reviewed and evaluated) of the SSAT or PHAST data files used in performing the assessment analyses.

\section{Comprehensive ReView of the 2006 SAVE Energy Now Assessment Results}

\subsection{Location and Industry of the Assessed Plants}

The assessments were conducted in 40 states and Puerto Rico, mostly in the midwestern, eastern, and southern United States, where the majority of large U.S. industrial sites are located. Figures 6 and 7 show the breakdown of the 2006 assessments by state, and Table 1 shows the industry sectors represented by the plants. The states with the most assessments were Texas, with 30, and Louisiana, with 15 . In 17 states, 4 or more assessments were completed. 


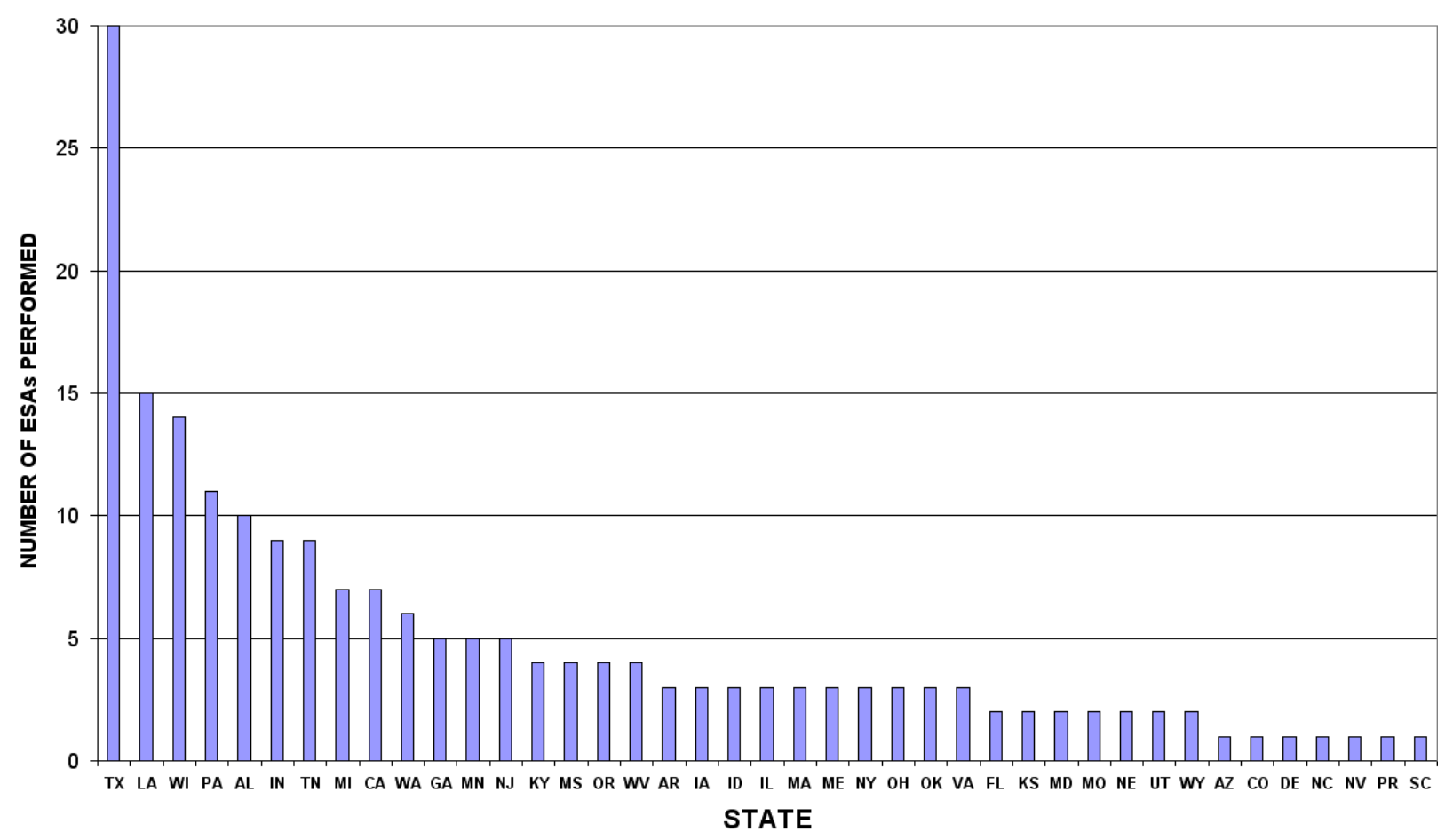

Figure 6. In 2006, 200 assessments were performed in 40 states and one territory (Puerto Rico). In 17 of these states, 4 or more assessments were conducted.

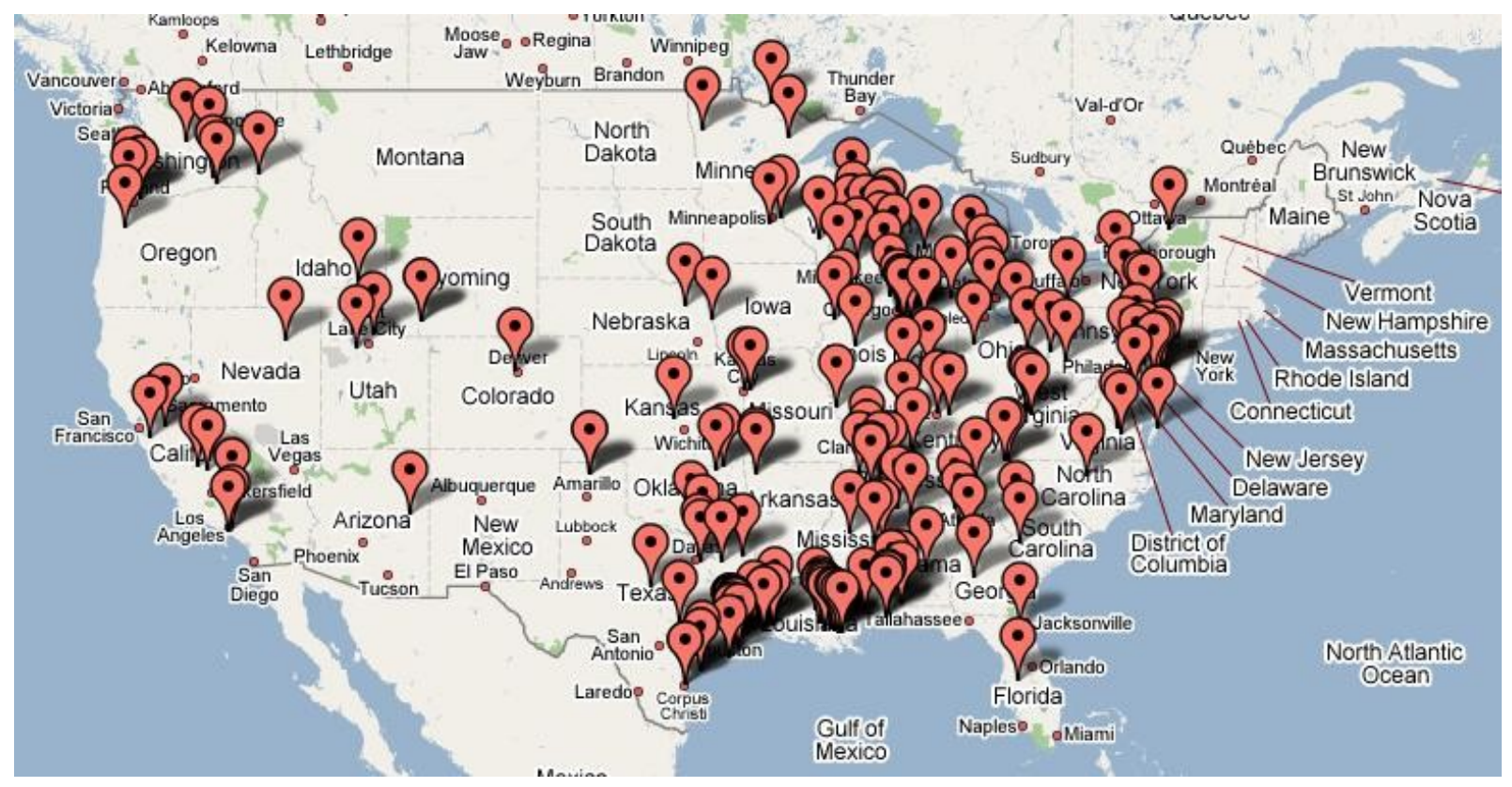

Figure 7. The majority of the year 2006 assessments were performed in the eastern, midwestern, and southern United States.

Table 1 and Figure 8 show the breakdown of the assessments by type and by industrial classification, with 114 steam assessments and 86 process heating assessments. Figure 8 shows that the 200 plants were in 18 major U.S. industry groups, with 163 of the assessments done in six industries: chemical manufacturing, paper manufacturing, primary metals, food, non-metallic mineral products, and fabricated metal products. 
Table 1. The 18 major industrial sectors represented by the 200 assessed plants.

\begin{tabular}{|c|c|c|c|}
\hline INDUSTRY SECTOR & Process Heating & Steam & TOTAL \\
\hline 325 Chemical manufacturing & 14 & 39 & 53 \\
\hline 322 Paper manufacturing & 4 & 30 & 34 \\
\hline 331 Primary metals & 23 & 1 & 24 \\
\hline 311 Food & 7 & 15 & 22 \\
\hline 327 Non-metallic mineral products & 18 & & 18 \\
\hline 332 Fabricated metal products & 8 & 4 & 12 \\
\hline 324 Petroleum and coal products & 2 & 6 & 8 \\
\hline 326 Plastics and rubber products & 2 & 3 & 5 \\
\hline 334 Computer and electronic products & 2 & 3 & 5 \\
\hline 336 Transportation equipment & & 5 & 5 \\
\hline 212 Mining & 2 & 1 & 3 \\
\hline 314 Textile product mills & & 3 & 3 \\
\hline 333 Machinery manufacturing & 2 & & 2 \\
\hline 312 Beverage and tobacco products & & 1 & 1 \\
\hline 313 Textile mills & & 1 & 1 \\
\hline 321 Wood products & 1 & & 1 \\
\hline 323 Printing and related support activities & 1 & & 1 \\
\hline 335 Electrical equipment, appliances, components & & 1 & 1 \\
\hline Other & & 1 & 1 \\
\hline Total & 86 & 114 & 200 \\
\hline
\end{tabular}

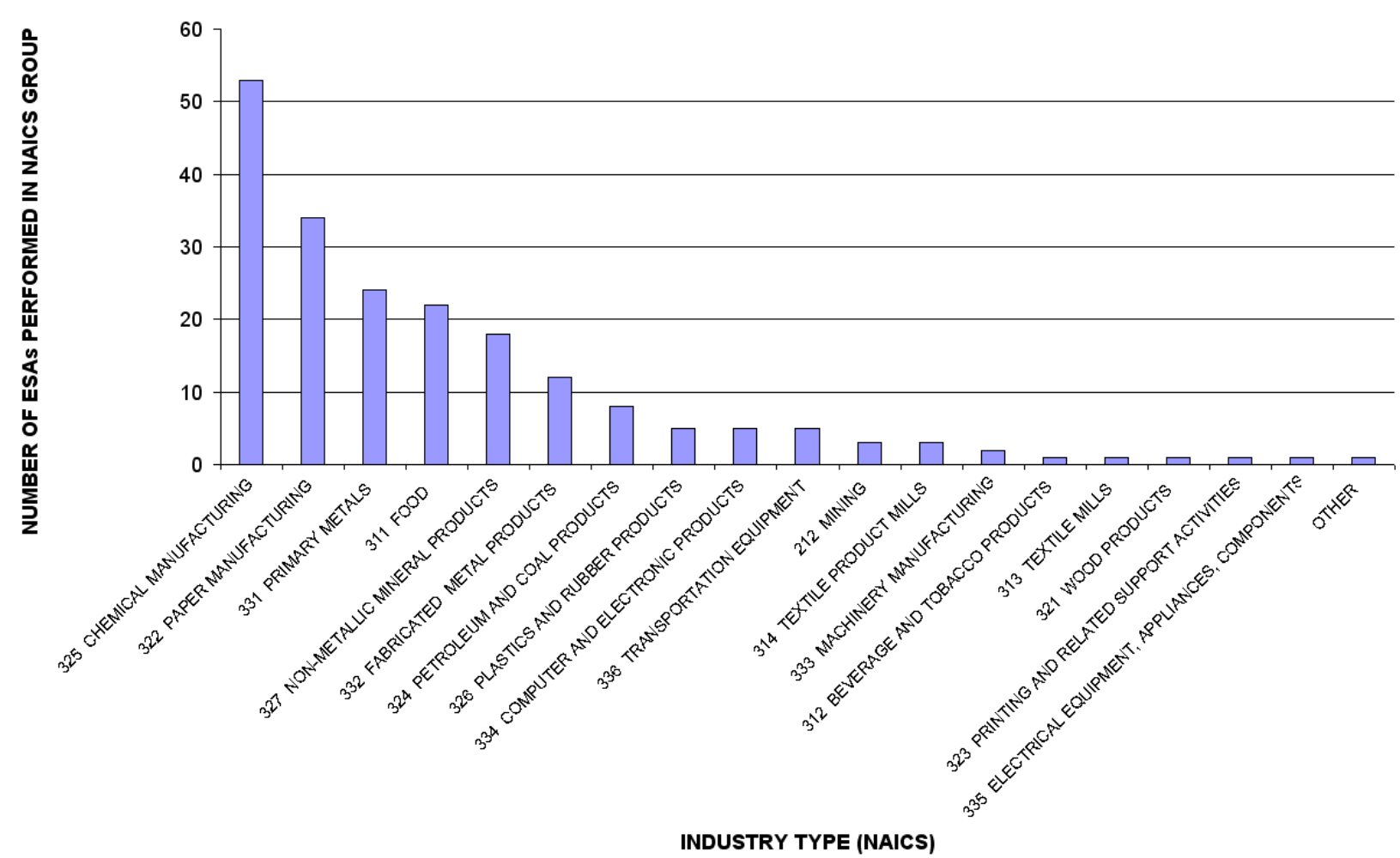

Figure 8. Assessments were completed in 18 major U.S. industry sectors, with 163 of the assessments in 6 industry sectors. 
Figures 9 and 10 show the potential savings for process heating and steam, respectively, by state. Process heating assessments were performed in 30 states, with about $82 \%$ of the potential energy cost savings in 12 states. Steam assessments were done in 36 states and one territory (Puerto Rico), and about $84 \%$ of the potential energy cost savings were in 12 states.

Figure 11 shows the distribution of identified potential energy cost savings across the 18 industrial groups represented in the 2006 assessments, with $89 \%$ of the total occurring in six industries: chemical manufacturing, paper manufacturing, primary metals, petroleum and coal products, food, and fabricated metal products.

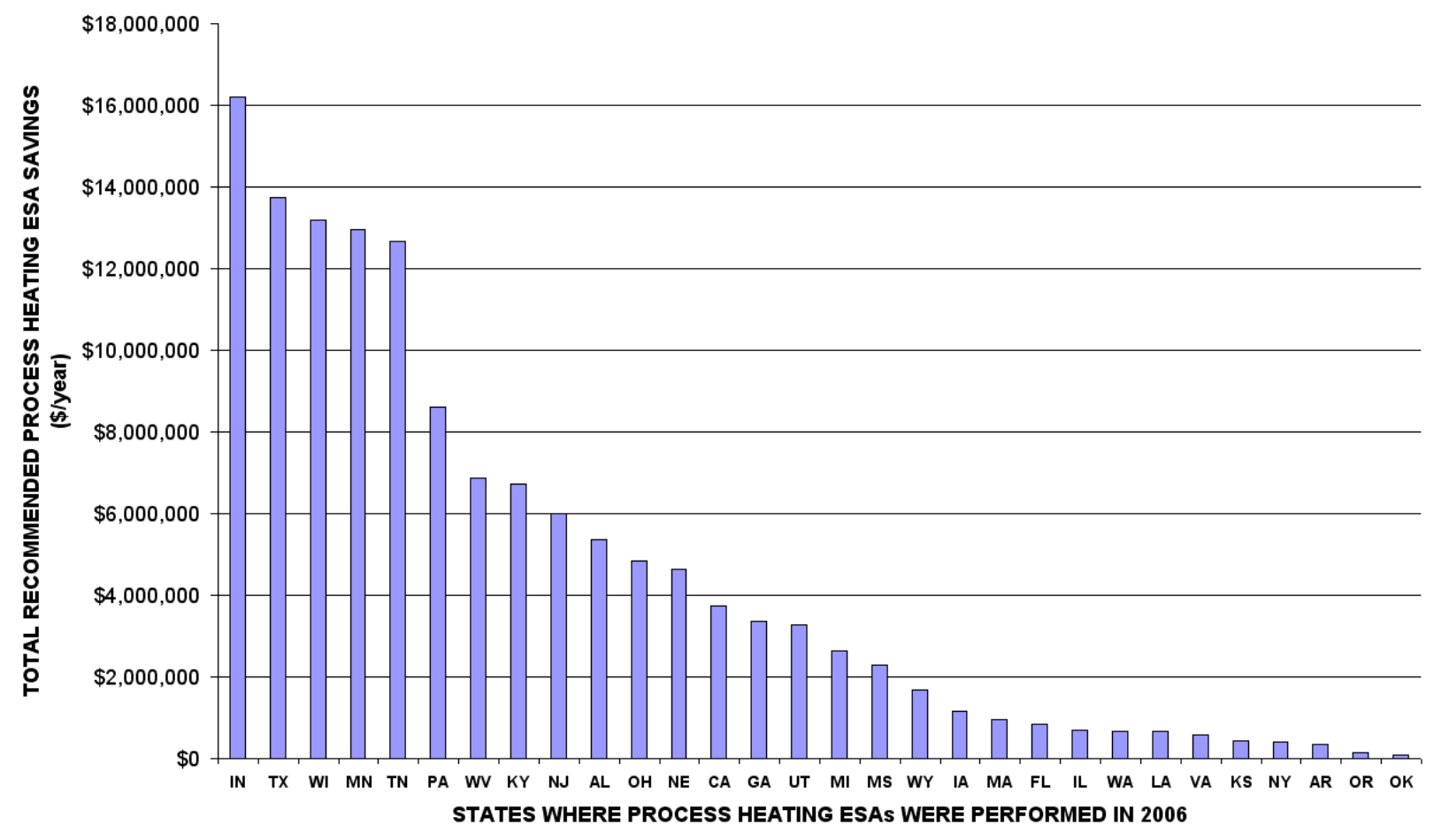

Figure 9. The year 2006 assessments included 86 process heating assessments in 30 states. The total potential energy cost savings from the identified opportunities in these assessments was \$136 million per year. 


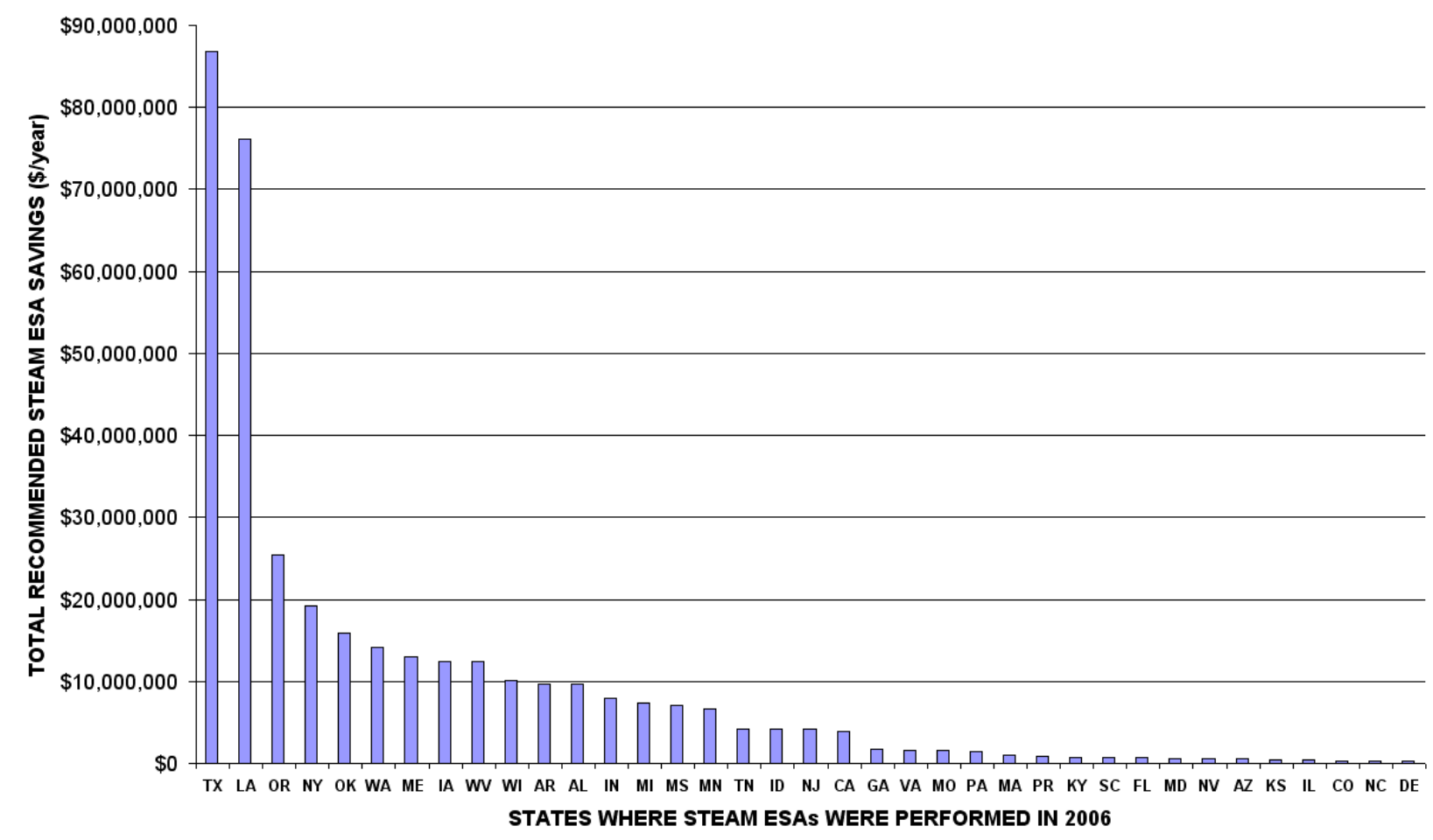

Figure 10. The year 2006 assessments included 114 steam assessments in 37 states. The total potential energy cost savings from the identified opportunities in these assessments was \$364 million per year.

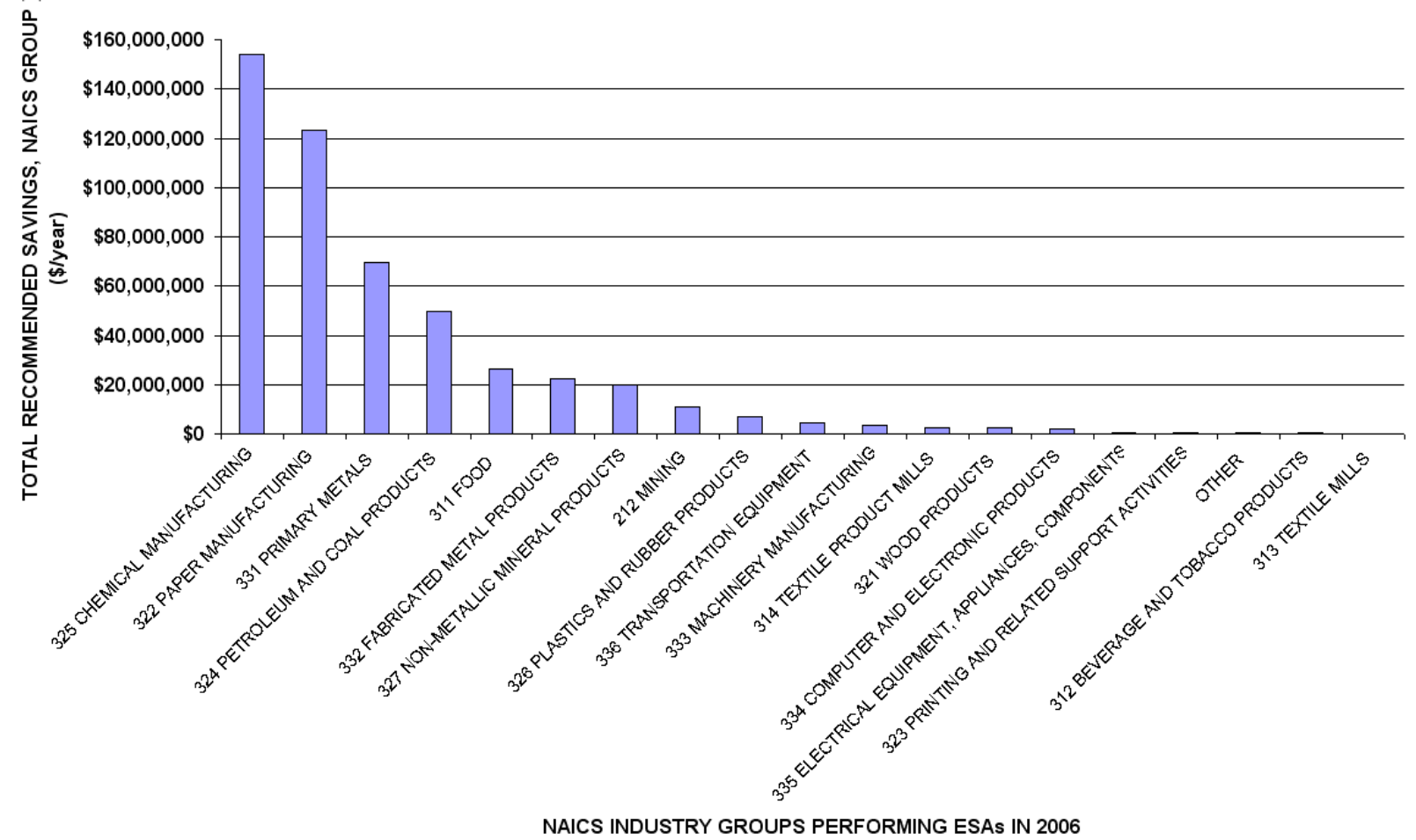

Figure 11. Assessments were performed for 18 major U.S. industry groups, with 6 of these industries accounting for potential cost savings from identified opportunities of $\$ 445$ million per year. 


\subsection{Summary of Overall Results}

The magnitude of the recommended potential cost, natural gas, and $\mathrm{CO}_{2}$ savings identified in the 2006 steam and process heating assessments is exceptionally large. An overall summary of the results from the 2006 assessments is presented in Table 2, for all assessments, for steam assessments, and for process heating assessments. Some key results include the following.

- The average recommended cost savings for all of the assessments taken together was about $\$ 2.5$ million per year, or $10.4 \%$ of the average plant energy bill for the assesssed plants.

- The results of the assessments clearly reflect the 2006 program's focus on natural gas savings. The assessments showed that $17.3 \%$ of the natural gas used in the plants could be saved if all of the recommendations from the assessments were implemented.

- The average potential cost and natural gas savings identified for both steam and process heating assessments was large - about \$3.2 million per year for steam and \$1.6 million per year for process heating. Considering that assessments were done in only three days, including a strong tool training element, the magnitude of potential savings is surprisingly large.

Table 2 shows some interesting differences between the results for steam and process heating. For steam the total energy savings of about 32 million MMBtu per year is less than the natural gas savings of about 39 million MMBtu per year. However, for process heating the total energy savings of about 17 million MMBtu per year is more than the natural gas savings of about 14 million MMBtu per year. This is because the steam assessments identified a significant number of opportunities involving energy switching - for example, switching from natural gas to a less costly fuel, or installing a turbine to generate electricity, which would result in needing additional fuel to run the turbine. In process heating assessments, energy switching opportunities were not as significant.

Estimates for $\mathrm{CO}_{2}$ emission reductions were calculated for each assessment based on the energy savings and fuel type data provided by the Energy Experts. Currently, 22 categories of industrial fuels including electricity, natural gas, light fuel oil (\#1, \#2, \#4), heavy fuel oil (\#5, \#6), coal, coke, coke oven gas, black liquor, blast furnace gas, propane, and hog fuel are analyzed for $\mathrm{CO}_{2}$ content. Coefficients for converting fuel consumption (MMBtu) into metric tons of $\mathrm{CO}_{2}$ were provided through direct consultation with EIA's greenhouse gas voluntary reporting team. These coefficients were applied to the appropriate fuel savings to develop estimates of emissions impacts. Table 3 identifies the coefficients that were used to convert energy savings into $\mathrm{CO}_{2}$ impacts. 
Table 2. Summary of results for all year 2006 assessments, steam assessments, and process heating assessments.

\begin{tabular}{|l|c|c|c|}
\hline & $\begin{array}{c}\text { For all 200 } \\
\text { assessments in } \\
\mathbf{2 0 0 6}\end{array}$ & $\begin{array}{c}\text { For the 114 } \\
\text { steam } \\
\text { assessments }\end{array}$ & $\begin{array}{c}\text { For the 86 } \\
\text { process } \\
\text { heating } \\
\text { assessments }\end{array}$ \\
\hline Total recommended cost savings (\$/year) & $\$ 500,200,000$ & $\$ 364,300,000$ & $\$ 135,900,000$ \\
\hline $\begin{array}{l}\text { Recommended cost savings per assessment } \\
\text { (\$/year) }\end{array}$ & $\$ 2,501,000$ & $\$ 3,200,000$ & $\$ 1,580,000$ \\
\hline $\begin{array}{l}\text { Average recommended cost savings per } \\
\text { assessment (\%/year) }\end{array}$ & $10.4 \%$ & $11.4 \%$ & $9.0 \%$ \\
\hline $\begin{array}{l}\text { Total recommended energy savings, site } \\
\text { (MMBtu/year) }\end{array}$ & $49,470,000$ & $32,370,000$ & $17,100,000$ \\
\hline $\begin{array}{l}\text { Recommended total energy savings, site, per } \\
\text { assessment (MMBtu/year) }\end{array}$ & 247,400 & 283,900 & 198,800 \\
\hline $\begin{array}{l}\text { Average recommended total energy savings, } \\
\text { site, per assessment (\%/year) }\end{array}$ & $8.8 \%$ & $7.8 \%$ & $10.1 \%$ \\
\hline $\begin{array}{l}\text { Total recommended natural gas savings } \\
\text { (MMBtu/year) }\end{array}$ & $52,870,000$ & $39,040,000$ & $13,830,000$ \\
\hline $\begin{array}{l}\text { Recommended natural gas savings per } \\
\text { assessment (MMBtu/year) }\end{array}$ & 264,400 & 342,500 & 160,800 \\
\hline $\begin{array}{l}\text { Average recommended natural gas savings per } \\
\text { assessment (\%/year) }\end{array}$ & $17.3 \%$ & $20.4 \%$ & $13.3 \%$ \\
\hline $\begin{array}{l}\text { Total recommended CO } \\
\text { tons } \mathrm{CO}_{2} / \text { /year) }\end{array}$ & 4.04 & 2.92 & 1.11 \\
\hline $\begin{array}{l}\text { Recommended CO } \\
\text { (metric tons } \mathrm{CO}_{2} / \text { /year) }\end{array}$ & 20,200 & 25,600 & 13,000 \\
\hline
\end{tabular}

Note: Savings designated as "site" savings refer to energy used at the site and do not include losses that occur in the generation, transmission and distribution of energy. 
Table 3. Coefficients used to convert energy savings results into $\mathrm{CO}_{2}$ impacts.

\begin{tabular}{|c|c|c|c|}
\hline Fuel & $\begin{array}{c}\text { EIA Factors } \\
\left.\text { (Ib } \mathrm{CO}_{2} / \mathrm{MMBtu}\right)\end{array}$ & Fuel & $\begin{array}{c}\text { EIA Factors } \\
\left.\text { (Ib } \mathrm{CO}_{2} / \mathrm{MMBtu}\right)\end{array}$ \\
\hline Black liquor & 0.00 & Gasoline & 154.79 \\
\hline Blast furnace gas & 604.78 & Isobutane & 142.04 \\
\hline Butane & 141.80 & Kerosene & 157.04 \\
\hline Butene & 141.80 & Liquified petroleum (LPG) & 137.72 \\
\hline Coal & 208.59 & Methane/landfill gas & 115.26 \\
\hline Coke & 225.13 & Municipal refuse (dry) & 145.88 \\
\hline Coke oven gas & 103.28 & Natural gas & 117.08 \\
\hline Crude petroleum & 170.50 & Peat & 246.56 \\
\hline Distillate fuel (light fuel oil) & 159.43 & Propane & 137.66 \\
\hline Electricity (purchased) & 1366.65 & Residual fuel oil (heavy fuel oil) & 173.73 \\
\hline Ethane & 130.03 & Wood waste (hog fuel) & 0.00 \\
\hline
\end{tabular}

Figure 12 illustrates the total estimated $\mathrm{CO}_{2}$ emission reductions for the U.S. industry groups that conducted assessments in 2006. The total potential $\mathrm{CO}_{2}$ emissions reduction - if all recommendations are implemented - is about 4.04 million metric tons of $\mathrm{CO}_{2}$.

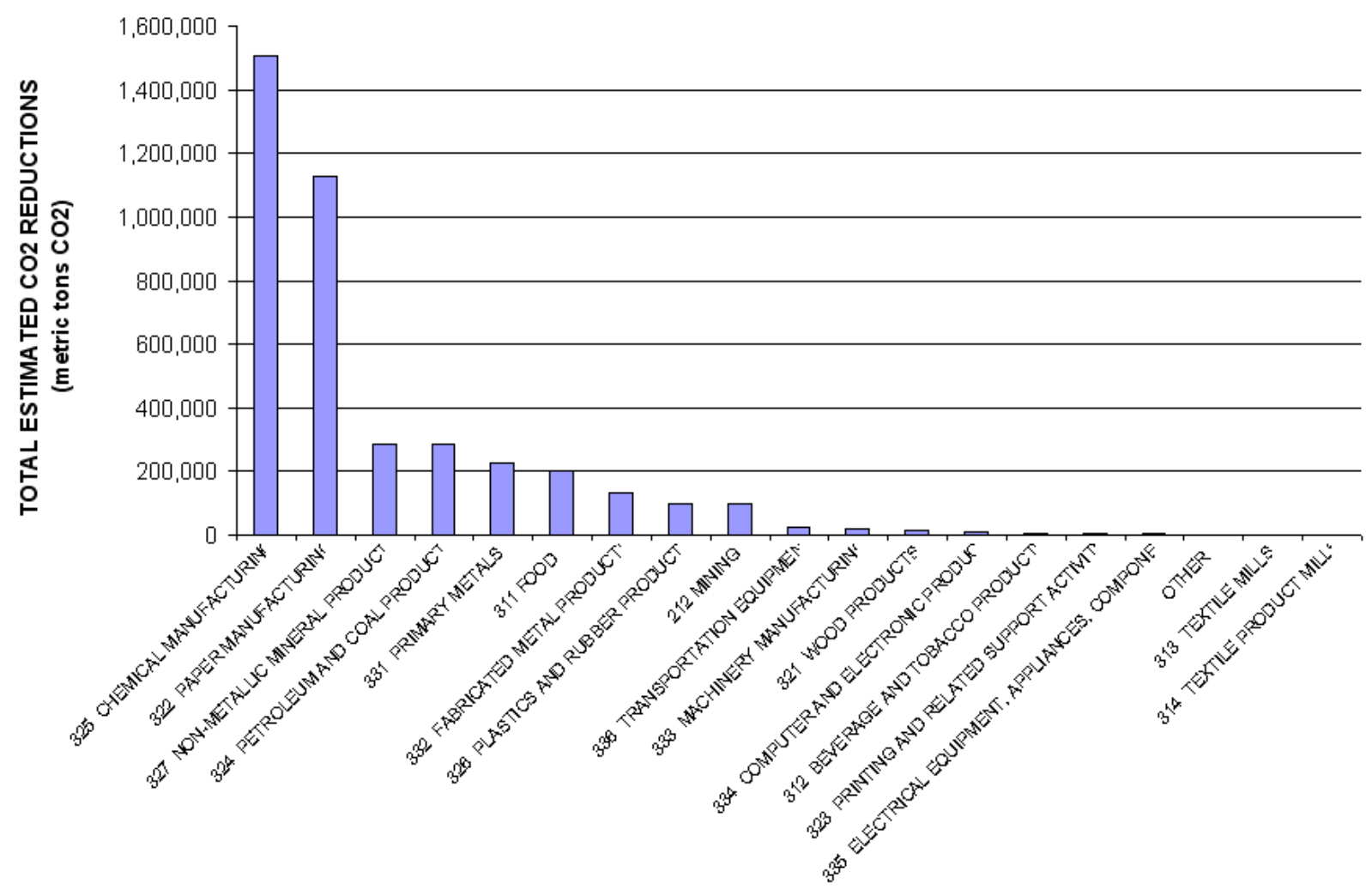

NAICS INDUSTRY GROUPS

Figure 12. The total potential $\mathrm{CO}_{2}$ emissions reduction for the year 2006 assessments was 4.04 million metric tons of $\mathrm{CO}_{2}$. Estimates of $\mathrm{CO}_{2}$ emission reductions were positive for 17 of the $18 \mathrm{U}$.S. industry groups that conducted assessments in 2006. 
It should be noted that a slight increase in $\mathrm{CO}_{2}$ emissions was calculated for Textile Product Mills (NAIC 314). This increase is traced to fuel switching from natural gas to a less costly fuel.

In performing the steam and process heating assessments, Experts used standard - or "pick-list" wordings whenever possible in classifying the identified opportunities. This was done so that the savings opportunity data could be analyzed by these pick-list categories. Tables 4 and 5 present the opportunity pick-list categories for steam and process heating, respectively, used for the assessments.

Tables 6 and 7 present detailed information on cost, energy, and $\mathrm{CO}_{2}$ emission reductions for the steam and process heating pick list categories. Figures 13 and 14 illustrate the cost savings that resulted from the "Top 10" energy savings opportunities for steam and process heating. For both steam and process heating assessments, the top 10 opportunities capture the majority of the energy cost savings identified in the assessments. For steam assessments, the top 10 opportunities captured $\$ 334$ million per year of potential savings $-92 \%$ of the total identified steam savings. For process heating assessments, the top 10 opportunities captured $\$ 100$ million per year of potential savings $-74 \%$ of the total identified process heating savings. 
Table 4. The steam system "pick-list" recommendation classifications that streamline assessments and data analysis.

\begin{tabular}{|c|c|}
\hline $\begin{array}{l}\text { Steam assessment "pick- } \\
\text { list" savings projects }\end{array}$ & Description \\
\hline $\begin{array}{l}1.1 \text { - Reduce steam demand } \\
\text { by changing the process } \\
\text { steam requirements }\end{array}$ & $\begin{array}{l}\text { Eliminating or optimizing the operation of steam-using process equipment reduces required steam generation } \\
\text { rates which in turn reduces boiler fuel (and energy) consumption rates. }\end{array}$ \\
\hline 1.2 - Use an alternate fuel & $\begin{array}{l}\text { When switching from a fuel with a lower theoretical combustion efficiency (e.g. natural gas) to a fuel with a higher } \\
\text { efficiency (e.g. fuel oil with a lower hydrogen content), a lower boiler fuel (and energy) consumption rate results. } \\
\text { Switching to a less costly fuel (on an energy basis) will reduce operating cost. }\end{array}$ \\
\hline $\begin{array}{l}1.3-\text { - Change boiler } \\
\text { efficiency }\end{array}$ & $\begin{array}{l}\text { Energy is saved if boiler efficiency is improved since boiler losses are reduced, and less fuel (and energy) is } \\
\text { needed to achieve a desired steam production rate. }\end{array}$ \\
\hline $\begin{array}{l}1.4-\text { Change boiler } \\
\text { blowdown rate }\end{array}$ & $\begin{array}{l}\text { Boiler blowdown constitutes a pressurized, hot water loss from a boiler (energy loss). Actions (e.g. improved } \\
\text { boiler water treatment) which allow a reduction in this loss improve boiler efficiency. }\end{array}$ \\
\hline $\begin{array}{l}1.5-\text { Install blowdown flash } \\
\text { to low-pressure steam }\end{array}$ & $\begin{array}{l}\text { Blowdown water (superheated liquid) flashes to steam when pressure is lowered in the exit stream. Flash steam } \\
\text { directed to a low pressure header reduces needed boiler steam generation rate. This in turn reduces boiler fuel } \\
\text { (and energy) use rate. }\end{array}$ \\
\hline $\begin{array}{l}1.6-\text { Change steam } \\
\text { generation conditions }\end{array}$ & $\begin{array}{l}\text { For boilers producing superheated steam, reducing output temperature (e.g. by removing a superheater) will } \\
\text { reduce boiler fuel (and energy) use. For boilers producing saturated steam, improving steam quality (decreasing } \\
\text { wetness) improves downstream process heating and lowers boiler steam output and fuel (and energy) } \\
\text { consumption rate is reduced. }\end{array}$ \\
\hline $\begin{array}{l}1.7 \text { - Add or modify } \\
\text { operation of backpressure } \\
\text { steam turbine }\end{array}$ & $\begin{array}{l}\text { If a backpressure turbine is taken out-of-service, steam usage, boiler load and fuel (and energy) consumption } \\
\text { rate are reduced. If a new backpressure turbine is added to reduce steam flow through pressure reducing valves, } \\
\text { steam flows through pressure reducing valves will be reduced but total steam usage will increase. This action will } \\
\text { reduce total energy costs if the electricity savings (related to the turbine drive) are greater than the increased } \\
\text { boiler fuel consumption rate. }\end{array}$ \\
\hline $\begin{array}{l}1.8 \text { - Add or modify } \\
\text { operation of condensing } \\
\text { steam turbine }\end{array}$ & $\begin{array}{l}\text { If the isentropic efficiency of a utilized condensing turbine is improved (e.g. by rebuilding), a lower steam flow is } \\
\text { required to drive the turbine load. This in turn reduces boiler load and fuel (and energy) consumption rates. If a } \\
\text { condensing turbine is taken out-of-service, steam usage is reduced, boiler load decreases and boiler fuel (and } \\
\text { energy) consumption is lowered. }\end{array}$ \\
\hline $\begin{array}{l}1.9 \text { - Modify feedwater heat } \\
\text { recovery exchanger using } \\
\text { condensate tank vent }\end{array}$ & $\begin{array}{l}\text { The main condensate receiver is typically vented to atmosphere when flash steam forms at the reduced receiver } \\
\text { pressure. Flash steam passed through a heat exchanger can be used for boiler feedwater heating. The addition } \\
\text { of hotter water to the feedwater system reduces boiler fuel (and energy) consumption rate. }\end{array}$ \\
\hline $\begin{array}{l}1.10-\text { Modify feedwater heat } \\
\text { recovery exchanger using } \\
\text { boiler blowdown }\end{array}$ & $\begin{array}{l}\text { When superheated blowdown water undergoes a pressure reduction after leaving the boiler, some water flashes } \\
\text { to steam and a hot water fraction remains. This hot water may be passed through a heat exchanger to heat } \\
\text { feedwater or process fluids thereby reducing steam use for heating. }\end{array}$ \\
\hline
\end{tabular}




\begin{tabular}{|c|c|}
\hline $\begin{array}{l}1.11 \text { - Change condensate } \\
\text { recovery rates }\end{array}$ & $\begin{array}{l}\text { If the amount of formed condensate returned to the boiler is increased, hotter water is fed back into the boiler } \\
\text { feedwater system, lowering feedwater heating requirements and feedwater chemical treatment needs. }\end{array}$ \\
\hline $\begin{array}{l}1.12 \text { - Modify the medium } \\
\text { pressure condensate flash } \\
\text { system }\end{array}$ & $\begin{array}{l}\text { When the pressure of condensate formed in a high-pressure system is reduced, flash steam forms. When this } \\
\text { steam is supplied to the medium-pressure steam header, an amount of boiler-produced steam is displaced and } \\
\text { boiler load and fuel (and energy) consumption rates are reduced. }\end{array}$ \\
\hline $\begin{array}{l}1.13 \text { - Modify the low } \\
\text { pressure condensate flash } \\
\text { system }\end{array}$ & $\begin{array}{l}\text { When the pressure of condensate formed at a given pressure is reduced flash steam forms. When this steam is } \\
\text { supplied to the low-pressure steam header, an amount of boiler-produced steam is displaced and boiler load and } \\
\text { fuel (and energy) consumption rates are reduced. }\end{array}$ \\
\hline $\begin{array}{l}1.14-\text { Implement steam trap } \\
\text { maintenance program }\end{array}$ & $\begin{array}{l}\text { An improved steam trap maintenance program results in a reduced number of traps failed in the leaking steam } \\
\text { mode. If trap steam leaks are reduced, less steam energy is lost in the condensate system and boiler load and } \\
\text { fuel (and energy) consumption rates are reduced. }\end{array}$ \\
\hline $\begin{array}{l}1.15-\text { Implement steam leak } \\
\text { maintenance program }\end{array}$ & $\begin{array}{l}\text { An improved steam leak maintenance program reduces the number of steam leaks (lost energy). Less steam } \\
\text { must be generated in the boiler to satisfy process loads and boiler fuel (and energy) consumption rates are } \\
\text { reduced. }\end{array}$ \\
\hline 1.16 - Improve insulation & $\begin{array}{l}\text { Improving insulation quality (e.g. replacing ineffective wet insulation or increasing insulation thickness) and } \\
\text { insulating uninsulated components will reduce energy loss from hot steam components. }\end{array}$ \\
\hline 1.17 - Other & $\begin{array}{l}\text { Miscellaneous projects may minimize or eliminate the need for boiler-generated steam. These projects save } \\
\text { energy by reducing the use of process energy or by improving the efficiency of converting fuel energy to process } \\
\text { heating (e.g. steam) energy. }\end{array}$ \\
\hline $\begin{array}{l}1.18-\text { Feedwater heat } \\
\text { recovery, general }\end{array}$ & $\begin{array}{l}\text { Available process waste heat other than condensate tank vent energy or liquid blowdown heat can be used in a } \\
\text { heat exchanger to heat boiler feedwater. Hotter water fed back into the boiler feedwater system lowers feedwater } \\
\text { heating requirements. }\end{array}$ \\
\hline $\begin{array}{l}1.19 \text { - Deaerator heat } \\
\text { recovery }\end{array}$ & $\begin{array}{l}\text { Boiler water deaerators are often vented to atmosphere. The installation of a heat exchanger can recover heat for } \\
\text { feedwater or process heating. This heating reduces needed boiler output. }\end{array}$ \\
\hline $\begin{array}{l}1.20-\text { Multiple boiler } \\
\text { optimization }\end{array}$ & $\begin{array}{l}\text { Optimization of overall steam generation efficiency in multi-boiler systems requires selection of individual boiler } \\
\text { loads to maximize their efficiencies and minimize total boiler fuel use while meeting total steam production } \\
\text { requirements. }\end{array}$ \\
\hline $\begin{array}{l}1.21-\text { Reduce or recover } \\
\text { vented steam }\end{array}$ & $\begin{array}{l}\text { Steam is vented from steam headers when steam supplied by backpressure turbines exceeds downstream } \\
\text { process needs. Steam is also vented from some plant processes (e.g. furnace decoking). If steam venting is } \\
\text { reduced or vented steam is recovered (for process heating) boiler steam load and fuel (and energy) consumption } \\
\text { rates are reduced. }\end{array}$ \\
\hline
\end{tabular}


Table 5. The process heating "pick-list" recommendation classifications that streamline assessments and data analysis.

\begin{tabular}{|c|c|}
\hline $\begin{array}{l}\text { Process heating assessment "pick- } \\
\text { list" savings project }\end{array}$ & Description \\
\hline $\begin{array}{l}1.1-\text { Reduce oxygen content of flue } \\
\text { (exhaust) gases }\end{array}$ & $\begin{array}{l}\text { Reduced oxygen reflects a reduction in excess air entering the heating equipment. This raises the } \\
\text { available heat, and consequently, the efficiency. Excess air can be lowered by adjusting burner air- } \\
\text { fuel ratios, closing off air leaks into the equipment or maintaining a slightly positive chamber pressure } \\
\text { to exclude outside air. }\end{array}$ \\
\hline $\begin{array}{l}1.2 \text { - Eliminate excess unburned } \\
\text { hydrocarbons }\left(\mathrm{CO}, \mathrm{H}_{2}, \mathrm{CH}_{4} \text {, soot in the }\right. \\
\text { exhaust gases) }\end{array}$ & $\begin{array}{l}\text { Unburned hydrocarbons represent unburned or partially-burned fuel. They can be lowered by } \\
\text { improving the thoroughness of air-fuel mixing in burners or avoiding operating burners fuel-rich or } \\
\text { with insufficient excess air. }\end{array}$ \\
\hline $\begin{array}{l}1.3 \text { - Use of proper heating methods - } \\
\text { replace inefficient and uneconomical } \\
\text { methods with economical/efficient } \\
\text { system }\end{array}$ & $\begin{array}{l}\text { Some heating equipment is either obsolete or poorly matched to the needs of the process. Replace it } \\
\text { with modern equipment which takes the unique needs of the process into account. }\end{array}$ \\
\hline $\begin{array}{l}1.4-\text { Use of alternate fuel or energy } \\
\text { source }\end{array}$ & $\begin{array}{l}\text { In certain situations, fuels like by-product gases may be available at lower cost than the primary fuel. } \\
\text { Waste energy from other nearby operations might be able to be used in the process under } \\
\text { consideration. }\end{array}$ \\
\hline 1.5 - Use of oxygen for combustion & $\begin{array}{l}\text { Using oxygen to enrich or replace combustion air lowers the weight flow of nitrogen in the exhaust } \\
\text { gases, increasing available heat and efficiency. Flame temperatures will also increase, and this may } \\
\text { enhance radiation heat transfer to the furnace and its load. }\end{array}$ \\
\hline $\begin{array}{l}1.6-\text { Use of process or exhaust air for } \\
\text { combustion }\end{array}$ & $\begin{array}{l}\text { If this air contains sufficient oxygen (usually } 18 \% \text { or more) and is at elevated temperature, it can be } \\
\text { used as a combustion air source. Its heat content will raise the available heat of the combustion } \\
\text { process. }\end{array}$ \\
\hline $\begin{array}{l}1.7 \text { - Use of outdoor air for combustion } \\
\text { or make-up air }\end{array}$ & $\begin{array}{l}\text { In a closed building with space heating in use, drawing combustion air from inside and then } \\
\text { exhausting it through the stack wastes the energy that air contains. Heated replacement air will be } \\
\text { needed. Drawing combustion air from outdoors bypasses the building heating system, reducing the } \\
\text { burden on it. }\end{array}$ \\
\hline $\begin{array}{l}1.8 \text { - Improving heat transfer in a } \\
\text { furnace-oven }\end{array}$ & $\begin{array}{l}\text { The work load must be exposed as effectively as possible to the source of radiant or convective heat. } \\
\text { This will entail steps like changing loading patterns, increasing burner or hot air nozzle velocities or } \\
\text { relocating heat sources so they "see" more of the load surface. }\end{array}$ \\
\hline $\begin{array}{l}1.9 \text { - Clean heat transfer surfaces - } \\
\text { radiant tubes, heat exchangers, heater } \\
\text { tubes, electrical heating elements }\end{array}$ & $\begin{array}{l}\text { Buildups of scale, soot and dirt reduce the thermal conductivity of tubes, heating elements and heat } \\
\text { exchangers. Heat turned back by these deposits short-circuits out the exhaust, increasing losses, } \\
\text { slowing the process and lowering efficiency. }\end{array}$ \\
\hline $\begin{array}{l}1.10-\text { Use of flue or exhaust gas heat for } \\
\text { combustion air preheating }\end{array}$ & $\begin{array}{l}\text { This is one of the most effective ways to recycle waste heat. Incoming ambient combustion air is } \\
\text { routed through a heat exchanger and preheated with energy extracted from the outgoing exhaust } \\
\text { gases. Every unit of energy transferred to the air is one less that must be provided by burning fuel. }\end{array}$ \\
\hline
\end{tabular}




\begin{tabular}{|c|c|}
\hline $\begin{array}{l}1.11 \text { - Load or charge preheating using } \\
\text { heat from flue or exhaust gas or other } \\
\text { source of waste heat }\end{array}$ & $\begin{array}{l}\text { Instead of exhausting flue gases from the process at high temperatures, they are passed over } \\
\text { incoming cold charge materials. This raises the load partway to its processing temperature and } \\
\text { lowers the amount of energy neeed to support the process. }\end{array}$ \\
\hline $\begin{array}{l}1.12 \text { - Heat cascading - use of flue or } \\
\text { exhaust gas heat from a higher } \\
\text { temperature process to supply heat to } \\
\text { lower temperature processes }\end{array}$ & Waste gases from one process can be used to heat a lower temperatuure process. \\
\hline $\begin{array}{l}1.13 \text { - Heat recovery from hot products } \\
\text { or other heat sources (i.e. from walls) } \\
\text { from a furnace - oven }\end{array}$ & $\begin{array}{l}\text { Products are often removed from ovens or furnaces at elevated temperatures and allowed to cool in } \\
\text { the open air. Cooling them with forced air in an enclosure will heat the air, which might be useful for } \\
\text { heating another process. }\end{array}$ \\
\hline $\begin{array}{l}1.14-\text { Use of waste heat for water or air } \\
\text { cooling, steam generation or absorption } \\
\text { cooling }\end{array}$ & $\begin{array}{l}\text { Heated exhaust gases can be routed through waste heat boilers, hot water generators or absorption } \\
\text { chillers to perform a variety of heating or cooling roles. }\end{array}$ \\
\hline $\begin{array}{l}1.15 \text { - Proper insulation and } \\
\text { maintenance of furnace structure or parts }\end{array}$ & $\begin{array}{l}\text { Maintain furnace and oven insulation to avoid localized losses through the walls, roof and floor. } \\
\text { Consider increasing the thickness or efficiency of the existing insulation to further lower wall losses. }\end{array}$ \\
\hline 1.16 - Reduce-eliminate internal cooling & $\begin{array}{l}\text { Some furnaces contain components protected from overheating with cooling water and air. Make } \\
\text { sure excessive amounts of cooling media aren't used. }\end{array}$ \\
\hline $\begin{array}{l}1.17 \text { - Reduce-eliminate openings and } \\
\text { air leakage in the furnace }\end{array}$ & $\begin{array}{l}\text { Openings allow radiant energy to escape and ambient air to leak in. As much as possible, seal those } \\
\text { openings and leaks. As an added measure, maintain the furnace or oven at a slightly positive internal } \\
\text { pressure to prevent in-leakage. }\end{array}$ \\
\hline $\begin{array}{l}1.18 \text { - Furnace scheduling, loading, shut } \\
\text { down - avoiding delays, waits, cooling } \\
\text { between operations etc. }\end{array}$ & $\begin{array}{l}\text { Heating equipment efficiency is highest at } 100 \% \text { of design capacity. Underloaded or overloaded } \\
\text { equipment will consume more energy per unit of production. }\end{array}$ \\
\hline $\begin{array}{l}1.19 \text { - Reducing weight of fixtures, trays, } \\
\text { baskets etc. }\end{array}$ & $\begin{array}{l}\text { If fixtures, baskets and conveyors leave the heating process at higher temperatures than they } \\
\text { entered, they contribute to wasted heat. Lowering their mass causes a corresponding decrease in the } \\
\text { amount of energy they extract from the process. }\end{array}$ \\
\hline $\begin{array}{l}1.20 \text { - Control (reduce) make up air for } \\
\text { ovens to meet the process safety } \\
\text { requirements }\end{array}$ & $\begin{array}{l}\text { Ovens handling flammable solvents or vapors must have sufficient fresh air ventilation to dilute those } \\
\text { combustible materials well below their lower flammable limit. Any ventilation in excess of the safe } \\
\text { required amount wastes energy. }\end{array}$ \\
\hline $\begin{array}{l}1.21 \text { - Eliminate use of continuous flame } \\
\text { curtains, pilots where possible }\end{array}$ & $\begin{array}{l}\text { Flame curtains and door pilots insure burnoff of flammable prepared atmospheres escaping around } \\
\text { furnace doors and out vents. If the process atmosphere has been changed to a non-flammable } \\
\text { mixture, these ignition sources are no longer necessary. }\end{array}$ \\
\hline
\end{tabular}


Table 6. Potential cost savings, energy savings, and reduction in $\mathrm{CO}_{2}$ emissions from identified steam opportunities in pick-list categories.

\begin{tabular}{|c|c|c|c|c|c|}
\hline $\begin{array}{l}\text { Year } 2006 \text { Steam Savings Opportunity } \\
\text { Recommendations }\end{array}$ & $\begin{array}{c}\text { Recommended } \\
\text { total cost savings } \\
\text { (\$/year) }\end{array}$ & $\begin{array}{l}\text { Recommended total } \\
\text { energy savings } \\
\text { (MMBtu/year) }\end{array}$ & $\begin{array}{l}\text { Recommended total } \\
\text { natural gas savings } \\
\text { (MMBtu/year) }\end{array}$ & $\begin{array}{l}\text { Recommended } \\
\text { total } \mathrm{CO}_{2} \text { savings } \\
\text { (metric tons } \\
\mathrm{CO}_{2} / \text { year) }\end{array}$ & $\begin{array}{l}\text { Number of times } \\
\text { the opportunity } \\
\text { applied }\end{array}$ \\
\hline 1.1. Reduce steam demand & $\$ 88,998,211$ & $17,095,100$ & $8,477,210$ & $1,185,383$ & 109 \\
\hline 1.2. Use alternate fuel & $\$ 77,872,418$ & $-767,204$ & $14,025,074$ & 376,056 & 18 \\
\hline 1.3. Improve boiler efficiency & $\$ 42,924,885$ & $5,331,486$ & $3,920,092$ & 283,791 & 130 \\
\hline 1.7. Add / modify backpressure steam turbine & $\$ 33,920,079$ & $-72,338$ & 130,360 & 165,894 & 54 \\
\hline 1.11. Improve condensate recovery & $\$ 23,611,773$ & $2,617,146$ & $2,137,589$ & 151,081 & 55 \\
\hline 1.8. Add / modify condensing steam turbine & $\$ 22,944,292$ & $-84,576$ & $2,323,230$ & 162,914 & 17 \\
\hline 1.14. Implement steam trap maintenance program & $\$ 15,059,433$ & $2,066,722$ & $1,936,950$ & 109,177 & 56 \\
\hline 1.16. Improve insulation & $\$ 10,492,536$ & $1,526,111$ & 986,368 & 100,953 & 77 \\
\hline 1.4. Improve boiler blowdown rate & $\$ 9,041,315$ & 845,627 & 802,898 & 46,438 & 41 \\
\hline 1.10. Improve blowdown feedwater heat recovery & $\$ 8,913,673$ & $1,164,823$ & $1,111,856$ & 61,020 & 49 \\
\hline 1.20. Optimize multiple boilers & $\$ 6,289,083$ & $-711,436$ & 407,380 & 69,235 & 10 \\
\hline 1.17. Other - miscellaneous steam & $\$ 6,123,237$ & 575,249 & 453,979 & 45,646 & 26 \\
\hline 1.18. Feedwater heat recovery - general & $\$ 6,075,461$ & 940,806 & 916,842 & 51,563 & 7 \\
\hline 1.15. Implement steam leak maintenance program & $\$ 2,618,451$ & 482,085 & 347,719 & 25,109 & 43 \\
\hline 1.21. Reduce / recover vented steam & $\$ 2,126,961$ & 390,332 & 245,652 & 26,518 & 12 \\
\hline 1.13. Improve low pressure condensate flash & $\$ 1,979,381$ & 312,877 & 309,438 & 14,522 & 10 \\
\hline 1.12. Improve medium pressure condensate flash & $\$ 1,385,000$ & 168,314 & 168,404 & 8,927 & 3 \\
\hline 1.6. Improve steam generation conditions & $\$ 1,124,000$ & 116,342 & $-8,970$ & 15,817 & 7 \\
\hline 1.19. Improve deaerator heat recovery & $\$ 774,734$ & 87,595 & 69,250 & 6,546 & 5 \\
\hline 1.5. Install blowdown flash to low pressure steam & $\$ 490,978$ & 90,218 & 100,714 & 3,442 & 5 \\
\hline $\begin{array}{l}\text { 1.9. Improve condensate tank vent feedwater heat } \\
\text { recovery }\end{array}$ & $\$ 437,900$ & 62,126 & 58,279 & 2,992 & 4 \\
\hline 3.1. Use flue / exhaust gas for combustion air preheating & $\$ 301,669$ & 38,379 & 27,499 & 2,318 & 2 \\
\hline 2.2. Clean heat transfer surfaces & $\$ 233,139$ & 32,471 & 32,471 & 1,724 & 1 \\
\hline 3.5. Use waste heat for cooling & $\$ 230,470$ & 24,325 & 24,325 & 1,292 & 2 \\
\hline 1.1. Reduce flue gas oxygen content & $\$ 201,614$ & 27,911 & 27,911 & 1,482 & 2 \\
\hline 5.1. Improve furnace scheduling, loading, shutdown & $\$ 73,900$ & 0 & 0 & 0 & 1 \\
\hline 6.2. Other - miscellaneous process heating & $\$ 41,821$ & $17,095,100$ & $5,286$. & 281 & 1 \\
\hline $\begin{array}{l}\text { TOTALS } \\
\end{array}$ & $\$ 364,286,414$ & $32,365,778$ & $39,037,806$ & $2,920,121$ & 747 \\
\hline
\end{tabular}


Table 7. Potential cost savings, energy savings, and reduction in $\mathrm{CO}_{2}$ emissions from identified process heating opportunities in pick-list categories.

\begin{tabular}{|c|c|c|c|c|c|}
\hline $\begin{array}{c}\text { Year } 2006 \text { process heating savings opportunity } \\
\text { recommendations }\end{array}$ & $\begin{array}{c}\text { Recommended total } \\
\text { cost savings } \\
\text { (\$/year) }\end{array}$ & $\begin{array}{l}\text { Recommended total } \\
\text { energy savings } \\
\text { (MMBtu/year) }\end{array}$ & $\begin{array}{l}\text { Recommended total } \\
\text { natural gas savings } \\
\text { (MMBtu/year) }\end{array}$ & $\begin{array}{l}\text { Recommended total } \\
\mathrm{CO}_{2} \text { savings } \\
\text { (metric tons } \mathrm{CO}_{2} / \text { year) }\end{array}$ & $\begin{array}{c}\text { Number of } \\
\text { times the } \\
\text { opportunity } \\
\text { applied }\end{array}$ \\
\hline 3.4. Furnace heat recovery & $\$ 19,639,200$ & $2,066,169$ & $1,379,149$ & 181,570 & 27 \\
\hline 3.3. Heat cascading & $\$ 16,201,119$ & $1,988,789$ & $1,508,206$ & 141,712 & 36 \\
\hline 6.2. Other - miscellaneous process heating & $\$ 13,978,712$ & $1,481,904$ & $1,407,733$ & 88,191 & 27 \\
\hline 1.3. Use of proper heating methods & $\$ 12,753,467$ & $1,400,583$ & $1,400,583$ & 74,380 & 22 \\
\hline 4.1. Proper furnace insulation / maintenance & $\$ 11,693,585$ & $1,903,439$ & $1,363,402$ & 123,501 & 49 \\
\hline 1.1. Reduce flue gas oxygen content & $\$ 8,696,097$ & $1,567,558$ & 877,950 & 111,134 & 74 \\
\hline 1.5. Use oxygen for combustion & $\$ 7,022,724$ & $1,106,595$ & 743,427 & 75,387 & 14 \\
\hline 1.6. Use process or exhaust air for combustion & $\$ 6,978,720$ & 709,900 & 709,900 & 37,700 & 7 \\
\hline 3.2. Improve load charge preheating & $\$ 6,926,397$ & 858,431 & 814,017 & 47,427 & 26 \\
\hline 4.3. Reduce / eliminate furnace openings and leakage & $\$ 5,249,615$ & 729,741 & 661,720 & 41,577 & 25 \\
\hline 5.1. Improve furnace scheduling, loading, shutdown & $\$ 4,687,509$ & 474,365 & 473,831 & 25,223 & 11 \\
\hline $\begin{array}{l}\text { 3.1. Use flue / exhaust gas for combustion air } \\
\text { preheating }\end{array}$ & $\$ 4,613,692$ & 630,986 & 417,531 & 47,676 & 18 \\
\hline 2.1. Improving furnace / oven heat transfer & $\$ 3,948,977$ & 435,839 & 435,839 & 23,146 & 12 \\
\hline 1.4. Use alternate fuel or energy source & $\$ 3,686,128$ & 877,792 & 877,792 & 46,617 & 3 \\
\hline 6.1. Other - non process heating measures & $\$ 3,271,917$ & 124,894 & 27,965 & 19,060 & 12 \\
\hline 1.16. Improve insulation & $\$ 1,919,891$ & 237,393 & 222,871 & 11,836 & 7 \\
\hline 5.3. Control oven makeup air & $\$ 1,911,641$ & 233,730 & 238,406 & 11,812 & 12 \\
\hline 3.5. Use waste heat for cooling & $\$ 1,378,430$ & 104,386 & 103,433 & 5,552 & 4 \\
\hline 2.2. Clean heat transfer surfaces & $\$ 824,622$ & 115,780 & 115,780 & 6,149 & 3 \\
\hline 1.3. Improve boiler efficiency & $\$ 175,882$ & 17,758 & 17,676 & 954 & 8 \\
\hline 5.4. Eliminate continuous flame curtains, pilots & $\$ 125,000$ & 17,361 & 17,361 & 922 & 1 \\
\hline 1.1. Reduce steam demand & $\$ 80,600$ & 7,670 & 7,670 & 407 & 3 \\
\hline 4.2. Reduce-eliminate internal cooling & $\$ 65,290$ & 7,613 & 7,613 & 404 & 2 \\
\hline 1.7. Use outdoor air for combustion or makeup air & $\$ 20,000$ & 2,500 & 2,500 & 134 & 1 \\
\hline 1.20. Optimize multiple boilers & $\$ 12,400$ & 1,630 & 1,630 & 87 & 1 \\
\hline 5.2. Reduce weight of fixtures, trays, etc. & $\$ 3,300$ & 330 & 330 & 18 & 1 \\
\hline Totals & $\$ 135,864,915$ & $17,103,135$ & $13,834,314$ & $1,121,572$ & 406 \\
\hline
\end{tabular}




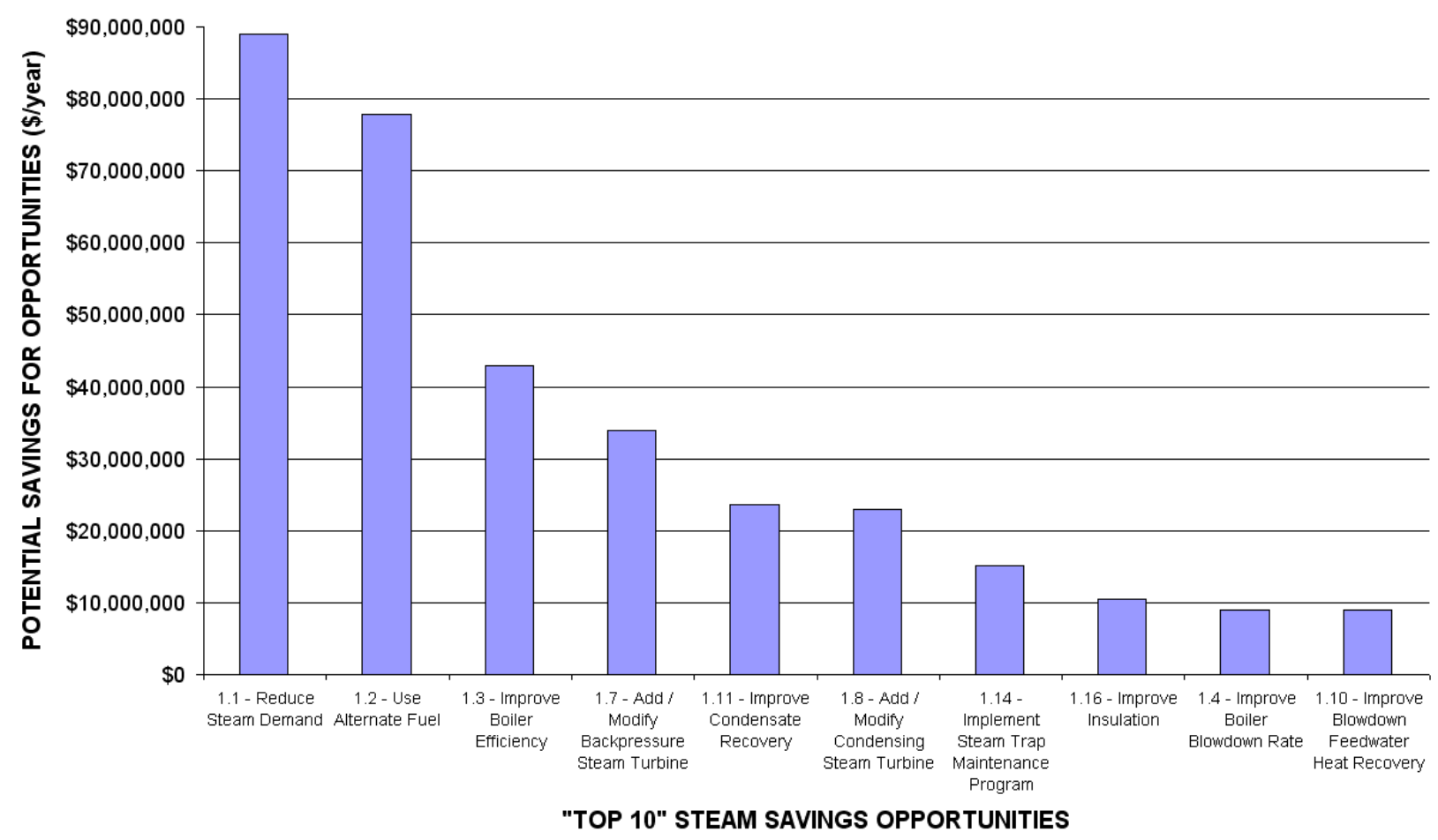

Figure 13. The top ten steam opportunity categories for the year 2006 assessments could result in \$334 million per year of plant energy savings.

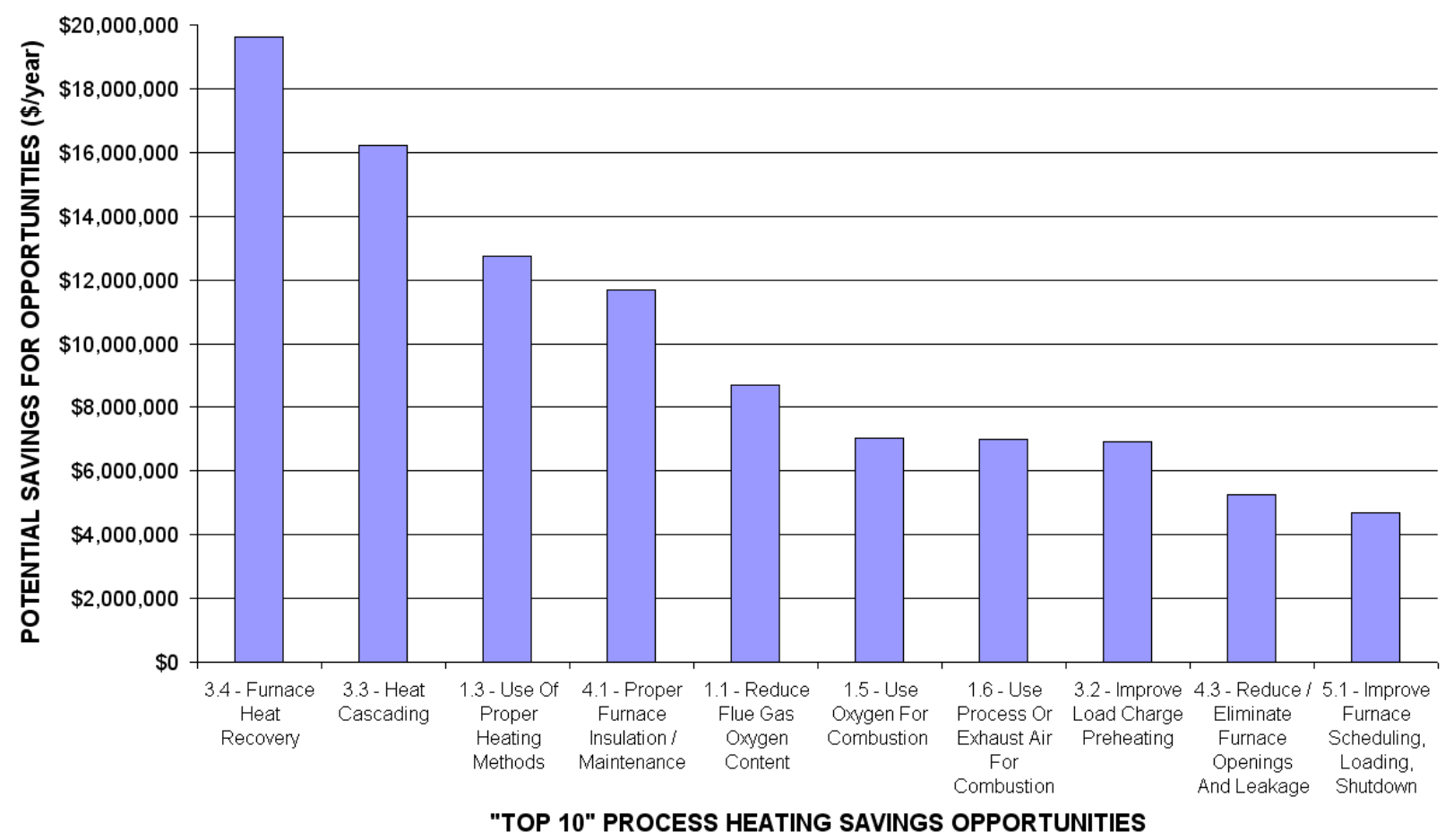

Figure 14. The top ten process heating opportunity categories for the year 2006 assessments could result in $\$ 100$ million per year of plant energy savings. 


\subsection{Estimated Paybacks Are Less Than Two Years for Most Identified Savings Opportunities}

While the magnitude of the potential cost and energy savings identified by the 2006 assessments is impressive, the impact on U.S. industry will only be proportional to the magnitude of implemented opportunities. A primary determinant of whether potential savings become real savings is the payback period for implementation. Savings payback period is defined as (cost to implement opportunity) / (yearly savings for the opportunity). Most industrial plants will not consider implementing savings opportunities that have paybacks of greater than two years.

The Energy Experts estimated high and low values of the capital costs for implementing each identified savings opportunity and used the higher values to estimate payback periods. The results, summarized in Table 8 and Figures 15 and 16, show that the majority of the estimated paybacks for the identified opportunities - $76 \%$ of all steam opportunities and $73 \%$ of all process heating opportunities - were less than two years.

The opportunities with estimated paybacks of less than two years also accounted for most of the potential cost savings for both steam and process heating - for steam assessments, $\$ 263$ million per year, or $72 \%$ of all potential savings; and for process heating assessments, $\$ 109$ million per year, or $80 \%$ of all potential savings.

Table 8. Estimated payback periods for identified energy savings opportunities.

\begin{tabular}{|c|c|c|c|c|}
\hline Payback category & $\begin{array}{c}\text { Number of identified } \\
\text { opportunities }\end{array}$ & $\begin{array}{c}\text { Potential cost savings } \\
\text { (\$/year) }\end{array}$ & $\begin{array}{l}\text { Potential total energy } \\
\text { savings (MMBtu/year) }\end{array}$ & $\begin{array}{l}\text { Potential total } \mathrm{CO}_{2} \\
\text { emission reduction } \\
\text { (metric Tons/year) }\end{array}$ \\
\hline \multicolumn{5}{|c|}{ Payback data summary for all assessments completed in 2006} \\
\hline $0-9$ months & 478 & $\$ 200,981,318$ & $26,959,540$ & $1,660,2284$ \\
\hline 9 months -2 years & 384 & $\$ 170,942,362$ & $19,486,394$ & $1,246,223$ \\
\hline $2-4$ years & 193 & $\$ 106,205,296$ & $2,893,349$ & 874,802 \\
\hline $4+$ years & 68 & $\$ 20,470,354$ & 104,694 & 259,060 \\
\hline Spinoff $^{a}$ & 30 & $\$ 1,552,000$ & 24,936 & 1,324 \\
\hline Totals & 1153 & $\$ 500,151,330$ & $49,468,913$ & $4,041,693$ \\
\hline \multicolumn{5}{|c|}{ Payback data summary for all steam assessments completed in 2006} \\
\hline $0-9$ months & 321 & $\$ 148,067,718$ & $21,064,974$ & $1,286,712$ \\
\hline 9 months -2 years & 243 & $\$ 115,063,965$ & $11,678,785$ & 731,436 \\
\hline $2-4$ years & 114 & $\$ 82,084,478$ & $-328,162$ & 663,481 \\
\hline $4+$ years & 53 & $\$ 17,918,253$ & $-69,756$ & 237,434 \\
\hline Spinoff & 16 & $\$ 1,152,000$ & 19,936 & 1,059 \\
\hline Totals & 747 & $\$ 364,286,414$ & $32,365,778$ & $2,920,121$ \\
\hline \multicolumn{5}{|c|}{ Payback data summary for all process heat assessments completed in 2006} \\
\hline $0-9$ months & 157 & $\$ 52,913,600$ & $5,894,566$ & 373,572 \\
\hline 9 months - 2 years & 141 & $\$ 55,878,396$ & $7,807,609$ & 514,787 \\
\hline $2-4$ years & 79 & $\$ 24,120,818$ & $3,221,511$ & 211,321 \\
\hline $4+$ years & 15 & $\$ 2,552,101$ & 174,450 & 21,627 \\
\hline Spinoff $^{a}$ & 14 & $\$ 400,000$ & 5,000 & 266 \\
\hline Totals & 406 & $\$ 135,864,915$ & $17,103,135$ & $1,121,572$ \\
\hline
\end{tabular}

${ }^{a}$ Spinoff is defined as an opportunity identified by an assessed plant as a direct and immediate result of their assessment experience. These opportunities may have been suggested by the Energy Expert, but not documented in the report, or the plant may have identified a new opportunity based on their assessment training or immediate application of the software tools. Plants report these opportunities during the follow-up interviews and only those that are identified as attributed to the assessment are recorded. 


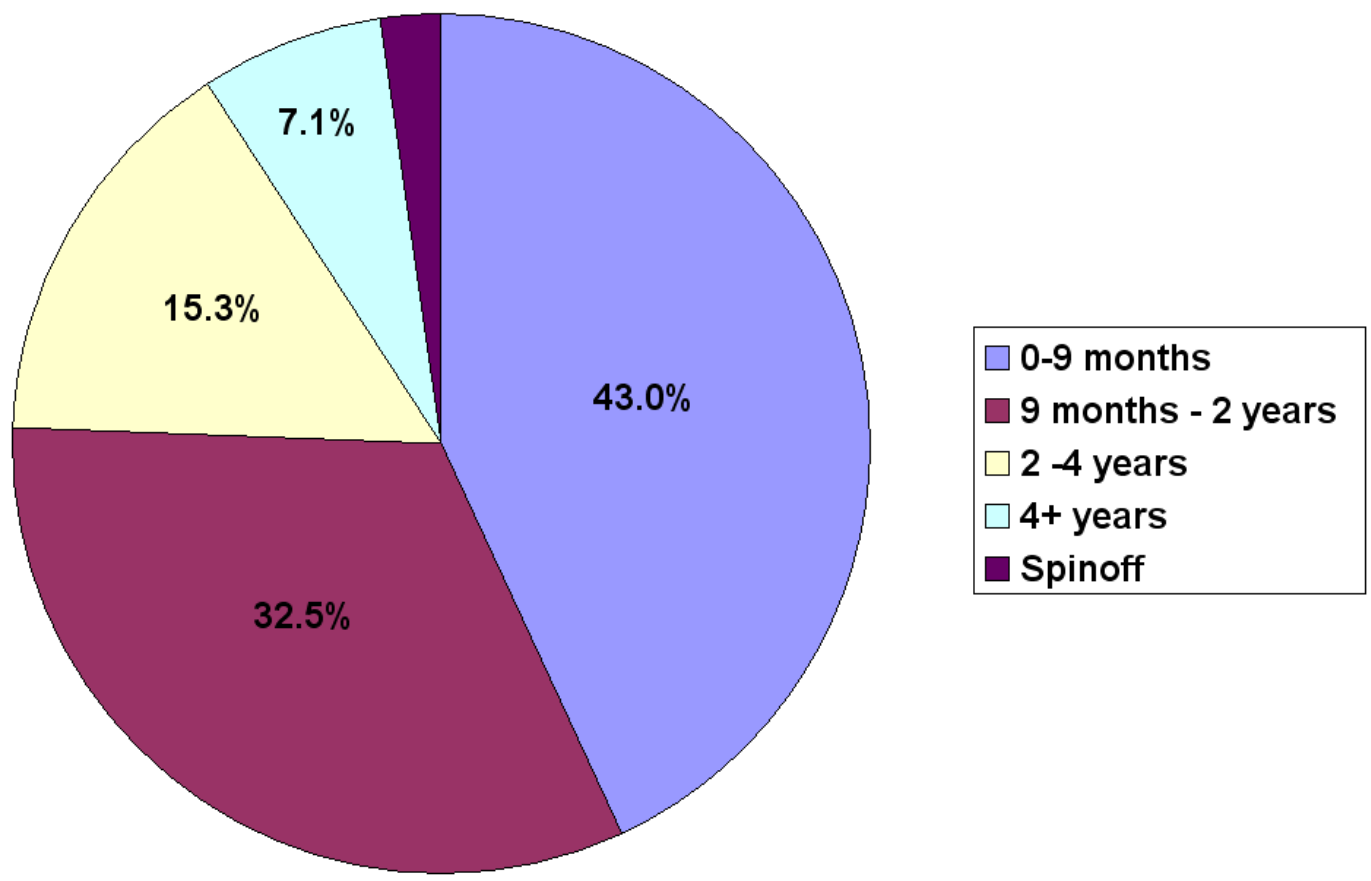

Figure 15. For the 2006 assessments, $76 \%$ of the steam recommendations had estimated paybacks of less than two years. The total recommended savings for steam opportunities with paybacks of less than 2 years was $\$ 263$ million/year.

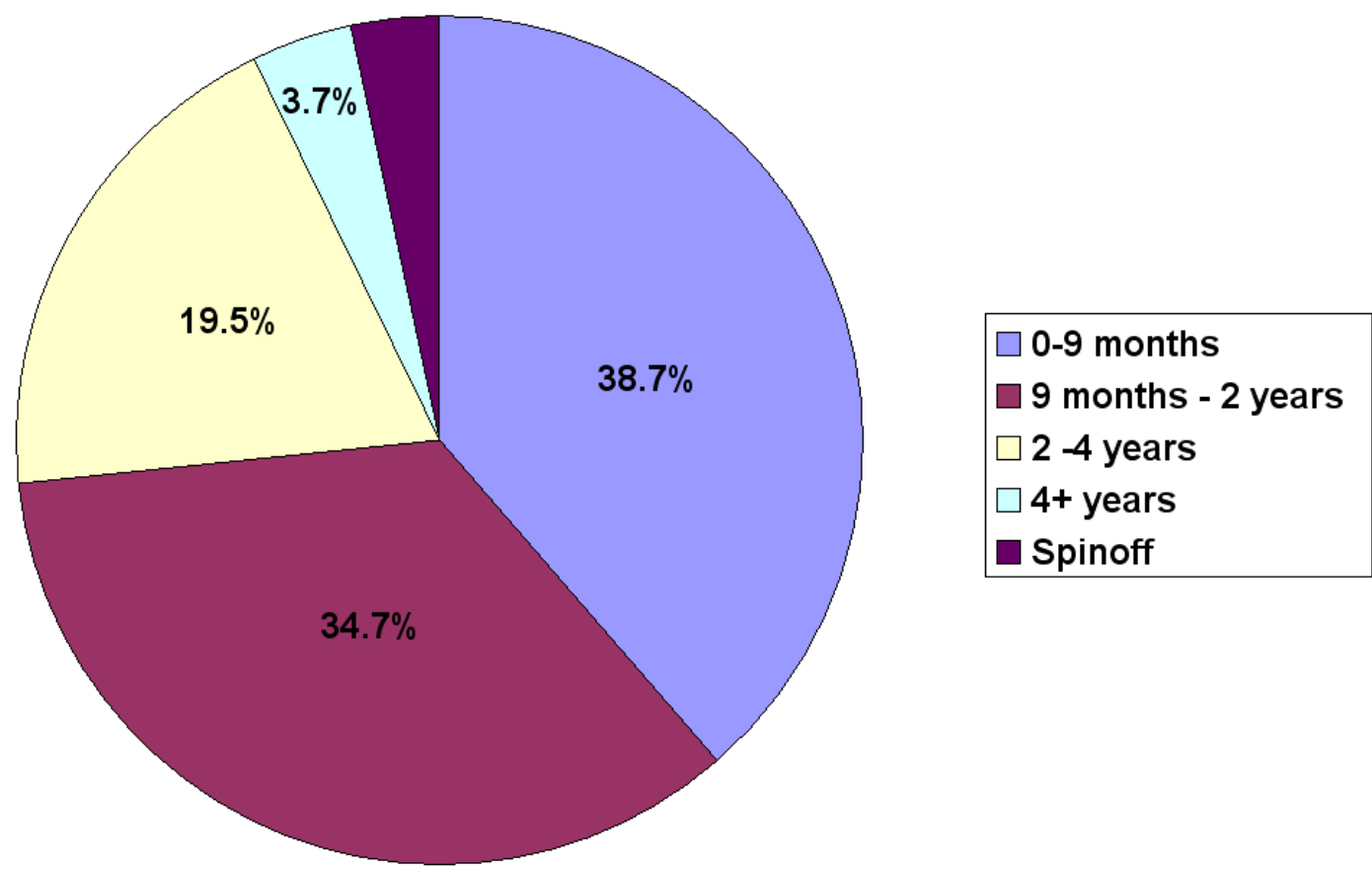

Figure 16. For the 2006 assessments, $73 \%$ of the process heating recommendations had estimated paybacks of less than two years. The total recommended savings for process heating opportunities with paybacks of less than 2 years was $\$ 109$ million/year. 
Tables 9 and 10 summarize the payback data for all of the steam and process heating opportunities by opportunity (pick list) category. The anticipated payback periods of the top ten most frequently identified steam and process heating opportunities show that they do hold promise for potential implementation.

The majority of the identified opportunities in the top ten steam categories have estimated paybacks of less than two years, as shown in Figure 17. Significant potential savings with estimated paybacks between two and four years were identified in four of these categories: use alternate fuel, improve boiler efficiency, add/modify backpressure steam turbine, and add/modify condensing steam turbine.

Most of the identified opportunities in the top ten process heating categories also had estimated paybacks of less than two years, as shown in Figure 18. Significant potential savings with estimated paybacks between two and four years were identified in four of these categories: furnace heat recovery, heat cascading, use of proper heating methods, and improve load charge preheating.

Tables 11 and 12 and Figures 19 and 20 present potential individual savings data in terms of the average percentages of plant energy use and energy cost represented by each category of opportunity. These results show that potential savings identified in many of these categories could be greater than $1 \%$ of total plant energy costs.

For the steam assessments, 14 of the opportunity categories showed average potential cost savings greater than $1 \%$ of plant energy costs (Table 11 ). For example, the average potential plant cost savings from reducing steam demand was greater than $3 \%$ of the plant energy costs.

For the process heating assessments, 17 of the opportunity categories showed average potential cost savings greater than $1 \%$ of plant energy costs (Table 12). For example, the average potential plant cost savings from heat cascading was greater than $3 \%$ of plant energy costs.

The estimated paybacks indicate that implementation of the majority of identified opportunities should be appealing to industrial plants. 
Table 9. Estimated annual cost savings and payback periods for assessment-identified steam system savings opportunities (opps).

\begin{tabular}{|c|c|c|c|c|c|c|c|c|c|c|}
\hline \multirow[b]{3}{*}{ Steam assessment opportunity type } & \multicolumn{10}{|c|}{ Payback periods } \\
\hline & \multicolumn{2}{|c|}{$0-9$ months } & \multicolumn{2}{|c|}{9 months -2 years } & \multicolumn{2}{|c|}{$2-4$ years } & \multicolumn{2}{|c|}{$4+$ years } & \multicolumn{2}{|c|}{ Spin-offs } \\
\hline & \# opps & Annual savings & \# opps & Annual savings & \# opps & Annual savings & \# opps & Annual savings & \# opps & Annual savings \\
\hline 1.1 - Reduce steam demand & 53 & $\$ 47,796,894$ & 29 & $\$ 35,422,406$ & 15 & $\$ 3,177,800$ & 9 & $\$ 2,263,111$ & 3 & $\$ 338,000$ \\
\hline 1.2 - Use alternate fuel & 8 & $\$ 23,752,103$ & 4 & $\$ 23,705,000$ & 4 & $\$ 22,953,815$ & 2 & $\$ 7,461,500$ & & \\
\hline 1.3 - Improve boiler efficiency & 58 & $\$ 13,063,094$ & 35 & $\$ 17,400,684$ & 21 & $\$ 11,287,107$ & 15 & $\$ 1,174,000$ & 1 & $\$ 0$ \\
\hline 1.7 - Add/modify backpressure steam turbine & 12 & $\$ 6,155,320$ & 12 & $\$ 4,372,284$ & 20 & $\$ 21,009,646$ & 8 & $\$ 2,382,829$ & 2 & $\$ 0$ \\
\hline 1.11 - Improve condensate recovery & 14 & $\$ 13,455,016$ & 25 & $\$ 7,334,357$ & 10 & $\$ 1,958,400$ & 5 & $\$ 373,000$ & 1 & $\$ 491,000$ \\
\hline 1.8 - Add/modify condensing steam turbine & 8 & $\$ 4,564,842$ & 3 & $\$ 2,046,500$ & 4 & $\$ 16,267,950$ & 1 & $\$ 65,000$ & 1 & \\
\hline 1.14 - Implement steam trap maintenance program & 30 & $\$ 11,169,397$ & 22 & $\$ 3,797,036$ & 1 & $\$ 16,000$ & 2 & $\$ 31,000$ & 1 & $\$ 46,000$ \\
\hline 1.16 - Improve insulation & 32 & $\$ 7,090,313$ & 37 & $\$ 2,987,023$ & 6 & $\$ 284,200$ & 1 & $\$ 54,000$ & 1 & $\$ 77,000$ \\
\hline 1.4 - Improve boiler blowdown rate & 20 & $\$ 6,147,466$ & 10 & $\$ 2,131,786$ & 6 & $\$ 592,604$ & 5 & $\$ 169,459$ & & \\
\hline 1.10 - Improve blowdown feedwater heat recovery & 24 & $\$ 4,690,674$ & 17 & $\$ 2,970,099$ & 7 & $\$ 1,240,900$ & 1 & $\$ 12,000$ & & \\
\hline 1.20 - Optimize multiple boilers & 4 & $\$ 1,584,754$ & 4 & $\$ 811,000$ & 1 & $\$ 42,329$ & 1 & $\$ 3,851,000$ & & \\
\hline 1.17 - Other - miscellaneous steam & 6 & $\$ 655,416$ & 10 & $\$ 4,570,289$ & 4 & $\$ 697,532$ & & & 6 & $\$ 200,000$ \\
\hline 1.18 - Feedwater heat recovery - general & 3 & $\$ 741,250$ & 2 & $\$ 3,534,211$ & 2 & $\$ 1,800,000$ & & & & \\
\hline 1.15 - Implement steam leak maintenance program & 21 & $\$ 1,907,230$ & 18 & $\$ 622,823$ & 3 & $\$ 80,974$ & 1 & $\$ 7,424$ & & \\
\hline 1.21 - Reduce / recover vented steam & 6 & $\$ 1,262,980$ & 3 & $\$ 602,981$ & 3 & $\$ 261,000$ & & & & \\
\hline 1.13 - Improve low pressure condensate flash & 1 & $\$ 533,000$ & 4 & $\$ 1,352,600$ & 4 & $\$ 86,321$ & 1 & $\$ 7,460$ & & \\
\hline 1.12 - Improve medium pressure condensate flash & 2 & $\$ 766,000$ & 1 & $\$ 619,000$ & & & & & & \\
\hline 1.6 - Improve steam generation conditions & 6 & $\$ 1,079,000$ & & & 1 & $\$ 45,000$ & & & & \\
\hline 1.19 - Improve deaerator heat recovery & 5 & $\$ 774,734$ & & & & & & & & \\
\hline 1.5 - Install blowdown flash to low pressure steam & 2 & $\$ 317,900$ & 3 & $\$ 173,078$ & & & & & & \\
\hline $\begin{array}{l}1.9 \text { - Improve condensate tank vent feedwater heat } \\
\text { recovery }\end{array}$ & 1 & $\$ 79,000$ & 1 & $\$ 76,000$ & 2 & $\$ 282,900$ & & & & \\
\hline $\begin{array}{l}3.1 \text { - Use flue/exhaust gas for combustion air } \\
\text { preheating }\end{array}$ & & & 2 & $\$ 301,669$ & & & & & & \\
\hline 2.2 - Clean heat transfer surfaces & & & 1 & $\$ 233,139$ & & & & & & \\
\hline 3.5 - Use waste heat for cooling & 1 & $\$ 164,000$ & & & & & 1 & $\$ 66,470$ & & \\
\hline 1.1 - Reduce flue gas oxygen content & 2 & $\$ 201,614$ & & & & & & & & \\
\hline $\begin{array}{l}\text { 5.1 - Improve furnace scheduling, loading, } \\
\text { shutdown }\end{array}$ & 1 & $\$ 73,900$ & & & & & & & & \\
\hline 6.2 - Other - miscellaneous process heating & 1 & $\$ 41,821$ & & & & & & & & \\
\hline Total & 321 & $\$ 148,067,718$ & 243 & $\$ 115,063,965$ & 114 & $\$ 82,084,478$ & 53 & $\$ 17,918,253$ & 16 & $\$ 1,152,000$ \\
\hline
\end{tabular}


Table 10. Estimated annual cost savings and payback periods for assessment-identified process heating system savings opportunities (opps).

\begin{tabular}{|c|c|c|c|c|c|c|c|c|c|c|}
\hline \multirow[b]{3}{*}{ Process Heating Opportunity Type } & \multicolumn{10}{|c|}{ Payback periods } \\
\hline & \multicolumn{2}{|c|}{$0-9$ months } & \multicolumn{2}{|c|}{9 months -2 years } & \multicolumn{2}{|c|}{$2-4$ years } & \multicolumn{2}{|c|}{$4+$ years } & \multicolumn{2}{|c|}{ Spin-offs } \\
\hline & \# opps & Annual savings & \# opps & Annual savings & \# opps & Annual savings & \# opps & Annual savings & \# opps & Annual savings \\
\hline 3.4 - Furnace Heat Recovery & 4 & $\$ 7,030,000$ & 12 & $\$ 9,216,918$ & 11 & $\$ 3,392,282$ & & & & \\
\hline 3.3 - Heat Cascading & 9 & $\$ 5,115,310$ & 16 & $\$ 8,352,112$ & 6 & $\$ 2,712,797$ & 2 & $\$ 20,900$ & 3 & \\
\hline 6.2 - Other - Miscellaneous Process Heating & 11 & $\$ 4,754,928$ & 8 & $\$ 4,547,984$ & 2 & $\$ 2,245,000$ & 4 & $\$ 2,030,800$ & 2 & $\$ 400,000$ \\
\hline 1.3 - Use Of Proper Heating Methods & 8 & $\$ 4,105,180$ & 7 & $\$ 4,453,259$ & 5 & $\$ 4,195,028$ & & & 2 & \\
\hline 4.1 - Proper Furnace Insulation / Maintenance & 15 & $\$ 3,720,060$ & 25 & $\$ 6,983,712$ & 6 & $\$ 949,885$ & 3 & $\$ 39,928$ & & \\
\hline 1.1 - Reduce Flue Gas Oxygen Content & 51 & $\$ 5,701,115$ & 15 & $\$ 2,213,663$ & 5 & $\$ 781,319$ & & & 3 & $\$ 0$ \\
\hline 1.5 - Use Oxygen For Combustion & 4 & $\$ 2,304,105$ & 4 & $\$ 3,558,462$ & 4 & $\$ 800,157$ & 1 & $\$ 360,000$ & 1 & \\
\hline $\begin{array}{l}1.6-\text { Use Process Or Exhaust Air For } \\
\text { Combustion }\end{array}$ & 5 & $\$ 6,391,720$ & & & 2 & $\$ 587,000$ & & & & \\
\hline 3.2 - Improve Load Charge Preheating & 5 & $\$ 825,036$ & 11 & $\$ 4,259,422$ & 10 & $\$ 1,841,939$ & & & & \\
\hline $\begin{array}{l}4.3 \text { - Reduce / Eliminate Furnace Openings And } \\
\text { Leakage }\end{array}$ & 8 & $\$ 1,268,628$ & 13 & $\$ 3,663,813$ & 4 & $\$ 317,174$ & & & & \\
\hline $\begin{array}{l}5.1 \text { - Improve Furnace Scheduling, Loading, } \\
\text { Shutdown }\end{array}$ & 7 & $\$ 4,334,529$ & 2 & $\$ 219,050$ & 2 & $\$ 133,930$ & & & & \\
\hline $\begin{array}{l}3.1 \text { - Use Flue / Exhaust Gas For Combustion } \\
\text { Air Preheating }\end{array}$ & 5 & $\$ 2,320,798$ & 9 & $\$ 2,152,430$ & 3 & $\$ 95,496$ & 1 & $\$ 44,968$ & & \\
\hline 2.1 - Improving Furnace / Oven Heat Transfer & 3 & $\$ 352,000$ & 5 & $\$ 2,545,960$ & 3 & $\$ 1,051,017$ & & & 1 & \\
\hline 1.4 - Use Alternate Fuel Or Energy Source & 2 & $\$ 2,156,128$ & & & 1 & $\$ 1,530,000$ & & & & \\
\hline 6.1 - Other - Non Process Heating Measures & 2 & $\$ 153,061$ & 3 & $\$ 720,262$ & 5 & $\$ 2,393,194$ & 1 & $\$ 5,400$ & 1 & \\
\hline 1.16 - Improve Insulation & 1 & $\$ 8,000$ & 3 & $\$ 1,829,588$ & 2 & $\$ 41,098$ & 1 & $\$ 41,205$ & & \\
\hline 5.3 - Control Oven Makeup Air & 7 & $\$ 864,480$ & 4 & $\$ 995,161$ & 1 & $\$ 52,000$ & & & & \\
\hline 3.5 - Use Waste Heat For Cooling & 2 & $\$ 516,600$ & & & 2 & $\$ 861,830$ & & & & \\
\hline 2.2 - Clean Heat Transfer Surfaces & 3 & $\$ 824,622$ & & & & & & & & \\
\hline 1.3 - Improve Boiler Efficiency & 1 & $\$ 7,900$ & 3 & $\$ 112,600$ & 3 & $\$ 49,782$ & 1 & $\$ 5,600$ & & \\
\hline $\begin{array}{l}5.4 \text { - Eliminate Continuous Flame Curtains, } \\
\text { Pilots }\end{array}$ & 1 & $\$ 125,000$ & & & & & & & & \\
\hline 1.1 - Reduce Steam Demand & 1 & $\$ 2,000$ & & & 1 & $\$ 78,600$ & & & 1 & \\
\hline 4.2 - Reduce-Eliminate Internal Cooling & & & 1 & $\$ 54,000$ & 1 & $\$ 11,290$ & & & & \\
\hline $\begin{array}{l}1.7 \text { - Use Outdoor Air For Combustion Or } \\
\text { Makeup Air }\end{array}$ & 1 & $\$ 20,000$ & & & & & & & & \\
\hline 1.20 - Optimize Multiple Boilers & 1 & $\$ 12,400$ & & & & & & & & \\
\hline 5.2 - Reduce Weight of Fixtures, Trays, etc. & & & & & & & 1 & $\$ 3,300$ & & \\
\hline Total & 157 & $\$ 52,913,600$ & 141 & $\$ 55,878,396$ & 79 & $\$ 24,120,818$ & 15 & $\$ 2,552,101$ & 14 & $\$ 400,000$ \\
\hline
\end{tabular}




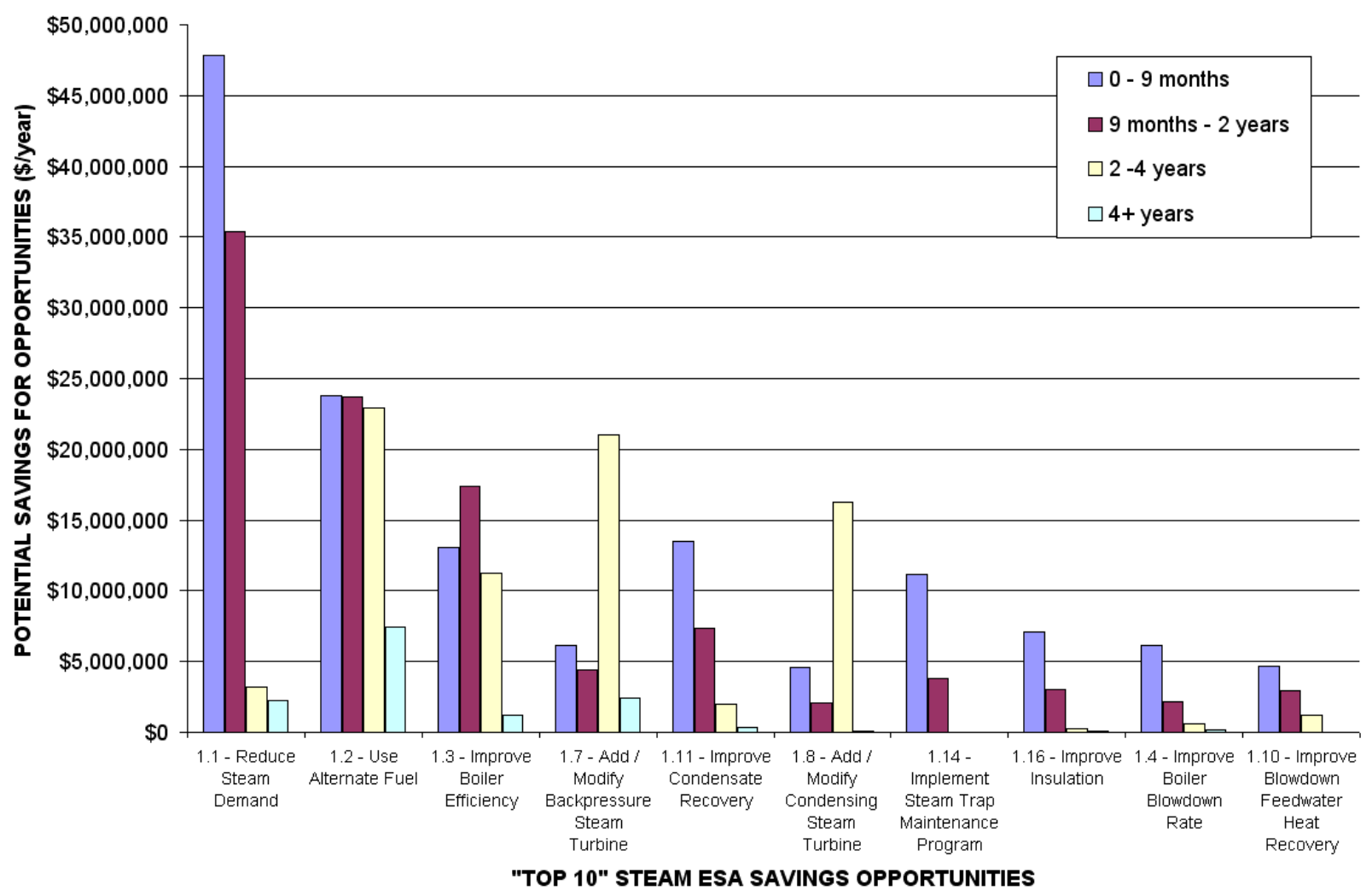

Figure 17. Most of the top ten steam opportunities had estimated paybacks of less than two years.

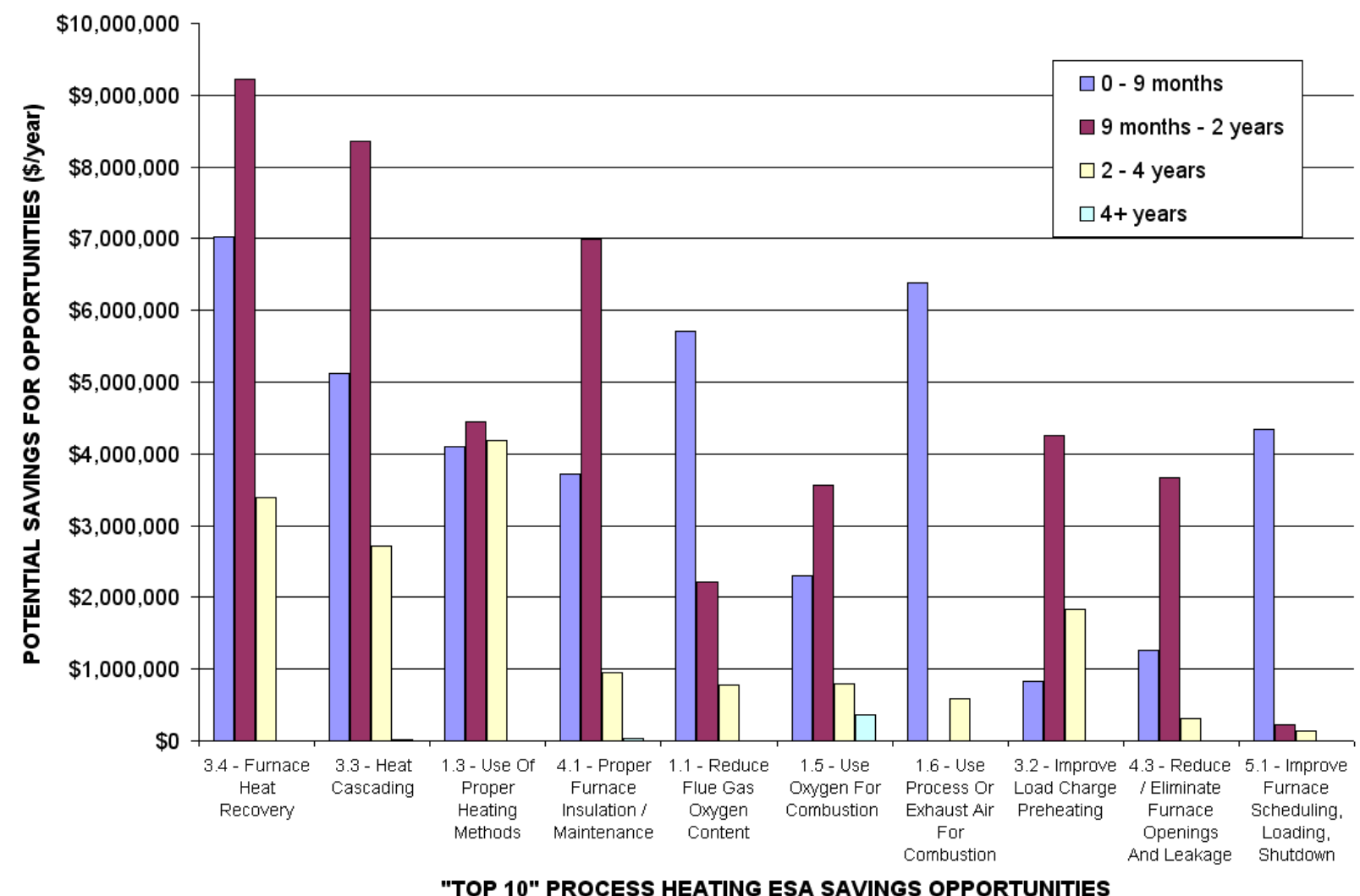

Figure 18. Most of the top ten process heating opportunities had estimated paybacks of less than two years. 
Table 11. Potential percentage savings in plant energy costs and plant energy use from steam opportunities (averages of all individual identified opportunities), by pick-list category.

\begin{tabular}{|c|c|c|}
\hline \multirow[b]{2}{*}{ Steam opportunity category } & \multicolumn{2}{|c|}{ Potential savings } \\
\hline & $\begin{array}{c}\text { Average } \\
\text { percentage of } \\
\text { plant energy } \\
\text { costs }\end{array}$ & $\begin{array}{c}\text { Average } \\
\text { percentage of } \\
\text { plant energy } \\
\text { use (site) }\end{array}$ \\
\hline 1.2 - Use alternate fuel & $15.1 \%$ & $-0.5 \%$ \\
\hline 1.1 - Reduce steam demand & $3.3 \%$ & $3.6 \%$ \\
\hline 1.20 - Optimize multiple boilers & $3.2 \%$ & $-0.3 \%$ \\
\hline 2.2 - Clean heat transfer surfaces & $2.6 \%$ & $3.2 \%$ \\
\hline 1.7 - Add / modify backpressure steam turbine & $2.4 \%$ & $0.1 \%$ \\
\hline 1.17 - Other - miscellaneous steam & $1.9 \%$ & $1.4 \%$ \\
\hline 1.21 - Reduce / recover vented steam & $1.9 \%$ & $2.4 \%$ \\
\hline 1.12 - Improve medium pressure condensate flash & $1.6 \%$ & $1.5 \%$ \\
\hline 1.18 - Feedwater heat recovery - general & $1.6 \%$ & $2.3 \%$ \\
\hline 1.8 - Add / modify condensing steam turbine & $1.5 \%$ & $0.6 \%$ \\
\hline 1.3 - Improve boiler efficiency & $1.5 \%$ & $1.6 \%$ \\
\hline 1.6 - Improve steam generation conditions & $1.0 \%$ & $0.8 \%$ \\
\hline 1.19 - Improve deaerator heat recovery & $1.0 \%$ & $1.1 \%$ \\
\hline 1.11 - Improve condensate recovery & $1.0 \%$ & $1.1 \%$ \\
\hline 1.13 - Improve low pressure condensate flash & $0.9 \%$ & $0.9 \%$ \\
\hline 1.1 - Reduce flue gas oxygen content & $0.8 \%$ & $1.0 \%$ \\
\hline 3.5 - Use waste heat for cooling & $0.7 \%$ & $0.6 \%$ \\
\hline 1.14 - Implement steam trap maintenance program & $0.7 \%$ & $0.8 \%$ \\
\hline 1.9 - Improve condensate tank vent feedwater heat recovery & $0.6 \%$ & $0.8 \%$ \\
\hline 1.10 - Improve blowdown feedwater heat recovery & $0.5 \%$ & $0.6 \%$ \\
\hline 1.16 - Improve insulation & $0.5 \%$ & $0.5 \%$ \\
\hline 3.1 - Use flue / exhaust gas for combustion air preheating & $0.4 \%$ & $0.4 \%$ \\
\hline 1.15 - Implement steam leak maintenance program & $0.4 \%$ & $0.3 \%$ \\
\hline 1.4 - Improve boiler blowdown rate & $0.4 \%$ & $0.3 \%$ \\
\hline 5.1 - Improve furnace scheduling, loading, shutdown & $0.4 \%$ & $0.0 \%$ \\
\hline 6.2 - Other - miscellaneous process heating & $0.2 \%$ & $0.2 \%$ \\
\hline 1.5 - Install blowdown flash to low pressure steam & $0.1 \%$ & $0.2 \%$ \\
\hline
\end{tabular}


Table 12. Potential percentage savings in plant energy costs and plant energy use from process heating opportunities (averages of all individual identified opportunities), by pick-list category.

\begin{tabular}{|c|c|c|}
\hline \multirow[b]{2}{*}{ Process heating opportunity category } & \multicolumn{2}{|c|}{ Potential savings } \\
\hline & $\begin{array}{c}\text { Average } \\
\text { percentage of } \\
\text { plant energy } \\
\text { costs }\end{array}$ & $\begin{array}{c}\text { Average } \\
\text { percentage of } \\
\text { plant energy } \\
\text { use (site) }\end{array}$ \\
\hline 1.4 - Use alternate fuel or energy source & $9.3 \%$ & $13.1 \%$ \\
\hline 3.5 - Use waste heat for cooling & $8.0 \%$ & $8.7 \%$ \\
\hline 3.3 - Heat cascading & $3.3 \%$ & $3.4 \%$ \\
\hline 3.4 - Furnace heat recovery & $2.9 \%$ & $3.5 \%$ \\
\hline 1.5 - Use oxygen for combustion & $2.8 \%$ & $3.6 \%$ \\
\hline 6.1 - Other - non process heating measures & $2.8 \%$ & $1.8 \%$ \\
\hline 1.3 - Use of proper heating methods & $2.7 \%$ & $3.1 \%$ \\
\hline 5.3 - Control oven makeup air & $2.7 \%$ & $2.7 \%$ \\
\hline 6.2 - Other - miscellaneous process heating & $2.6 \%$ & $3.1 \%$ \\
\hline 2.1 - Improving furnace / oven heat transfer & $2.4 \%$ & $3.0 \%$ \\
\hline 3.1 - Use flue / exhaust gas for combustion air preheating & $2.1 \%$ & $2.2 \%$ \\
\hline 3.2 - Improve load charge preheating & $1.7 \%$ & $1.9 \%$ \\
\hline 5.1 - Improve furnace scheduling, loading, shutdown & $1.4 \%$ & $1.4 \%$ \\
\hline 1.6 - Use process or exhaust air for combustion & $1.4 \%$ & $1.5 \%$ \\
\hline 1.1 - Reduce steam demand & $1.2 \%$ & $1.5 \%$ \\
\hline 4.3 - Reduce / eliminate furnace openings and leakage & $1.2 \%$ & $1.3 \%$ \\
\hline 4.1 - Proper furnace insulation / maintenance & $1.1 \%$ & $1.3 \%$ \\
\hline 1.1 - Reduce flue gas oxygen content & $0.9 \%$ & $1.1 \%$ \\
\hline 1.3 - Improve boiler efficiency & $0.8 \%$ & $1.1 \%$ \\
\hline 1.16 - Improve insulation & $0.7 \%$ & $0.9 \%$ \\
\hline 2.2 - Clean heat transfer surfaces & $0.4 \%$ & $1.6 \%$ \\
\hline 5.2 - Reduce weight of fixtures, trays, etc. & $0.2 \%$ & $0.2 \%$ \\
\hline 4.2 - Reduce-eliminate internal cooling & $0.1 \%$ & $0.1 \%$ \\
\hline 5.4 - Eliminate continuous flame curtains, pilots & $0.1 \%$ & $0.07 \%$ \\
\hline 1.7 - Use outdoor air for combustion or makeup air & $0.05 \%$ & $0.02 \%$ \\
\hline 1.20 - Optimize multiple boilers & $0.01 \%$ & $0.03 \%$ \\
\hline
\end{tabular}




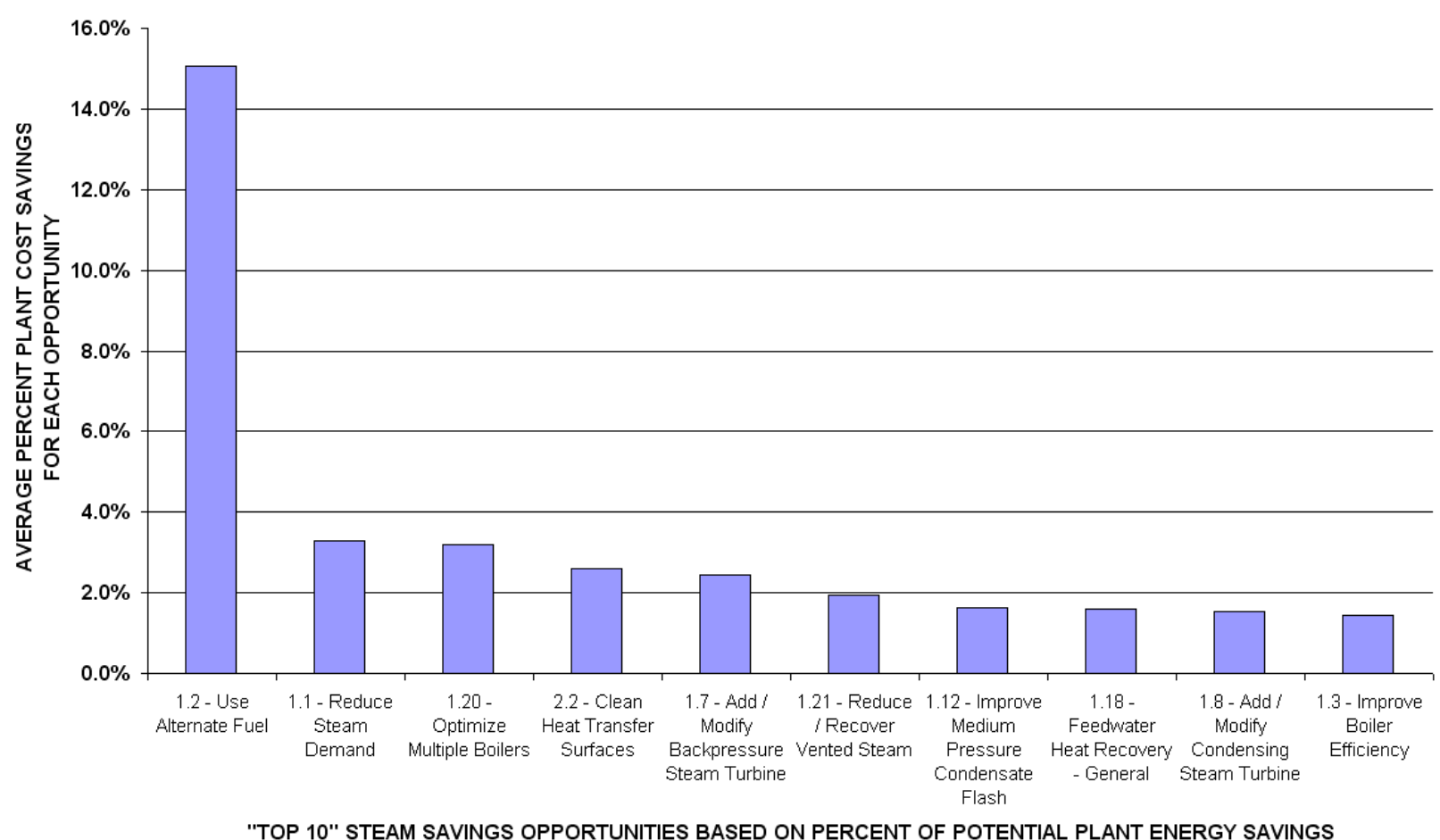

Figure 19. Many of the identified steam savings opportunities could individually save industrial plants more than $1 \%$ of their total energy costs.

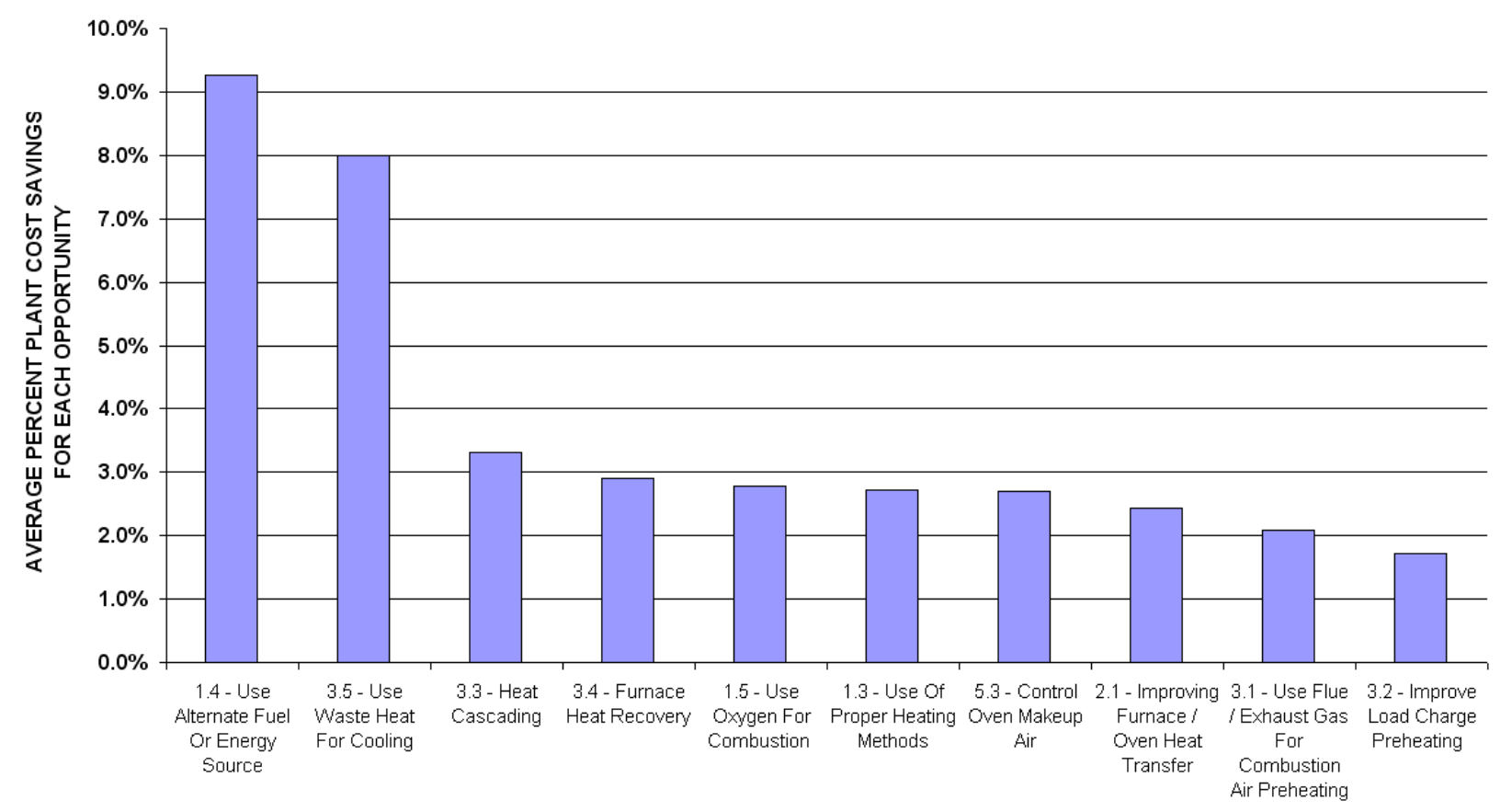

"TOP 10" PROCESS HEATING SAVINGS OPPORTUNITIES BASED ON PERCENT OF POTENTIAL PLANT ENERGY SAVINGS

Figure 20. Many of the identified process heating savings opportunities could individually save industrial plants more than $1 \%$ of their total energy costs. 


\subsection{Six-Month Results: Immediately Implemented Measures Are Saving \$30.4 Million Per Year}

Implementation results for assessed plants were reported about six months after the 2006 assessments were completed. Participants are committed to reporting results at intervals of 6,12 , and 24 months after their assessments. At the writing of this report, 179 follow-up calls were completed - 103 on steam assessments and 76 on process heating assessments.

The six-month results included the implementation status of each savings opportunity identified in the assessment reports, categorizing each as either 1) immediately implemented, 2) in progress, 3) planning, under review, or awaiting funding, 4) rejected, or 5) tried and rejected. Savings results for the first three categories are summarized in Tables 13 through 16.

The six-month results indicated that most plants had embraced their assessments and were making progress on implementing the savings opportunities. The percentages noted below are data based on the 179 plant responses. Several key trends are indicated in these tables:

- Assessed plants reporting results have implemented or are pursuing implementation of $70 \%$ of the potential energy cost savings identified in their assessments. Projects representing the remaining $30 \%$ of identified cost savings have been either rejected or tried and rejected.

- At six months, according to reports from 179 plants, about $7 \%$ of identified potential energy cost savings had been implemented, another $23 \%$ were in progress, and another $41 \%$ were planned, under review, or awaiting funds for implementation.

- Assessed plants reporting results at 6 months are pursuing 52\% of the natural gas energy savings and $71 \%$ of the total site energy savings identified in the assessments.

- Plants select measures with near-term paybacks for immediate implementation (see Table 16). Those opportunities with longer-term paybacks are more likely to undergo additional technical review or require additional planning.

Table 13. Six-month results for 179 year-2006 assessments ${ }^{a}$

\begin{tabular}{|l|c|c|c|}
\hline & $\begin{array}{c}\text { Immediately } \\
\text { implemented }\end{array}$ & In progress & $\begin{array}{c}\text { Planned, under review, } \\
\text { or awaiting funding }\end{array}$ \\
\hline Total cost savings (\$/year) & $\$ 30,397,400$ & $\$ 98,109,200$ & $\$ 179,430,300$ \\
\hline Cost savings per assessment (\$/year) & $\$ 169,800$ & $\$ 548,100$ & $\$ 1,002,400$ \\
\hline $\begin{array}{l}\text { Average cost savings per assessment as \% of } \\
\text { annual plant energy costs }\end{array}$ & $1.0 \%$ & $2.0 \%$ & $4.5 \%$ \\
\hline Total site energy savings (MMBtu/year) & $4,035,800$ & $16,685,600$ & $9,771,600$ \\
\hline Site energy savings per assessment (MMBtu/yr) & 22,500 & 93,200 & 54,600 \\
\hline $\begin{array}{l}\text { Average site energy savings per assessment as } \\
\% \text { of annual site energy }\end{array}$ & $1 \%$ & $1.9 \%$ & $3.6 \%$ \\
\hline Total natural gas savings (MMBtu/year) & $3,495,000$ & $10,161,200$ & $18,449,100$ \\
\hline $\begin{array}{l}\text { Natural gas savings per assessment } \\
\text { (MMBtu/year) }\end{array}$ & 19,500 & 56,800 & 103,100 \\
\hline $\begin{array}{l}\text { Average natural gas savings per assessment } \\
\text { (\%/year) }\end{array}$ & $1.4 \%$ & $4.8 \%$ & $6.9 \%$ \\
\hline Total $\mathrm{CO}_{2}$ savings (metric tons/year) & 234,000 & 984,300 & $1,285,800$ \\
\hline $\mathrm{CO}_{2}$ Savings per assessment (metric tons/year) & 1,307 & 5,500 & 7,200 \\
\hline
\end{tabular}

${ }^{a}$ All percentages in the table and associated text are based only on energy and costs data for the 179 responding plants.

Note: Savings designated as "site" savings refer to energy used at the site and do not include losses that occur in the generation, transmission and distribution of energy. 
Table 14. Six-month results for 103 steam assessments completed in $2006^{\mathrm{a}}$

\begin{tabular}{|l|c|c|c|}
\hline & $\begin{array}{c}\text { Immediately } \\
\text { implemented }\end{array}$ & In progress & $\begin{array}{c}\text { Planned, under } \\
\text { review or } \\
\text { awaiting funding }\end{array}$ \\
\hline Total cost savings (\$/year) & $\$ 24,006,000$ & $\$ 75,104,100$ & $\$ 129,122,800$ \\
\hline Cost savings per assessment (\$/year) & $\$ 233,100$ & $\$ 729,200$ & $\$ 1,253,600$ \\
\hline $\begin{array}{l}\text { Average cost savings per assessment as \% of } \\
\text { annual plant energy costs }\end{array}$ & $1.1 \%$ & $2.3 \%$ & $5.5 \%$ \\
\hline Total site energy savings (MMBtu/year) & $3,281,400$ & $12,622,700$ & $4,109,700$ \\
\hline $\begin{array}{l}\text { Site energy savings per assessment } \\
\text { (MMBtu/yr) }\end{array}$ & 31,900 & 122,600 & 39,900 \\
\hline $\begin{array}{l}\text { Average site energy savings per assessment } \\
\text { as \% of annual site energy }\end{array}$ & $1 \%$ & $1.9 \%$ & $3.4 \%$ \\
\hline Total natural gas savings (MMBtu/year) & $2,744,600$ & $7,314,400$ & $13,697,600$ \\
\hline $\begin{array}{l}\text { Natural gas savings per assessment } \\
\text { (MMBtu/year) }\end{array}$ & 26,600 & 71,000 & 133,000 \\
\hline $\begin{array}{l}\text { Average natural gas savings per assessment } \\
\text { (\%/year) }\end{array}$ & $1.7 \%$ & $6.7 \%$ & $8.2 \%$ \\
\hline Total CO $\mathrm{CO}_{2}$ savings (metric tons/year) & 193,400 & 716,200 & 896,600 \\
\hline $\begin{array}{l}\mathrm{CO} \mathrm{O}_{2} \text { Savings per assessment (metric } \\
\text { tons/year) }\end{array}$ & 1,900 & 7,000 & 8,700 \\
\hline
\end{tabular}

${ }^{a}$ All percentages in the table and associated text are based only on energy and costs data for the 103 responding plants that had steam assessments.

Table 15. Six-month results for 76 process heating assessments completed in $2006^{a}$

\begin{tabular}{|l|c|c|c|}
\hline & $\begin{array}{c}\text { Immediately } \\
\text { implemented }\end{array}$ & In progress & $\begin{array}{c}\text { Planned, under } \\
\text { review or } \\
\text { awaiting funding }\end{array}$ \\
\hline Total cost savings (\$/year) & $\$ 6,391,400$ & $\$ 23,005,000$ & $\$ 50,307,400$ \\
\hline Cost savings per assessment (\$/year) & $\$ 84,100$ & $\$ 302,700$ & $\$ 662,000$ \\
\hline $\begin{array}{l}\text { Average cost savings per assessment as \% of } \\
\text { annual plant energy costs }\end{array}$ & $1 \%$ & $1.6 \%$ & $3.2 \%$ \\
\hline Total site energy savings (MMBtu/year) & 754,350 & $4,062,900$ & $5,661,900$ \\
\hline $\begin{array}{l}\text { Site energy savings per assessment } \\
\text { (MMBtu/yr) }\end{array}$ & 9,900 & 53,500 & 74,500 \\
\hline $\begin{array}{l}\text { Average site energy savings per assessment } \\
\text { as \% of annual site energy }\end{array}$ & $1 \%$ & $1.9 \%$ & $3.7 \%$ \\
\hline Total natural gas savings (MMBtu/year) & 750,400 & $2,846,800$ & $4,751,500$ \\
\hline $\begin{array}{l}\text { Natural gas savings per assessment } \\
\text { (MMBtu/year) }\end{array}$ & 9,900 & 37,500 & 62,500 \\
\hline $\begin{array}{l}\text { Average natural gas savings per assessment } \\
\text { (\%/year) }\end{array}$ & $1 \%$ & $2.2 \%$ & $5.3 \%$ \\
\hline Total CO 2 savings (metric tons/year) & 40,570 & 268,100 & 389,100 \\
\hline $\begin{array}{l}\text { CO }{ }_{2} \text { Savings per assessment (metric } \\
\text { tons/year) }\end{array}$ & 500 & 3,500 & 5,100 \\
\hline
\end{tabular}

${ }^{a}$ All percentages in the table and associated text are based only on energy and costs data for the 76 responding plants that had process heating assessments. 
Table 16. Distribution of payback periods for savings opportunities, by implementation status.

\begin{tabular}{|c|c|c|c|c|c|}
\hline Payback category & $\begin{array}{l}\text { Immediately } \\
\text { implemented }\end{array}$ & In progress & Planned & Rejected & $\begin{array}{l}\text { Tried and } \\
\text { rejected }\end{array}$ \\
\hline Spinoff $^{a}$ & $0.1 \%$ & $0.9 \%$ & $0.9 \%$ & $1.0 \%$ & $0.0 \%$ \\
\hline $0-9$ months & $9.6 \%$ & $10.2 \%$ & $14.7 \%$ & $6.9 \%$ & $0.3 \%$ \\
\hline 9 months -2 years & $4.7 \%$ & $7.0 \%$ & $14.5 \%$ & $6.8 \%$ & $0.0 \%$ \\
\hline $2-4$ years & $0.9 \%$ & $3.1 \%$ & $8.2 \%$ & $4.7 \%$ & $0.0 \%$ \\
\hline $4+$ years & $0.7 \%$ & $0.9 \%$ & $2.3 \%$ & $1.8 \%$ & $0.0 \%$ \\
\hline
\end{tabular}

${ }^{a}$ Spin-off measures are identified by assessed plants during follow-up interviews; some spin-off measures do not include estimates of implementation cost and are listed as a separate category.

\subsection{Assessment Process Deemed Highly Useful and Influential in Plants' Decisions to Implement Savings Opportunities}

The six-month interviews with participants at industrial plants also provided feedback to help ITP measure the success of the assessment process and its focus on training plant personnel and fostering their adoption of energy assessment tools. Interviewers asked them about the usefulness of the assessments in their adopting DOE software tools and technical products (Fig. 21) and the degree of influence that the assessment had on implementation of savings opportunities. Recall that in the Save Energy Now assessment protocol, not only were potential energy savings identified, but Energy Experts also trained participants to use the steam and process heating energy assessment software in their own facilities and introduced other DOE technical tools and resources as well. Nearly $75 \%$ of plants reported that the assessment encouraged the use of DOE software and other products.

Slightly more than $90 \%$ reported that the assessment played an influential or highly influential role in their decisions to implement identified energy savings projects. Only $9 \%$ of assessment participants reported that assessments had slight or no influence on implementation (Fig. 22).

Assessed plants were also asked about the culture in their organizations with respect to energy efficiency. Nearly $70 \%$ of assessed plants reported having a written CEO- or board-approved policy in place that includes the reduction of energy consumption (Fig. 23). 


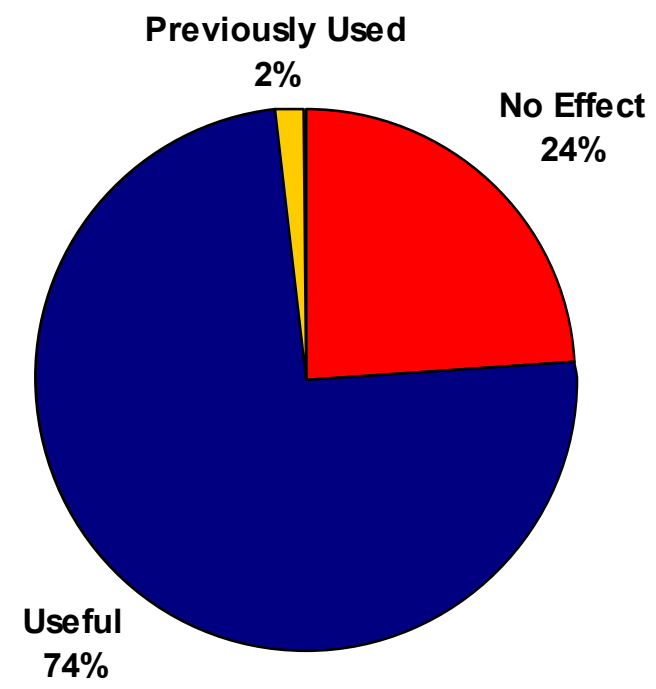

Figure 21. Nearly $75 \%$ of participants found that the assessments were influential in their use of the software tools following the assessments.

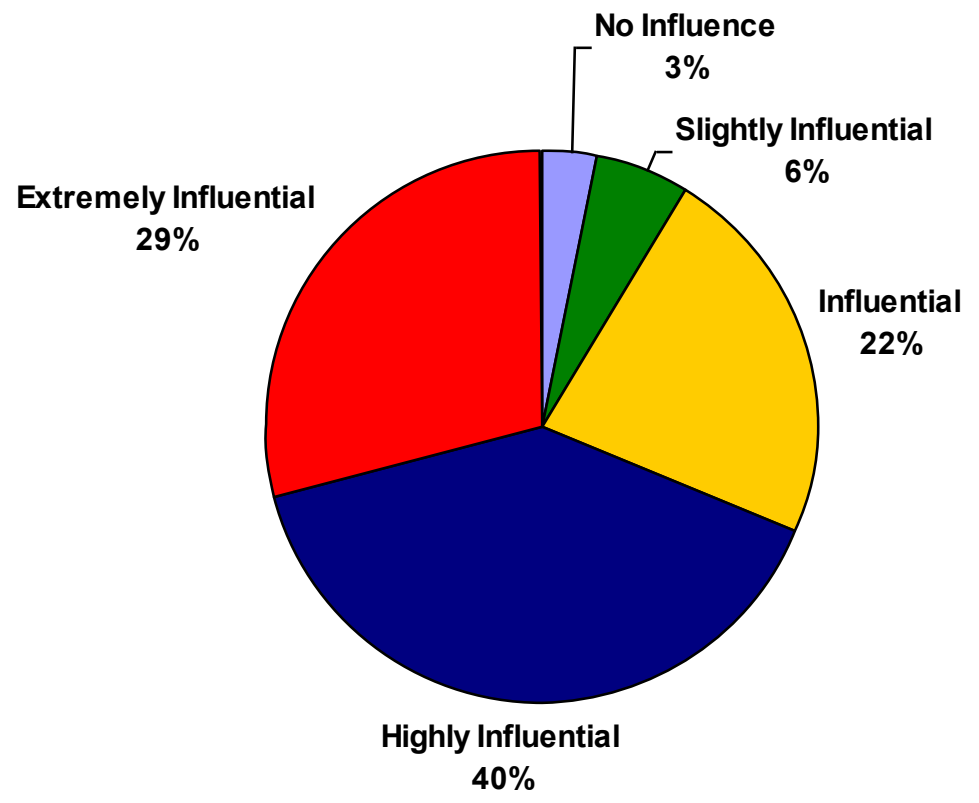

Figure 22. More than $90 \%$ of participants found that the assessments played an influential or highly influential role in their implementation of energy savings projects. 


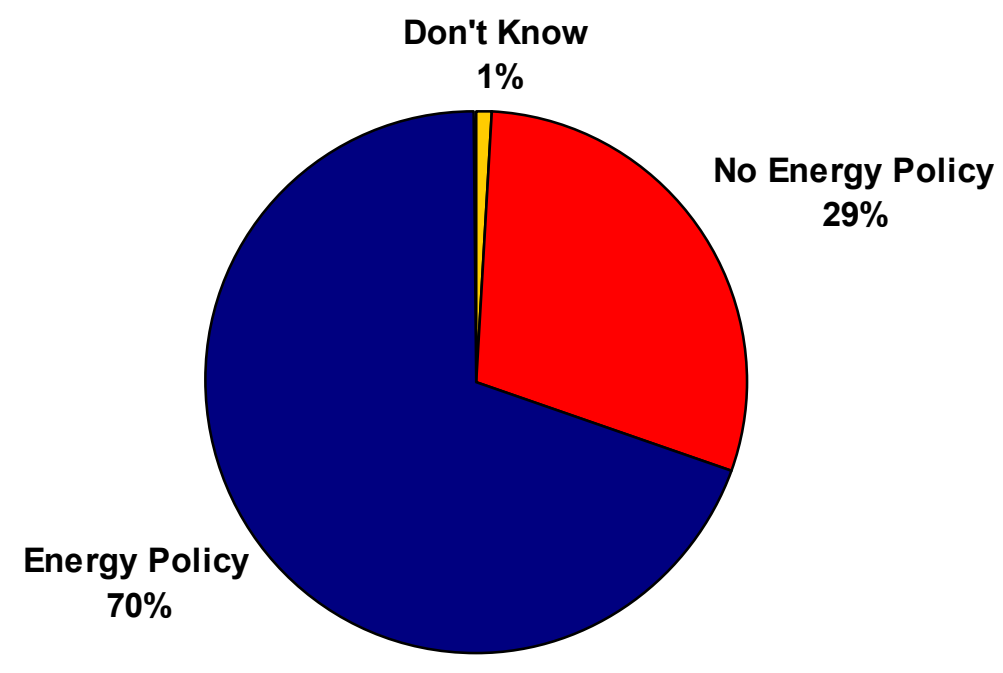

Figure 23. Most of the assessed plants reported having an energy policy in place at the time of the six-month follow-up.

\subsection{Implementation of Identified Opportunities by State and Industry}

ORNL also reviewed 6-month implementation results by state and three-digit NAIC industry categories. Tables 17 and 18 summarize implementation data for energy cost savings by state and by industry. (Similar data on total energy savings, natural gas savings, and emissions reductions is available, but is not presented here for the sake of brevity.) The tables track the progress towards implementation of the identified projects, by state and by industry. 
Table 17. Identified energy cost savings opportunities by state. Plants in Oregon, Texas and Louisiana top implemented cost savings at the six-month anniversary of the assessments.

\begin{tabular}{|c|c|c|c|c|c|}
\hline State & $\begin{array}{l}\text { Number } \\
\text { of ESAs }\end{array}$ & $\begin{array}{l}\text { Total Identified } \\
\text { Energy Cost } \\
\text { Savings, } \$ / y r\end{array}$ & $\begin{array}{l}\text { Implemented: } \\
\text { Energy Cost } \\
\text { Savings, } \$ / y r\end{array}$ & $\begin{array}{l}\text { In-Progress: } \\
\text { Energy Cost } \\
\text { Savings, } \$ / y r\end{array}$ & $\begin{array}{l}\text { Planned, Under- } \\
\text { Review or Awaiting } \\
\text { Funding: Energy } \\
\text { Cost Savings, \$/yr }\end{array}$ \\
\hline$\overline{A L}$ & 10 & $\$ 15,085,072$ & $\$ 353,472$ & $\$ 3,824,094$ & $\$ 3,847,557$ \\
\hline AR & 3 & $\$ 10,108,941$ & $\$ 23,000$ & $\$ 20,772$ & $\$ 9,570,502$ \\
\hline$A Z$ & 1 & $\$ 524,311$ & & & $\$ 524,311$ \\
\hline $\mathrm{CA}$ & 7 & $\$ 7,611,038$ & $\$ 109,808$ & $\$ 1,382,005$ & $\$ 1,644,993$ \\
\hline $\mathrm{CO}$ & 1 & $\$ 331,159$ & $\$ 135,214$ & $\$ 99,050$ & $\$ 51,997$ \\
\hline $\mathrm{DE}$ & 1 & $\$ 232,000$ & $\$ 162,000$ & & $\$ 44,000$ \\
\hline $\mathrm{FL}$ & 2 & $\$ 1,567,121$ & & $\$ 179,200$ & $\$ 373,246$ \\
\hline $\mathrm{GA}$ & 5 & $\$ 5,038,232$ & $\$ 2,198,025$ & $\$ 38,000$ & $\$ 1,661,133$ \\
\hline $\mathrm{IA}$ & 3 & $\$ 13,552,519$ & $\$ 15,000$ & $\$ 1,421,752$ & $\$ 14,211,500$ \\
\hline ID & 3 & $\$ 4,216,158$ & $\$ 157,000$ & $\$ 505,200$ & $\$ 2,654,280$ \\
\hline $\mathrm{IL}$ & 3 & $\$ 1,120,714$ & $\$ 193,000$ & & $\$ 240,384$ \\
\hline IN & 9 & $\$ 24,145,756$ & $\$ 2,214,498$ & $\$ 8,614,000$ & $\$ 12,661,660$ \\
\hline KS & 2 & $\$ 920,100$ & $\$ 251,000$ & $\$ 635,100$ & $\$ 196,000$ \\
\hline $\mathrm{KY}$ & 4 & $\$ 7,487,772$ & $\$ 188,411$ & $\$ 1,760,668$ & $\$ 1,737,093$ \\
\hline LA & 15 & $\$ 76,717,879$ & $\$ 3,626,350$ & $\$ 1,962,485$ & $\$ 47,768,862$ \\
\hline MA & 3 & $\$ 1,983,277$ & $\$ 423,730$ & $\$ 608,685$ & $\$ 707,874$ \\
\hline $\mathrm{MD}$ & 2 & $\$ 630,000$ & $\$ 12,000$ & $\$ 37,000$ & $\$ 581,000$ \\
\hline $\mathrm{ME}$ & 3 & $\$ 13,037,514$ & $\$ 755,000$ & $\$ 62,000$ & $\$ 10,799,000$ \\
\hline $\mathrm{Ml}$ & 7 & $\$ 10,084,202$ & $\$ 840,000$ & $\$ 1,481,400$ & $\$ 2,439,162$ \\
\hline $\mathrm{MN}$ & 5 & $\$ 19,555,960$ & $\$ 2,770,000$ & $\$ 3,893,461$ & $\$ 2,551,224$ \\
\hline $\mathrm{MO}$ & 2 & $\$ 1,642,492$ & $\$ 350,000$ & $\$ 494,170$ & $\$ 219,007$ \\
\hline MS & 4 & $\$ 9,339,099$ & $\$ 36,000$ & $\$ 2,230,046$ & $\$ 4,403,750$ \\
\hline $\mathrm{NC}$ & 1 & $\$ 243,647$ & $\$ 88,569$ & $\$ 182,700$ & $\$ 28,720$ \\
\hline $\mathrm{NE}$ & 2 & $\$ 4,639,103$ & & & $\$ 2,953,777$ \\
\hline $\mathrm{NJ}$ & 5 & $\$ 10,120,105$ & & $\$ 2,586,170$ & $\$ 2,421,477$ \\
\hline NV & 1 & $\$ 562,515$ & & $\$ 95,770$ & $\$ 42,919$ \\
\hline $\mathrm{NY}$ & 3 & $\$ 19,680,760$ & & $\$ 19,197,198$ & $\$ 193,437$ \\
\hline $\mathrm{OH}$ & 3 & $\$ 4,853,467$ & $\$ 823,298$ & $\$ 125,937$ & $\$ 28,000$ \\
\hline OK & 3 & $\$ 15,981,368$ & $\$ 189,368$ & $\$ 2,847,080$ & $\$ 2,555,000$ \\
\hline OR & 4 & $\$ 25,542,128$ & $\$ 3,903,400$ & $\$ 3,110,000$ & $\$ 287,094$ \\
\hline $\mathrm{PA}$ & 11 & $\$ 10,061,386$ & $\$ 479,300$ & $\$ 1,378,600$ & $\$ 3,463,433$ \\
\hline PR & 1 & $\$ 803,800$ & & $\$ 310,000$ & $\$ 20,000$ \\
\hline SC & 1 & $\$ 730,000$ & & & $\$ 460,000$ \\
\hline $\mathrm{TN}$ & 9 & $\$ 16,919,771$ & $\$ 425,233$ & $\$ 5,586,279$ & $\$ 5,697,697$ \\
\hline TX & 30 & $\$ 100,563,593$ & $\$ 7,488,752$ & $\$ 25,024,604$ & $\$ 19,811,912$ \\
\hline UT & 2 & $\$ 3,271,485$ & & $\$ 1,037,005$ & $\$ 2,234,480$ \\
\hline $\mathrm{VA}$ & 3 & $\$ 2,231,309$ & $\$ 1,307,000$ & $\$ 260,000$ & $\$ 395,309$ \\
\hline WA & 6 & $\$ 14,878,773$ & $\$ 311,960$ & $\$ 156,993$ & $\$ 2,995,114$ \\
\hline WI & 14 & $\$ 23,232,795$ & $\$ 204,000$ & $\$ 3,025,311$ & $\$ 10,755,283$ \\
\hline WV & 4 & $\$ 19,226,450$ & $\$ 363,000$ & $\$ 3,277,450$ & $\$ 5,366,020$ \\
\hline WY & 2 & $\$ 1,677,558$ & & $\$ 659,000$ & $\$ 832,066$ \\
\hline Grand Total & 200 & $\$ 500,151,330$ & $\$ 30,397,388$ & $\$ 98,109,185$ & $\$ 179,430,273$ \\
\hline
\end{tabular}


Table 18. Distribution of energy cost savings identified and for each category of implementation. Chemical plants (325) had the highest level of identified cost savings, as well as the highest implemented energy cost savings after six months.

\begin{tabular}{|c|c|c|c|c|c|}
\hline Industry & $\begin{array}{c}\text { Number of } \\
\text { assessment } \\
s\end{array}$ & $\begin{array}{l}\text { Total identified } \\
\text { energy cost } \\
\text { savings, } \$ / y r\end{array}$ & $\begin{array}{l}\text { Implemented: } \\
\text { energy cost } \\
\text { savings, } \$ / y r\end{array}$ & $\begin{array}{l}\text { In progress: } \\
\text { energy cost } \\
\text { savings, } \$ / y r\end{array}$ & $\begin{array}{l}\text { Planned, under- } \\
\text { review or awaiting } \\
\text { funding: energy } \\
\text { cost savings, } \$ / y r\end{array}$ \\
\hline OTHER & 1 & $\$ 413,000$ & $\$ 193,000$ & & $\$ 220,000$ \\
\hline 212 MINING & 3 & $\$ 11,099,657$ & $\$ 1,000,000$ & $\$ 2,519,231$ & $\$ 2,643,828$ \\
\hline $311 \mathrm{FOOD}$ & 22 & $\$ 26,154,832$ & $\$ 1,781,500$ & $\$ 2,977,300$ & $\$ 18,568,939$ \\
\hline $\begin{array}{l}312 \text { BEVERAGE AND TOBACCO } \\
\text { PRODUCTS }\end{array}$ & 1 & $\$ 331,159$ & $\$ 135,214$ & $\$ 99,050$ & $\$ 51,997$ \\
\hline 313 TEXTILE MILLS & 1 & $\$ 36,000$ & $\$ 12,000$ & $\$ 1,000$ & $\$ 23,000$ \\
\hline 314 TEXTILE PRODUCT MILLS & 3 & $\$ 2,606,490$ & $\$ 1,000,000$ & $\$ 39,000$ & $\$ 94,550$ \\
\hline 321 WOOD PRODUCTS & 1 & $\$ 2,256,000$ & & $\$ 334,000$ & $\$ 622,000$ \\
\hline 322 PAPER MANUFACTURING & 34 & $\$ 123,440,781$ & $\$ 9,074,168$ & $\$ 8,934,817$ & $\$ 49,499,717$ \\
\hline $\begin{array}{l}323 \text { PRINTING AND RELATED } \\
\text { SUPPORT ACTIVITIES }\end{array}$ & 1 & $\$ 479,196$ & & $\$ 13,311$ & $\$ 452,574$ \\
\hline $\begin{array}{l}324 \text { PETROLEUM AND COAL } \\
\text { PRODUCTS }\end{array}$ & 8 & $\$ 49,604,807$ & $\$ 976,210$ & $\$ 4,125,837$ & $\$ 4,260,579$ \\
\hline $\begin{array}{l}325 \text { CHEMICAL } \\
\text { MANUFACTURING }\end{array}$ & 53 & $\$ 154,129,656$ & $\$ 9,119,987$ & $\$ 42,066,352$ & $\$ 60,794,323$ \\
\hline $\begin{array}{l}326 \text { PLASTICS AND RUBBER } \\
\text { PRODUCTS }\end{array}$ & 5 & $\$ 7,044,359$ & $\$ 171,411$ & $\$ 3,614,516$ & $\$ 1,534,251$ \\
\hline $\begin{array}{l}327 \text { NON-METALLIC MINERAL } \\
\text { PRODUCTS }\end{array}$ & 18 & $\$ 19,886,864$ & $\$ 286,538$ & $\$ 4,652,277$ & $\$ 4,100,300$ \\
\hline 331 PRIMARY METALS & 24 & $\$ 69,463,821$ & $\$ 3,363,580$ & $\$ 11,429,829$ & $\$ 29,465,975$ \\
\hline $\begin{array}{l}332 \text { FABRICATED METAL } \\
\text { PRODUCTS }\end{array}$ & 12 & $\$ 22,585,645$ & $\$ 2,417,050$ & $\$ 15,627,570$ & $\$ 2,450,802$ \\
\hline $\begin{array}{l}333 \text { MACHINERY } \\
\text { MANUFACTURING }\end{array}$ & 2 & $\$ 3,295,930$ & $\$ 50,000$ & $\$ 390,000$ & $\$ 2,205,000$ \\
\hline $\begin{array}{l}334 \text { COMPUTER AND } \\
\text { ELECTRONIC PRODUCTS }\end{array}$ & 5 & $\$ 2,092,604$ & $\$ 304,730$ & $\$ 677,095$ & $\$ 464,071$ \\
\hline $\begin{array}{l}335 \text { ELECTRICAL EQUIPMENT, } \\
\text { APPLIANCES, COMPONENTS }\end{array}$ & 1 & $\$ 517,000$ & & $\$ 412,000$ & $\$ 105,000$ \\
\hline $\begin{array}{l}336 \text { TRANSPORTATION } \\
\text { EQUIPMENT }\end{array}$ & 5 & $\$ 4,713,528$ & $\$ 512,000$ & $\$ 196,000$ & $\$ 1,873,367$ \\
\hline Grand Total & 200 & $\$ 500,151,330$ & $\$ 30,397,388$ & $\$ 98,109,185$ & $\$ 179,430,273$ \\
\hline
\end{tabular}




\section{KeY ACCOMPLISHMENTS AND Findings From the 2006 SAVE ENERGY NoW AsSESSMENT EFFORTS}

When the Save Energy Now "call to arms" was made by Secretary of Energy Bodman in October 2005, it is unlikely that anyone anticipated the impact that the assessment efforts would have on U.S. industry. The following key accomplishments and findings illustrate the value of the 2006 assessment efforts.

From October 2005 to December 2006, the DOE Industrial Technology Program mobilized to direct and support the Save Energy Now assessment effort and accomplish the goal of conducting 200 industrial plant assessments by the end of 2006. The ability of DOE and its support contractors to achieve this goal was due largely to ITP's past initiatives, including software tool and training development, the IAC program, the Collaborative Targeted Assessment efforts, and the Plant-Wide Assessment program. These programs provided the foundation for development of the protocols for conducting Save Energy Now assessments - specifically, the aspects of the program that defined them as "training assessments."

Large industry and the states have, and continue to, enthusiastically support and value the Save Energy Now assessment efforts. The 2006 assessments were done in 41 states and Puerto Rico for industry plants in 18 U.S. industrial groups. The program's efforts are continuing in 2007 with the goal of conducting 250 assessments, and at this writing (summer 2007), more than 250 plants have been identified for the 2007 assessments. In addition, states including Wisconsin and California are working with DOE to support assessment efforts through cost sharing. The broad-based participation of U.S. industry and expansion of the program are clear reflections of the value of the assessments to U.S. industry and the states.

No one anticipated that the average assessment in 2006 would recommend improvements to annually save $\$ 2.5$ million in energy costs, 247,000 MMBtu of natural gas, and 20,200 metric tons of plant $\mathrm{CO}_{2}$ emissions. These results are far larger than anticipated. Focusing on large U.S. industrial plants having total energy use greater than 1 trillion Btu per year was a major factor in identifying large potential savings, as was the focus on steam and process heating. The capabilities of the Energy Experts who performed the assessments and the quality of the DOE steam and process heating software tools also contributed to finding large potential savings in the plants.

Even though assessments were done in only three days, they identified potential energy savings that on average equaled about $10 \%$ of the assessed plant's energy costs. Considering the assessments' tight schedules and training focus, it was encouraging that the average identified potential energy cost savings was about $10 \%$ of plant energy bills. Potential natural gas savings identified through the 2006 assessments was even larger, averaging about $17 \%$ of plant natural gas usage. These results show that it is not necessary to perform long-duration plant energy assessments to identify significant potential savings. The results also indicate that in large plants where assessments have not yet been performed, we can realistically expect savings in the range of $10 \%$ of total plant energy costs to be identified.

For the assessments completed in 2006, the majority of the identified savings opportunities had estimated paybacks of less than two years. This is a very important and unanticipated result. Large potential plant energy savings were identified, and the majority of these savings were for opportunities with paybacks that made their implementation very attractive to plant managers. And, these large savings with attractive paybacks were found in training assessments that were done in just three days.

Many of the individual steam and process heating assessment recommendations have the potential to save more than $1 \%$ of industrial plant energy costs. On average, the recommendations from each of 14 steam opportunity categories and 17 process heating opportunity categories have the potential to save more than $1 \%$ of plant energy costs. Many of the other savings recommendations, in individual plant 
applications, can also result in substantial energy cost savings. These results suggest the substantial value of implementing the findings from the assessments.

Based on the six-month follow-up interviews with 179 assessed plants, about $7 \%$ of the total number of recommendations for these plants have already been implemented, and an additional $64 \%$ are either in progress or undergoing additional analysis, indicating the potential for the implementation of three quarters of all recommendations. So far, these 179 plants have implemented measures accounting for energy cost savings totaling $\$ 30.4$ million per year, natural gas savings of 3.5 trillion Btu per year, and 0.2 million metric tons of reduced $\mathrm{CO}_{2}$ emissions per year. It is likely that one reason for this high rate of implementation is that most recommendations had estimated paybacks of less than two years. The follow-up results at 12 months and 24 months will provide a better picture of the level of implementation of the recommendations.

The philosophy and approach for conducting Save Energy Now assessments - focusing on "training assessments" rather than audits - is clearly a success. The results from six-month followups indicated that $74 \%$ of the participating plants found that the assessments were useful with respect to encouraging their organizations to adopt DOE software and technical products. Also, over $90 \%$ of the plants found that the assessments played influential to extremely influential roles in their implementing energy savings projects. ORNL conducted immediate follow-up phone calls with Plant Leads immediately after their assessments to discuss how they went. The results from these immediate followup calls were overwhelmingly positive. Plant Leads perceived high value in the assessment activities, further confirming the effectiveness of the Save Energy Now assessment approach. 